\title{
Examining the Sensory Characteristics of Preschool Children with Retentive Fecal Incontinence
}

Isabelle Beaudry-Bellefeuille

Virginia Commonwealth University

Follow this and additional works at: https://scholarscompass.vcu.edu/etd

Part of the Occupational Therapy Commons

() The Author

\section{Downloaded from}

https://scholarscompass.vcu.edu/etd/3327

This Thesis is brought to you for free and open access by the Graduate School at VCU Scholars Compass. It has been accepted for inclusion in Theses and Dissertations by an authorized administrator of VCU Scholars Compass.

For more information, please contact libcompass@vcu.edu. 
(C) Isabelle Beaudry Bellefeuille

2014

All Rights Reserved 
Examining the Sensory Characteristics of Preschool Children with Retentive Fecal Incontinence

A thesis submitted in partial fulfillment of the requirements for the degree of Master of Science in Occupational Therapy at Virginia Commonwealth University.

by

Isabelle Beaudry Bellefeuille

BScOT, McGill University, 1991

Director: Shelly J Lane, Ph.D., OTR/L, FAOTA

Professor, Department of Occupational Therapy

Virginia Commonwealth University

Richmond, Virginia

February, 2014. 


\section{Acknowledgement}

First and foremost, I would like to thank Dr. Shelly Lane, director of this thesis and patient instructor, academic adviser, mentor and friend throughout the last 3 and half years. I would also like to thank the following people:

- Ms. Jayne Shepherd, Dr. Leroy Thacker, Dr. Eduardo Ramos, members of the committee and providers of indispensible guidance throughout this project.

- Members of the expert committee for the validation of the THPQ.

- Miguel Sanz Ovies, linguistic and cultural consultant.

- Covadonga Pola, Veronica Fainburg and Maria Redondo, collaborators in the recruitment of participants for the control group.

- My family and friends spread over three countries, for their assistance, support and patience.

- All of the parents who kindly took the time to participate in this study. 
Table of Contents

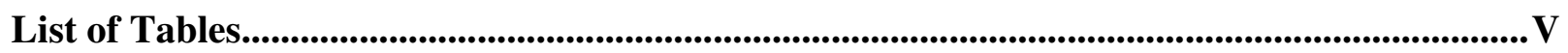

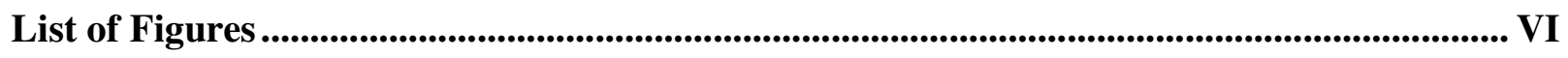

List of Abbreviations...................................................................................................................... VII

Disclosure .................................................................................................................................... VIII

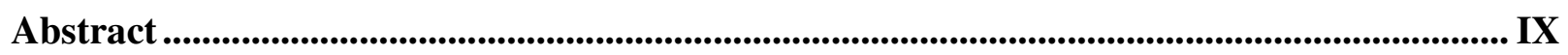

CHAPTER 1 INTRODUCTION AND SIGNIFICANCE ............................................................1

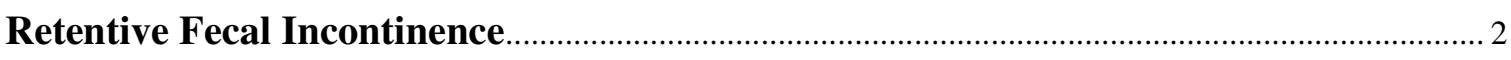

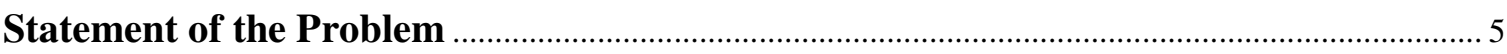

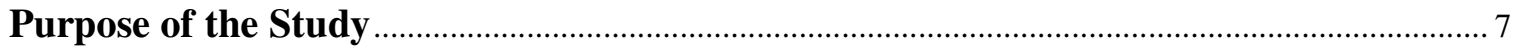

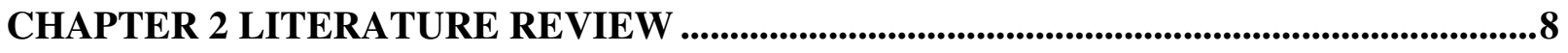

Factors Associated with Constipation and Retentive Fecal Incontinence in Children .... 8

Diagnostic Criteria for Constipation and Fecal Incontinence …………………………….... 20

Current Treatment Methods for Retentive Fecal Incontinence ............................................ 21

Occupational Therapy in the Treatment of Retentive Fecal Incontinence ......................... 27

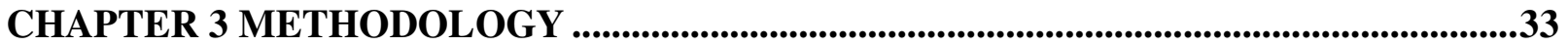

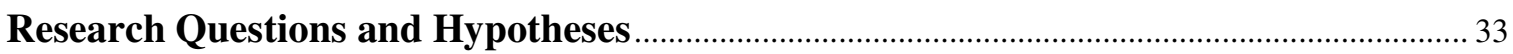

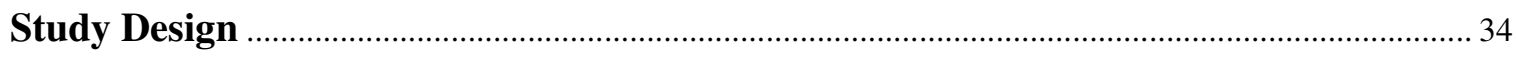

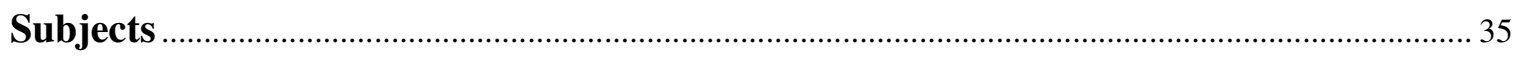

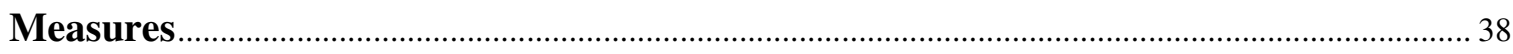

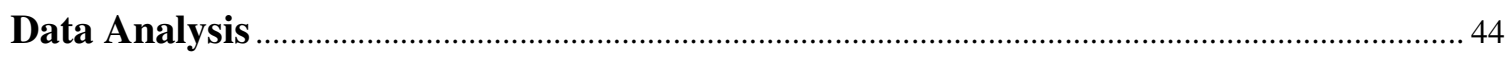

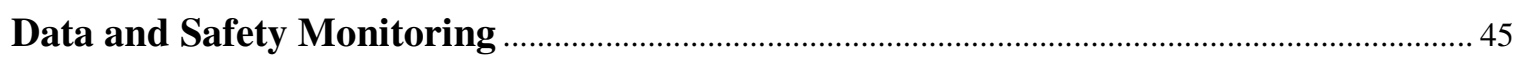

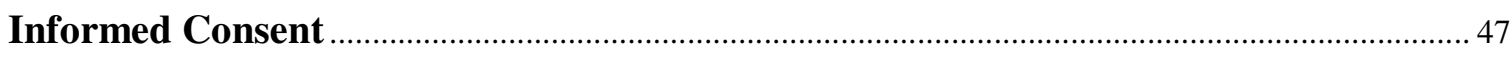

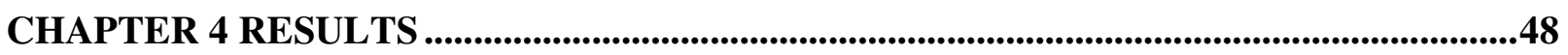

Face validity of the Toileting Habit Profile Questionnaire .................................................. 48

Validity of the Spanish version of the SSP (S-SSP) for Spanish (Spain) caregivers ....... 54 
Participant Responses

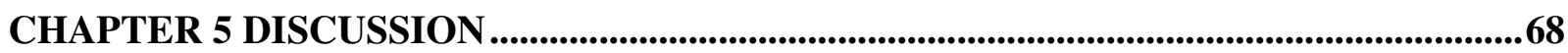

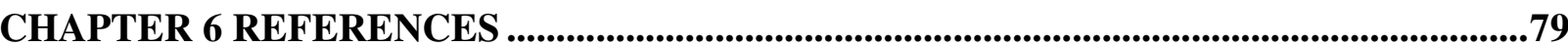

APPENDIX A

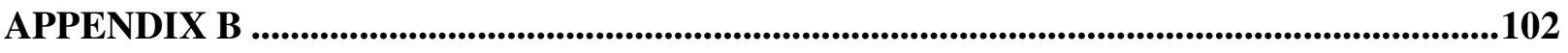

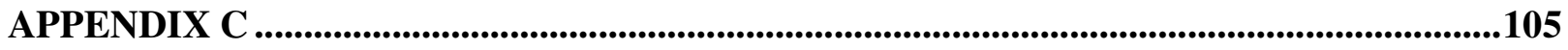

VITA 


\section{List of Tables}

Table 1: Research Question and Hypotheses.

46

Table 2: Expert panel responses to probe question 2: Why do you think a child would have such a behavior?

Table 3: Expert panel responses to probe question 3: Do you think that typically developing

children have this behavior? .50

Table 4: Descriptive Statistics of Participants in Cognitive Interviews .55

Table 5: Modifications for items of the S- SSP that were understood but adapted. 59

Table 6: Descriptive Statistics of Participants. 62

Table 7: Basic information about the child's routines and habits 63 


\section{List of Figures}

Figure 1: Process of retentive fecal incontinence.........................................2

Figure 2: Expert panel responses to probe question 4: Do you think that this behavior is common in children with constipation and fecal incontinence? .51

Figure 3: Expert panel responses to probe question 5: Do you think that this behavior could be related to over-responsivity to the sensations related to defecation (feel of potty/toilet on skin; anal/rectal distention; smell of feces, etc.)?. .54

Figure 4: Boxplot of THPQ-RFI vs THPQ-TYP .65

Figure 5: Boxplot of SOR scores. .66

Figure 6: Scatter plot of SOR scores versus THPQ scores .67 


\section{List of Abbreviations}

ADLs: activities of daily living

CBCL: Childhood Behavioral Checklist

DES: dysfunctional elimination syndrome

DDIP: Data Driven Intervention Process

DSM: Diagnostic and Statistical Manual of Mental Disorders

IBS: irritable bowel syndrome

OT: occupational therapy

RFI: retentive fecal incontinence

SOR: sensory over-responsivity

SP: Sensory Profile

SSP: Short Sensory Profile

S-SSP: Spanish version of the Short Sensory Profile

THPQ: Toileting Habit Profile Questionnaire

TES: transcutaneous electrical stimulation 


\section{Disclosure}

Ms Beaudry is the owner and operator of the Clínica de Terapia Ocupacional Pediátrica BeaudryBellefeuille, the pediatric occupational therapy clinic where this research was conducted. 


\begin{abstract}
EXAMINING THE SENSORY CHARACTERISTICS OF PRESCHOOL CHILDREN WITH RETENTIVE FECAL INCONTINENCE
\end{abstract}

By Isabelle Beaudry Bellefeuille, BScOT

A thesis submitted in partial fulfillment of the requirements for the degree of Master of Science in Occupational Therapy at Virginia Commonwealth University.

Virginia Commonwealth University, 2014.

Director: Shelly J. Lane, Ph.D., OTR/L, FAOTA,

Professor, Department of Occupational Therapy

Occupational therapists are concerned with individuals' abilities to engage in daily occupations. When a daily activity such as bowel management is problematic, participation in key occupations can be limited. Retentive fecal incontinence is a common disorder in children. Behavior seems to be partly responsible for this condition. Occupational therapists have hypothesized that some behaviors could be related to sensory over-responsivity. This study investigated the relationship between retentive fecal incontinence and sensory over-responsivity and examined the Toileting Habit Profile Questionnaire, a tool designed to screen for toileting difficulties. The study showed that a group of children $(n=16)$ with retentive fecal incontinence presented with significantly more behaviors related to sensory over-responsivity than a group of typically developing children $(n=27)$ as measured by the Short Sensory Profile. The study also revealed that the Toileting Habit Profile Questionnaire effectively discriminates between children with retentive fecal incontinence and those without toileting difficulties. 


\section{Chapter 1 Introduction and Significance}

Occupational therapists are concerned with individuals' abilities to engage in and perform required and desired daily occupations. Activities of daily living are considered a central area of occupation and include all occupations related to self care. Bowel and bladder management as well as toilet hygiene are important activities of daily living (American Occupational Therapy Association, 2008). Issues in these areas can limit an individual's independence and social participation. Acquiring voluntary continence of bowel and bladder as well as independence in toilet hygiene is considered an important milestone of childhood.

Fecal incontinence is a common, under-treated and often misinterpreted disorder in children that often leads to impaired social acceptance, relationships and development (Friman, Hofstader, \& Jones, 2006). The unpleasant odors caused by feces are often the cause of rejection and ridicule by peers, which can affect social participation and participation in key activities of childhood (Handley-More, Richards, Macauley, \& Tierra, 2009). For example some schools do not admit children with fecal incontinence or do not provide assistance for cleaning up, forcing parents to be available at all times to assist their children when soiling accidents occur.

Fecal incontinence is the most common symptom of constipation (Loening-Baucke, 1996). It is generally defined as the repeated passage of feces in inappropriate places at least once a month for at least 3 months in a child that is at least 4 years of age and without an underlying physical condition (American Psychiatric Association, 2013). In children younger than 4 years of 
age, fecal incontinence is considered a symptom of constipation when it occurs at least once per week in children who had previously well established toileting skills (Drossman et al., 2006).

Children with long lasting symptoms of constipation are at risk for experiencing lower health-related quality of life. For example many children with fecal incontinence suffer bullying at school due to their defecation problem or report feeling worried about the odor arising from their fecal incontinence (Bongers, Van Dijk, Benninga, \& Grootenhuis, 2009; Joinson, Heron, Butler, \& Von Gontard, 2006). Parents also perceive lower quality of life for their children and themselves (Kaugars et al., 2010; Youssef, Langseder, Verga, Mones, \& Rosh, 2005).

\section{Retentive Fecal Incontinence}

Fecal incontinence is one of the main symptoms of constipation, and constipation is probably one of the most common gastrointestinal complaints in children (Tabbers, Boluyt, Berger, \& Benninga, 2011a). The term retentive fecal incontinence (RFI) is used to specify the presence of constipation and differentiate it from non-retentive fecal incontinence, a condition that occurs in the absence of stool retention. Children with RFI often soil due to rectal overflow, an involuntary process where soft stool from the bowel slips around a hard mass of stool that remains accumulated in the rectum (Cohn, 2011) (see Figure 1).

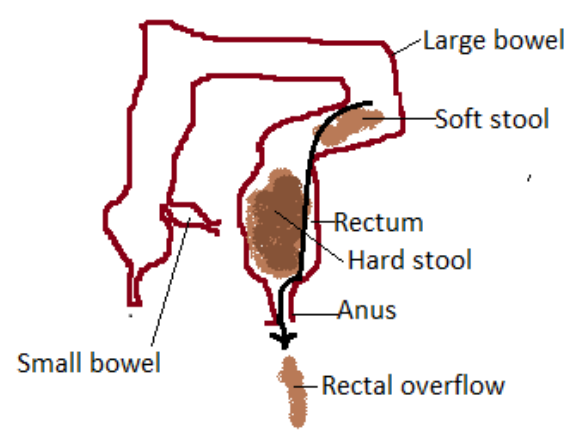

Figure 1: Process of retentive fecal incontinence 
While the cause of RFI has not been clearly identified, the behavior of children with RFI seems to be partly responsible for the development and/or maintenance of the condition. Stool withholding behavior has been recognized as one of the most common causes of development and maintenance of childhood constipation (Cohn, 2011; Tabbers et al., 2011a; Whitehead, Di Lorenzo, Leroi, Porrett, \& Rao, 2009).Various factors seem to be responsible for the onset of this behavior. One of the most accepted views is that in order to avoid painful bowel movements due to hard stools, many children develop the habit of responding to the urge to defecate by withholding feces (Cohn, 2011; Tabbers et al., 2011a). The issue of pain was underscored in a study by Borowitz and colleagues (2003) in which $80 \%$ of families of children with constipation reported the passage of a large or painful bowel movement as the cause of their child's constipation. Expressing worry about future defecations was also present in $75 \%$ of the children with constipation (Borowitz et al., 2003).

Another possible factor responsible for the onset of stool withholding behavior is thought to be avoidance of using a toilet outside the home. For example many children avoid using the toilets at school (Inan et al., 2007; Kistner, 2009; Lundblad \& Hellström, 2005; Tam et al., 2012). Situations when the child is outside of his regular environment such as vacations, relocations, or when the child starts school are reported to be times when parents should be vigilant for signs of constipation (Borowitz et al., 2003).

Stool toileting refusal or fear of sitting on the potty are other identified behavior problems in children that have been associated with constipation, stool withholding, late toilet training, and fecal incontinence (Bellman, 1966; Taubman, 1997; Taubman, Blum, \& Nemeth, 2003; Blum, Taubman, \& Nemeth 2004). Children with stool toileting refusal will use the potty/toilet to urinate but refuse to use it to defecate. Stool toileting refusal seems to be the result of 
experiencing repeated hard or painful bowel movements (Blum et al., 2004). It appears that constipation is present before the appearance of stool toileting refusal and therefore this behavior is not a factor in the development of RFI but may represent a factor in the maintenance of the condition (Blum et al., 2004; Taubman \& Buzby, 1997).

Refusal behaviors are also reported to contribute to the maintenance of RFI in that they interfere with conventional medical management. Treatment for constipation and RFI often consists of dietary recommendations, stool softener and/or laxative medication and implementation of toileting routines (Cohn, 2011). Taubman and Buzby (1997) reported that children who were difficult to treat refused to sit on the toilet at regular times, continued to withhold stool and refused to take their medication. Vitito (2000) also reports that refusal to take medication and adhere to toileting routines are frequent problems in the treatment of children with RFI. Refusal behaviors related to adherence of liquid and fiber intake recommendations are also documented and considered a factor limiting treatment success rates in children with constipation (Karagiozoglou-Lampoudi et al., 2012; Kuhl, Felt, \& Patton, 2009; Sullivan, Alder, Shrestha, Turton, \& Lambert, 2012).

Clinicians working with children with RFI and their families often hear how difficult it is to have their children follow the treatment. The words of one mother, "if she'd just follow protocol and do what she's suppose to do", reported in a recent qualitative study (Kaugars et al., 2010, p. 751), seem to reflect the thoughts of many parents whose children struggle with constipation and fecal incontinence.

It has been hypothesized that difficulty processing and integrating sensory information could be a factor contributing to the development of certain problematic behaviors in children (Dunn, 2007; Hazen et al., 2008; Roberts, King-Thomas, \& Boccia, 2007; Schaaf et al., 2010). 
Exaggerated responses to normal sensory stimuli, often referred to as sensory over-responsivity, have been associated with refusal to comply with parental demands or atypical habits in relation to other types of selfcare activities such as dressing or feeding (Cermak, Curtin, \& Bandini, 2010; Chatoor, 2002; Dunn, 2007; Hazen et al., 2008; Nadon, Ehrmann-Feldman, Dunn, \& Gisel, 2011; Schaaf et al., 2010). In the classic study on encopresis by Bellman (1966), food refusal was observed to be more prevalent among children with fecal incontinence than among controls suggesting a possible common underlying issue to both conditions.

Occupational therapists working with children with RFI have hypothesized that some of the above mentioned behaviors typical of children with RFI could be related to sensory overresponsivity (Beaudry Bellefeuille \& Ramos Polo, 2011; Beaudry, Schaaf, \& Ramos, 2013; Handley-More et al., 2009). For example tactile over-responsivity could be the underlying issue responsible for both refusal to sit on the potty and avoidance of certain high fiber foods. At present there is little documentation of a potential relationship between sensory over-responsivity and RFI. Investigating the relationship between sensory over-responsivity and RFI will be the focus of this study.

\section{Statement of the Problem}

Research has strongly highlighted the behavioral issues involved in RFI and it has been documented that children with constipation and fecal incontinence have more behavioral problems than typically developing children (Bellman, 1966; Cox, Morris, Borowitz, \& Sutphen, 2002; Benninga, Voskuijl, Akkerhuis, Taminiau, \& Büller, 2004; Gabel, Hegedus, Wald, Chandra, \& Chiponis, 1986; Van Dijk, Benninga, Grootenhuis, \& Last, 2010; Young, Brennen, Baker, \& Baker, 1995). However the role of behavioral components in the etiology of defecation disorders has been subject of debate amongst researchers. The importance of behavioral 
disturbances emphasized by some authors, suggest that constipation and fecal incontinence may require psychiatric or psychological treatment (Cox et al., 2002; Levine \& Bakow, 1976; McGrath, Mellon, \& Murphy, 2000; Rappaport, Landman, Fenton, \& Levine, 1986). The inclusion of encopresis (fecal incontinence) in the Diagnostic and Statistical Manual of Mental Disorders of the American Psychiatric Association (DSM) also underscores the views of many clinicians and researchers regarding the role of behavioral components in the etiology of fecal incontinence (APA, 2013). Others have argued that these psychological disturbances are mild and possibly secondary to the fecal incontinence, and recommend medical management within pediatric settings (Benninga et al., 2004; Friman, Mathews, Finney, Christophersen, \& Leibowitz, 1988; Gabel et al., 1986).

There is increasing evidence suggesting that physiological factors as well as emotional, behavioral, and psychosocial factors may all play a role in the etiology, maintenance, and treatment of functional gastrointestinal disorders (Culbert \& Banez, 2007; Devanarayana \& Rajindrajith, 2011; Drossman, 2006; Mugie, Di Lorenzo, \& Benninga, 2011; Van den Berg, Benninga, \& Di Lorenzo, 2006).Researchers and clinicians increasingly recognize the importance of considering all factors involved in constipation and RFI and recommend approaching this common childhood health problem from a biopsychosocial perspective (Drossman, 2006; Drossman et al., 2006; Friman et al., 2006; Mearin, Rey, \& Balboa, 2011).

In clinical practice the child's behaviors are often central to either: a) the development of the condition such as in the case of stool withholding behavior (Cohn, 2011; Tabbers et al., 2011a) or b) the correct implementation of the treatment program such as when the child refuses to sit on the toilet/ potty or adhere to fiber and fluid intake recommendations (Von Gontard, 
Baeyens, Van Hoecke, Warzak, \& Bachmann, 2011; Kuhl et al., 2009; Stark et al., 1997; Taubman et al., 2003; Vitito, 2000).

Success rates in the treatment of childhood constipation and RFI are limited. Currently only about $50 \%$ of patients are free of complaints and off laxatives after 6 to 12 months of medical management (Pijpers, Bongers, Benninga, \& Berger, 2010). Children who are resistant to initial medical management will be object of this study.

More children who fail standard medical management are reported to have behavior problems than children who succeed (Levine \& Bakow, 1976; Stark, Spirito, Lewis, \& Hart, 1990; Taubman \& Buzby, 1997). Difficulty processing and integrating sensory information has been hypothesized to be a factor in behavioral problems in children (Dunn, 2007; Hazen et al., 2008; Roberts et al., 2007; Schaaf et al., 2010). Sensory over-responsivity, has been associated with behavior problems in other types of selfcare activities (Cermak et al., 2010; Chatoor, 2002; Dunn, 2007; Hazen et al., 2008; Nadon et al., 2011; Schaaf et al., 2010). Sensory over responsivity is also documented to be associated to certain gastrointestinal dysfunctions (Bakker, Boer, Benninga, Koelman, \& Tijssen, 2010; Mazurek et al., 2012). Clarifying the underlying issues related to the behavior problems associated with constipation and retentive fecal incontinence would contribute to developing more effective treatment programs.

\section{Purpose of the Study}

This study will investigate the relationship between RFI and sensory over-responsivity. This study will also examine the Toileting Habit Profile Questionnaire, a tool designed to screen for sensory based toileting difficulties, and determine its utility in distinguishing between typical children and those with RFI that has not responded to routine medical intervention. 


\section{Chapter 2 Literature Review}

Children learn bowel and bladder management as well as toilet hygiene as important activities of daily living (ADLs) (American Occupational Therapy Association, 2008). When there is organic or non organic chronic constipation, the development of these ADLs is limited and may affect a child's independence and social participation. Chronic constipation in children is a common problem worldwide (Van den Berg, et al., 2006). A review of international epidemiological studies of constipation in children found prevalence rates ranging from $0.7 \%$ to 29.6\% (Mugie, Benninga, \& Di Lorenzo, 2011). Constipation accounts for up to $30 \%$ of referrals to pediatric gastroenterologists (Sonnenberg \& Koch, 1989). Fecal incontinence is present in nearly all children with constipation (Mugie, Di Lorenzo, \& Benninga, 2011; Youssef et al., 2002) and profoundly affects a child's social and emotional development (Joinson et al., 2006). Different factors have been identified in relation to the development and maintenance of constipation in children, however success rates for treatment remain limited and many children continue to experiment constipation and fecal incontinence into adulthood (Van Ginkel et al., 2003; Michaud, Lamblin, Mairesse, Turck, \& Gottrand, 2009; Pijpers et al., 2010). Currently only about $50 \%$ of patients are free of complaints and off laxatives after 6 to 12 months of medical management (Pijpers et al., 2010).

\section{Factors Associated with Constipation and Retentive Fecal Incontinence in Children}

The pathophysiology of constipation in children is recognized to be multifactorial and remains incompletely understood (Mugie, Di Lorenzo, \& Benninga, 2011). Assessment of 
children with constipation and RFI must include consideration of both organic and non-organic factors that may be at the root of the problem or contribute in some way to its maintenance.

Organic causes. In most cases no clear organic cause can be identified and constipation and RFI are therefore said to be functional (Canadian Paediatric Society, 2011; Rubin \& Dale, 2006; Tabbers, Boluyt, Berger, \& Benninga, 2010). Through careful history taking and examination, physicians determine if there are symptoms that suggest organic disease and may recommend laboratory and radiographical investigation to confirm organic causes of constipation and RFI (Canadian Paediatric Society, 2011). Possible organic causes include the following:

Gastrointestinal abnormalities. Hirschsprung disease, anorectal malformations and neuronal intestinal dysplasia are conditions that may be at the root of defecation disorders (Mugie, Di Lorenzo, \& Benninga, 2011). These conditions are rare but must be ruled out before considering other causes (Tabbers et al., 2010).

Anorectal sensorimotor issues. Rectal sensorimotor functions are central to defecation (Scott, Van den Berg, \& Benninga, 2011). Abnormal rectal motor physiology and visceral sensory dysfunction may be involved in the pathogenesis of constipation (Raghunath et al., 2011; Scott et al., 2011). However the question remains whether the sensorimotor dysfunctions are the cause of constipation or a consequence of long standing rectal distention due to fecal retention (Mugie, Di Lorenzo, \& Benninga, 2011).

Reduced colonic transit time. Slow colonic transit time has been associated with poorer treatment outcomes (De Lorijn, et al., 2004). Colonic transit studies may be useful in children with treatment-resistant constipation to determine colonic transit abnormalities (Rajindrajith \& Devanarayana, 2011). 
Diet. Low consumption of fiber, fruit and vegetables, have been suggested to contribute to the development of childhood constipation (Aziz, Fakih, \& Di Lorenzo, 2011; Inan et al., 2007; Tam et al., 2012). Constipation and fecal incontinence has been found to be more prevalent in obese children (Vd Baan-Slootweg et al., 2011; Costa, Oliveira, Tahan, \& Morais, 2011; Fishman, Lenders, Fortunato, Noonan, \& Nurko, 2004; Jennings, Davies, Costarelli, \& Dettmar, 2010).

Food allergies. Food allergies and celiac disease can be the cause of constipation in children (Kamer, Dółka, Pyziak, \& Blomberg, 2011). For example allergy to cow’s milk is a frequent and often overlooked cause of constipation in young children (Ikeda et al., 2011).

Genetics. Several authors have pointed to genetic predisposition as having a role in the development of childhood constipation (Chan, et al., 2007; Inan et al., 2007; Ostwani, Dolan, \& Elitsur, 2010; Pang \& Croaker, 2011). However, one study was identified that showed that children with constipation were no more likely to have a parent or a sibling with a history of constipation than children without constipation (Borowitz et al., 2003).

Many genetic syndromes are associated with defecation disorders. A recent review examining the relationship between childhood constipation and genetic syndromes indicated that syndromic gene mutations may affect the physiological aspects of normal human defecation (Peeters, Benninga, \& Hennakam, 2011). The researchers underscored the fact that mutations in genes specifically associated with constipation remain to be found but stressed that syndromic causes of childhood constipation should be considered in the evaluation of children with constipation (Peeters et al., 2011).

Sensory responsivity. Researchers have begun to examine the relationship between sensory over-responsivity, constipation and other gastrointestinal problems (abdominal pain, 
nausea, bloating, diarrhea) in children with autism spectrum disorder (Mazurek et al., 2012). Findings indicated that children with any type of gastrointestinal problem, including chronic constipation, had higher levels of sensory over-responsivity than children without such problems. Using logistic regression analyses, the researchers found that sensory over-responsivity significantly contributed to the prediction of constipation, abdominal pain, nausea and bloating (Mazurek et al., 2012).

Pollock (2012) has recently studied the prevalence of sensory processing disorder (SPD) in a group $(n=19)$ of 5-10 year old children diagnosed with dysfunctional elimination syndrome (DES). DES considers under a single diagnostic category, a variety of elimination difficulties such as urinary frequency, urinary incontinence, holding maneuvers, urgency, constipation, and encopresis (Neveus et al., 2006; Norgaard, Van Gool, Hjalmas, Djurhuus, \& Hellstrom, 1998). Using the Short Sensory Profile (McIntosh, Miller, Shyu, \& Dunn, 1999) the study revealed that $52.6 \%$ of participants in the DES group had SPD as opposed to $7.3 \%$ of the children in the control group ( $\mathrm{n}=55)$. Participants were considered to have SPD if their Short Sensory Profile score fell beyond two standard deviations as compared to the mean of the normative population used in the development of this evaluation tool. Although the study did not differentiate between the specific elimination difficulties which are considered within the diagnostic category of DES, the fact that RFI can be included under the DES diagnostic criteria points to possible sensory processing difficulties for this subgroup of children.

Another recent study by Bakker et al. (2010) revealed a link between auditory startle reflexes, irritable bowel syndrome (IBS) and functional abdominal pain syndrome; two conditions described in the Rome III Criteria for Functional Gastrointestinal Disorders and characterized by abdominal pain in the absence of a known physiological cause (Drossman et al., 
2006). Constipation in absence of organic causes, and with fecal incontinence as one of the main symptoms, is also a functional gastrointestinal disorder according to Rome III criteria (Drossman et al., 2006). The auditory startle reflex is considered a measure of hyperarousal (Guthrie \& Bryant, 2005). Bakker and colleagues (2010) found that children with IBS and functional abdominal pain syndrome demonstrated significantly greater auditory startle reflexes than a sample of typical children. The authors consider that these results may provide evidence of a general hypersensitivity of the central nervous system among children with gastrointestinal disorders. Although this study did not include children with constipation and fecal incontinence the fact that RFI is also a functional gastrointestinal disorder points to the possibility that these children may also have general hypersensitivity.

Refusal behavior is a common characteristic of children with RFI (Blum et al., 2004; Taubman, 1997; Taubman et al., 2003; Taubman \& Buzby, 1997; Vitito, 2000) and children with feeding problems (for example food refusal or food selectivity).Sensory over-responsivity is well documented in children with feeding problems (Cermak et al., 2010; Chatoor, 2002; Dunn, 2007; Hazen et al., 2008; Nadon et al., 2011; Schaaf et al., 2010). Feeding disorders appear to have common etiological and maintenance factors with constipation (Ibrahim, Voight, Katusic, Weaver, \& Barbaresi, 2009). Several authors report a higher prevalence of food refusal among subjects with constipation and/or fecal incontinence. The classic study by Bellman (1966) documented a high prevalence of food refusal among children with fecal incontinence. More recently, in a sample of institutionalized children and adults with intellectual disability, food refusal was also found to be more frequent in individuals with constipation than in a control group without constipation (Böhmer, Taminiau, Klinkenberg-Knol1, \& Meuwissen, 2001). A case report linking food refusal as a causal factor of RFI is also documented (Tang, Piazza, 
Dolezal, \& Stein, 2011). In addition, Ibrahim et al. (2009) found that the cumulative incidence of constipation and feeding issues and/or food selectivity was significantly higher in children with autism relative to children in the control group. The authors of this study state that constipation and feeding issues often have a behavioral etiology, suggesting that a neurobehavioral etiology may account for the higher incidence of both of these conditions in children with autism (Ibrahim et al., 2009). Sensory over-responsivity has been hypothesized to affect behavior and could represent the common neurobehavioral etiology referred to by Ibrahim et al. (2009). Contrary to the well established relation between food refusal and sensory-over-responsivity, our knowledge concerning the relation between sensory over-responsivity and RFI is very limited.

Non organic causes and links. The landmark study by Bellman (1966) referenced above marked the beginning of a structured approach to quantifying the characteristics of children with constipation and fecal incontinence. Researchers have since then looked at a myriad of distinguishing features in an effort to identify the most relevant traits and personal circumstances that characterize children with constipation and fecal incontinence.

Behavior. The prevalence of behavioral problems in children with constipation and fecal incontinence has been a long standing issue of study. There are many reports that children with constipation and fecal incontinence have more behavioral problems than typically developing children (Bellman, 1966; Cox et al., 2002; Benninga et al., 2004; Gabel et al., 1986; Von Gontard et al., 2011; Hesapçıoğlu, Goker, Aktepe, Topbaş, \& Kandil, 2009; Joinson et al., 2006; Van Djik et al., 2010; Young et al., 1995). For example Dutch investigators examined the prevalence of behavioral problems in 133 children aged 4 to 18 years and identified as having constipation. Using the Childhood Behavioral Checklist (CBCL) (Achenbach, 1991) investigators found considerable rates of overall (36.1\%), internalizing (27.1\%) and externalizing (36.8\%) behavior 
problems in children with constipation. Compared with the Dutch norm research sample of the CBCL, overall and internalizing behavior problems were 4 times higher and externalizing problems were 3 times higher among children with constipation (Van Djik et al., 2010).

Further, more children who fail standard medical management for RFI are reported to have behavior problems than children who succeed (Burket et al., 2006; Levine \& Bakow, 1976; Stark et al., 1990; Taubman \& Buzby, 1997). The issue of stubbornness and its relation to response to treatment by a primary care physician was investigated in 101 children with constipation (Burket et al., 2006). The investigators measured general stubbornness with selected items from the Child Development Inventory (Ireton, 1992), the CBCL (Achenbach, 1991), and a question, answered by the parent, from the Virginia Encopresis-Constipation Apperception Test (VECAT) (Cox et al., 2003) concerning the child's general behavior. Toilet-specific stubbornness was measured in 3 ways: a) a question answered by the child's parent from the VECAT concerning toileting behavior, b) parents' observations of daily toilet behavior recorded in a diary and (3) direct observation by a blind rater of the child's compliance to parental instruction to go to the bathroom, sit on the toilet, and try to have a bowel movement (Burket et al., 2006). Children who failed medical management showed more stubbornness on all of the measures, however only the VECAT reached statistical significance.

Levine and Bakow (1976) considered compliance with treatment and behavior problems in relation to treatment outcomes. Compliance was assessed through parental report and behavior problems were assessed with a structured behavioral inventory. Both poor compliance and the presence of behavioral problems were related to poorer outcomes (Levine \& Bakow, 1976). Other studies reporting a relationship between poorer treatment outcomes and behavior problems 
rely mainly on subjective impressions of the child's behavior and do not describe specific tools for measuring behavior (Stark et al., 1990; Taubman \& Buzby, 1997).

Although the number of reports of behavioral problems associated with constipation and fecal incontinence is substantial, there are also some reports that the behavioral characteristics of children with constipation and fecal incontinence do not differ from healthy youngsters (Blum, Taubman, \& Osborne, 1997; Friman et al., 1988; Ozokutan, Zoroglu, Ceylan, \& Ozkan 2005). For example a sample of 32 Turkish children with constipation aged between 4 and 14 did not score significantly different on the CBCL (Achenbach, 1991) or the Symptom Checklist-90 revised (Derogatis, 1994) than a comparison group of children with inguinal hernia (Ozokutan et al., 2005). Previous studies using the Eyberg Child Behavior Inventory (Eyberg \& Pincus, 1999) with children presenting fecal incontinence (Friman et al., 1988) and the CBCL (Achenbach, 1991) with children presenting stool toileting refusal (Blum et al., 1997) showed no significant differences in the behavioral scores of children with toileting difficulties as compared with controls.

Problems during toilet training. There have been reports of a relationship between early toilet training and the development of constipation and/or fecal incontinence (Garrard \& Richmond, 1952; Kocaay, Egritas, \& Dalgic, 2011; Richmond, Eddy, Garrard, 1954). However, some of these reports are over 50 years old and the identified links may be due to the toilet training practices of the time. Since the landmark paper by Brazelton (1962) in which a child oriented method to toilet training was outlined, views and expectations concerning toilet training have changed. What is known at this time is that parents of children with constipation report more difficulty with toilet training (resistance or later age of completion for example) than parents of typical children (Aziz et al., 2011; Borowitz et al., 2003; Inan et al., 2007; Schonwald, 
Sherritt, Stadtler, \& Bridgemohan, 2004). More recent debates concerning the link between toilet training and RFI have focused on the following questions: 1) are toilet training difficulties responsible for the development of RFI or 2) is constipation the cause of toilet training difficulties (Shaikh, 2004)?

Current evidence seems to point to constipation as the cause of toilet training difficulties. Excluding coercive methods, timing and style of toilet training do not appear to be associated with the development of early childhood constipation (Blum, Taubman, \& Nemeth, 2003; Borowitz et al., 2003; Rugolotto, Sun , Bouke, Caló, \& Tató, 2008). Furthermore, Blum, Taubman and Nemeth (2004) report that stool toileting refusal (a common toilet training difficulty) is preceded by painful defecation (a sign of constipation), and conclude that undetected constipation may be the cause of toilet training difficulties.

Psychosocial and emotional factors. There is increasing evidence suggesting that emotional and psychosocial factors may play a role in the etiology, maintenance, and treatment of functional gastrointestinal disorders (Devanarayana \& Rajindrajith, 2011; Drossman, 2006; Culbert \& Banez, 2007; Mugie, Di Lorenzo, \& Benninga, 2011; Van den Berg et al.,2006). Possible psychosocial and emotional factors include the following:

Abuse. Sexual abuse has been linked to fecal incontinence. Investigating the bowel habits of children known to have been sexually abused, Mellon, Whiteside and Friedrich (2006) identified significantly higher rates of occasional fecal soiling among this group when compared to a normative sample of children. However, no difference in the rate of occasional fecal soiling was found between the group of children with known sexual abuse when compared to a group of children who were referred for psychiatric problems. The authors concluded that occasional fecal soiling, taken as an isolated symptom, was not useful in identifying sexual abuse status in 
children. However Drossman (2011), in his review of the association between abuse, trauma and gastrointestinal dysfunction, concludes that many adult patients with functional gastrointestinal disorders present with a history of sexual and/or physical abuse that must be considered in the clinical management of these patients.

Stress and anxiety. Experiencing anxiety or stressful life events is reported to be linked to childhood constipation and fecal incontinence (Amendola, De Angelis, Dall'Oglio, Federici di Abriola, \& Di Lorenzo, 2003; Bellman, 1966; Devanarayana \& Rajindrajith, 2010; Hesapçıoğlu et al., 2009; Inan et al., 2007; Mugie, Benninga, \& Di Lorenzo, 2011; Waters, Schilpzand, Bell, Walker, \& Baber, 2012). Australian investigators recently examined the incidence and correlates of functional gastrointestinal symptoms in 54 children aged from 6 to13 years and diagnosed with one or more anxiety disorders (Waters et al., 2012). The study revealed that in children with anxiety the incidence of symptoms consistent with a functional gastrointestinal disorder was significantly higher in comparison with healthy typically developing peers $(40.7 \%$ vs $5.9 \%)$. Functional constipation was the most common functional gastrointestinal disorder present in this sample of anxious children (Waters et al., 2012).

The study by Bellman (1966) documented a high prevalence of anxiety among children with fecal incontinence. Using a structured questionnaire developed by Jonsonn and Kälvesten (as cited in Bellman, 1966) Bellman measured reactions related to anxiety. Very strong anxiety reactions were present in 5 of the 75 children $(6.7 \%)$ with fecal incontinence compared to none in the control group. Strong anxiety reactions were present in 33 children (44\%) with fecal incontinence compared to $13(18 \%)$ in the control group. In a more recent study of 107 children with non-organic fecal incontinence, referred to a Turkish university hospital clinic for treatment, investigators found that 29 children (27.1\%) had anxiety disorders (Hesapçığlu et al., 2009). 
War is without a doubt a stressful life event which can lead to significant emotional stress and anxiety. Using a validated, self-administered questionnaire with 10 to 16 year old children, researchers in Sri Lanka have repeatedly shown that constipation was more frequent among those living in areas submerged in war (Devanarayana \& Rajindrajith, 2010, 2011; Rajindrajith, Mettananda, \& Devanarayana, 2011). Follow-up studies carried out after the end of the war, once public facilities (school, roads, hospitals, etc.) had been restored, showed an overall decrease in the prevalence of constipation (Rajindrajith et al., 2011).

Emotional stress and anxiety are therefore frequently associated with some forms of functional gastrointestinal diseases, but their role in the etiology of functional constipation and fecal incontinence remains unclear (Devanarayana \& Rajindrajith, 2010). It has been hypothesized that stress may modulate the brain-gut axis and affect gut motility and anorectal functions (Devanarayana \& Rajindrajith, 2010; Tam et al., 2012). The brain-gut axis represents a complex reflex circuit that involves bidirectional communication between the central nervous system and the digestive system (Mayer \& Tillisch, 2011; Gaman \& Kuo, 2008). Bowel activity is also partially neuromodulated by intrinsic neural systems but the digestive system depends on the brain-gut axis for proper functioning (Mayer \& Tillisch, 2011; Gaman \& Kuo, 2008). When the neuromodulatory processes of the brain-gut axis are disturbed, this may generate functional digestive disorders related to pain symptoms and intestinal motility disorders.

Parental presence. A recent study points to the presence of parents in children's lives as a factor predictive of constipation (Tam et al., 2012). A cross-sectional questionnaire survey conducted in Hong Kong elementary schools revealed that children living with neither parent and children eating dinner with parents less than $50 \%$ of the time had more constipation than children whose parents were more present (Tam et al., 2012). 
Demographic features. Gender, race and socioeconomic status have all been issues of interest in the investigation to better understand constipation and fecal incontinence. Most of these issues remain under debate; the most recent findings are presented.

Socioeconomic status. Prevalence rates of constipation and fecal incontinence according to socioeconomic status remain under debate. Many studies report that adults and children of lower socioeconomic levels have higher prevalence of constipation (Bytzer et al., 2001; Chung et al., 2010; Devanarayana \& Rajindrajith, 2011; Mugie, Benninga, \& Di Lorenzo, 2011). Low levels of parental education have also been associated to higher prevalence of childhood constipation (Chung et al., 2010). However the lack of association between the socioeconomic status of the family and constipation in children has also been supported by some authors (Tam et al., 2012; Van den Berg et al., 2006).

Gender. Prevalence rates of RFI according to gender are diverse. The classic study on encopresis by Bellman (1966) showed a higher prevalence among boys and other authors have also reported similar results (Christophersen \& Mortweet, 2001). However more recent publications generally conclude that constipation is equally common in children of both genders (Tam et al., 2012; Whitehead et al., 2009; Van den Berg et al., 2006).

Race. Prevalence rates of RFI according to race are equally diverse. There exists a common belief that constipation is less frequent in non-western societies (Van den Berg et al., 2006) and more frequent in individuals of African descent (Mugie, Benninga, \& Di Lorenzo, 2011). However current reports reveal that constipation is equally common in all races (Mugie, Benninga, \& Di Lorenzo, 2011;Tam et al., 2012; Van den Berg et al., 2006; Whitehead et al., 2009; Wu et al., 2011). 


\section{Diagnostic Criteria for Constipation and Fecal Incontinence}

The diagnostic criteria for constipation proposed by the Rome Foundation is generally agreed to be the most adequate for diagnosis by current clinicians and researchers (Chogle, Dhroove , Sztainberg , Di Lorenzo, \& Saps, 2010; Drossman et al., 2006; Drossman, 2006; Lucak, 2007; Mostafa, 2008; Sheth, 2007). The Rome Foundation is a non-profit organization that brings together scientists and clinicians from around the world to classify and appraise the science supporting the diagnosis and treatment of functional gastrointestinal disorders.

The diagnosis of functional constipation in children with a developmental age of at least 4 years old is made in the presence of at least two of the following signs:

a) two or fewer defecations in the toilet per week, b) at least one episode of fecal incontinence per week, c) history of retentive posturing or excessive volitional stool retention, d) history of painful or hard bowel movements, e) presence of a large fecal mass in the rectum, f) history of large diameter stools which may obstruct the toilet, with criteria fulfilled at least once per week for at least 2 months prior to diagnosis (Drossman et al., 2006, p. 897).

In infants and toddlers younger than 4 years of age the criteria for the diagnosis of functional constipation are:

a) two or fewer defecations per week, b) at least one episode/week of incontinence after the acquisition of toileting skills, c) history of excessive stool retention, d) history of painful or hard bowel movements, e) presence of a large fecal mass in the rectum, f) history of large diameter stools which may obstruct the toilet. Symptoms may also include irritability, decreased appetite, and/or early satiety which disappear immediately following passage of a large stool (Drossman et al., 2006, p. 895). 
The diagnosis of encopresis (fecal incontinence) is given in the case of repeated passage of feces in inappropriate places at least once a month for at least 3 months in a child that is at least 4 years of age and without an underlying physical condition (American Psychiatric Association, 2013). Currently, researchers favor the Rome-III criteria based on a biopsychosocial model (Drossman et al., 2006).

\section{Current Treatment Methods for Retentive Fecal Incontinence}

Management of constipation and fecal incontinence has involved a wide variety of approaches. Some of the most prominent approaches include conventional medical treatment, behavioral and cognitive interventions, diet modification, biofeedback, massage protocols, and treatments based on neuromodulation.

Conventional medical treatment. Current reviews of available evidence on treatments for constipation and RFI (Brazzelli, Griffiths, Cody, \& Tappin, 2011;Tabbers, Boluyt, Berger, \& Benninga, 2011b) support the use of conventional medical management. This treatment regime consists of : 1) education for the family concerning the prevalence and pathophysiology of constipation and RFI, 2) disimpaction of accumulated feces when spontaneous expulsion is improbable (laxatives, enemas, surgical removal), 3) prevention of re-accumulation of feces (stool softener medication and/or laxatives), and 4) a non-punitive parental attitude which includes basic behavioral strategies such as log keeping and praise or small rewards for appropriate toileting behaviors and bowel movements (North American Society for Pediatric Gastroenterology, Hepatology and Nutrition, 2006; Van Dijk et al., 2008). Although conventional medical management is the most recommended and supported by current evidence, follow-up studies reveal that $25 \%$ to $50 \%$ of children do not respond to this treatment (Bongers, 
Van Wijk, Reitsma, Benninga 2010; Van Ginkel et al., 2003; Michaud et al., 2009; Pijper et al., 2010; Procter \& Loader, 2003; Staiano, Andreotti, Greco, Basile, \& Auricchio, 1994).

Behavioral and cognitive interventions. Specific behavioral treatments are often recommended in managing RFI in children who are resistant to conventional medical management alone, but evidence supporting the use of behavioral and cognitive therapies is weak (Brazzelli et al., 2011; Tabbers et al., 2010). Behavioral approaches for constipation and RFI involve: 1) direct psychological therapy aimed at reducing phobic reactions to defecation, 2) parent education on behavioral procedures, and 3) behavioral play therapy (Van Dijk, Benninga, Grootenhuis, Van Onland Nieuwenhuizen, \& Last, 2007). The goal of the intervention is that children acquire adequate toileting behavior and appropriate defecation straining. However comprehensive behavioral treatments carried out by pediatric psychologists do not appear to offer any advantage over the basic, general behavioral strategies included in conventional medical management (Van Dijk et al., 2008). To date there has been only one rigorous randomized controlled trial that specifically described and compared conventional medical management and behavioral therapy (Van Dijk et al., 2008). The study involved 134 children assigned either to conventional medical treatment or to behavioral therapy for 12 visits during 22 weeks with similar intervals between treatment sessions and similar laxative therapy for all children. One week before the onset of the interventions all children were assessed for constipation and fecal incontinence. Those with organic causes of defecation disorders were excluded. Both groups showed significant improvement, and fecal incontinence and the proportion of children withholding stool was not significantly different between the 2 interventions. The authors conclude that behavioral therapy with laxatives had no advantage over conventional medical management alone. 
In contrast to the intense and closely managed behavioral program provided in the Van Dijk investigation (2008), Ritterband and colleagues (2003) compared an internet based program which provided education on toilet training and behavioral modifications to routine medical care. The study included 24 children aged 6 to 12 years, soiling at least once a week, and having no medical diagnosis, other than constipation, that could explain their fecal incontinence. Participants were provided with a personal computer, a printer and internet to access the 27 modules of the web-based program. The authors reported a significant reduction in the average weekly number of fecal incontinence episodes in the internet group compared to the no internet group; the proportion of cured children ( 0 soling incidents per week) in the web-based program was $70 \%$ compared to $45 \%$ in the conventional treatment group (Ritterband et al., 2003). A closer look at the frequency of visits to the different modules of the web based program revealed that modules dealing with fear of painful bowel movements, fear of sitting on the toilet and other toilet related fears received one or no visits compared to modules dealing with diet, taking trips and school strategies, which received between 8 and 16 visits. It is possible that the small group of children $(n=12)$ in the internet group were not experiencing the behaviors typical of young children with RFI. Further, while this supports the use of a novel type of behavioral intervention for fecal incontinence, investigators did not clearly distinguish between children with retentive and non-retentive fecal incontinence, a factor of utmost importance since the underlying issues between the two conditions are very different (Bischoff \& Tovila, 2010).

Diet modification. Treatments aimed at increasing fiber intake in children are described by many investigators (Karagiozoglou-Lampoudi et al., 2012; Kuhl et al., 2009; Sullivan et al., 2012). A recent review of the efficacy of non-pharmalogical therapies for constipation concludes that current evidence related to increased fiber intake is weak (Tabbers et al., 2011b). Sullivan 
and colleagues (2012) confirm these findings. In this study children aged 2 to 14 , were given a color coded chart entitled "How to Collect Your Fibre Points". Detailed information on the fiber content of commonly consumed foods was included. Children were encouraged to achieve their recommended daily intake of fiber by accumulating "Fibre Points", $1 \mathrm{~g}$ of fiber being equivalent to one "Fibre Point". Stickers, managed by the parents, were given to the child to put in his chart if the targeted amount of fiber intake was achieved. Their program was successful in increasing and maintaining fiber intake, however, no significant benefit in terms of a reduction in laxative use or increased stool frequency was demonstrated.

Biofeedback. Biofeedback has been used to teach children how to control their sphincter muscles. It may be employed in the case of children with pelvic floor dyssynergia to teach them to relax their sphincter muscles or in the case of weakness of pelvic floor muscles to teach contraction of sphincter muscles (Brazzelli et al., 2011; Chiarioni \& Whitehead, 2008). The technique involves registering anal sphincter muscle tone through a small probe in the anus of the child or from surface electrodes taped to the perianal skin. The muscle tone of the external anal sphincter is then displayed on a screen or a sound modulation device. Trials using biofeedback have shown improvement in pelvic floor dyssynergia but improvements in constipation and fecal incontinence were not sustained (Loening-Baucke 1995; Plas et al., 1996). This technique appears to be more useful in children who have non retentive fecal incontinence than those with RFI (Chiarioni \& Whitehead, 2008). Moreover this technique requires sustained attention and complex cognitive abilities that may be beyond the capabilities of young children (Chiarioni \& Whitehead, 2008).

Massage protocols. Support for the use of massage in the treatment of constipation is limited in the mainstream scientific literature but is reported to abound among the practitioners of 
traditional Indian, Chinese, Arabian, Egyptian, and Greek medicine (Culbert \& Banez, 2007; Silva, Cignolini, Warren, Budden, \& Skowron-Gooch, 2007).

Culbert and Banez (2007) in their review of complementary and alternative medicine for the treatment of constipation and encopresis describe different massage techniques and qualify them as promising although little evidence is provided. The authors describe a technique which consists of a) imagining the abdomen as a clock, with the navel representing the center of the clock, b) applying gentle, clockwise massage of the abdomen at a 2 to 3 inch span from the navel, administered with mild-to-moderate pressure, 30 seconds to 1 minute at each location (hours on the imaginary clock). They report that in their experience this technique has been beneficial for promoting bowel activity in young children (Culbert \& Banez, 2007).

Other massage techniques not specifically applied to the abdomen have been associated with improved bowel function in children (Barlow \& Cullen, 2002; Silva et al., 2007). Silva et al. (2007) describe a Chinese massage applied to the entire body in children with autism. The children received 5 months of daily massage. The technique was applied by both a trained practitioner (twice a week during 2 five week blocks of treatment) and the parent who learnt the technique as the massage was being applied to her child. All of the parents were asked to comment on their child's bowel habits before the start of the intervention. Three of the children in the study $(\mathrm{n}=15)$ were reported to have constipation. All three children were reported to have more frequent bowel movements following the treatment. No specific medical assessments of bowel function or log keeping methods were reported.

Barlow and Cullen (2002) also document parent reports of improved bowel function following a seven week massage program for 42 children with developmental disabilities. Parents were instructed weekly (one hour sessions) by a trained qualified practitioner on how to apply the 
massage techniques and encouraged to apply these techniques to their child on their own. Once again no reports of specific medical assessments of bowel function or log keeping methods are provided.

Treatments based on neuromodulation. Recent research on the role of the brain-gut axis in the etiology of functional gastrointestinal disorders has opened the way to new and promising treatment approaches based on neuromodulation. Treatments using neuromodulatory interventions include behavioral interventions (relaxation techniques, cognitive therapy), pharmacological treatments and direct electrical stimulation of neural circuits (Bonaz \& Sabate, 2009; Lackner et al., 2006; Mayer, Tillisch, \& Bradesi, 2006; Chase, Robertson, Southwell, Hutson, \& Gibb, 2005; Gaman \& Kuo, 2008; Ismail et al., 2009; Leong et al., 2011). Most of the investigation in neuromodulatory treatments has focused on irritable bowel syndrome (IBS) (Mayer \& Tillisch, 2011). Although not directly applicable to children with RFI at this time, research is this area could become relevant to childhood constipation and fecal incontinence because many adults with IBS report childhood gastrointestinal motility disorders suggesting a common etiology (Halder et al., 2007; Mayer \& Tillisch, 2011).

In children with constipation, neuromodulation treatment has been extensively studied by an Australian research group with focus on the use of abdominal transcutaneous electrical stimulation (TES) (Chase et al., 2005; Clarke et al., 2009; Ismail et al., 2009; Leong et al., 2011; Yik, Ismail, Hutson, \& Southwell, 2012.). Long term follow-up of children treated with this technique offers promising results (Leong et al., 2011). Children with slow transit constipation were treated with TES for 1 to 2 months in a randomized controlled trial. Physiotherapists administered 1 to 2 months of TES to 39 children (20 minutes, 3 times a week) and 15 children continued to self-administer TES (30 minutes daily) for more than 2 months. Follow-up of 30 of 
the 39 patients was conducted using a questionnaire. Seventy-three percent of patients perceived improvement in at least 1 symptom (defecation, soiling, abdominal pain) after the clinical trial. Improvement lasted more than 2 years in $33 \%$ of the children. Defecation frequency improved in $30 \%$, soiling improved in $75 \%$ and abdominal pain in 59\%. Programmed toilet time switched to urge-initiated defecations in $80 \%$ of the children (Leong et al., 2011).

Although treatment results are promising, researchers have yet to clarify the mechanism of TES. It appears that electrical stimulation could be activating sensory nerve fibers in the skin, sensory and motor nerves in the spinal nerves, sympathetic and parasympathetic nerves, intestinal muscle cells, enteric nerves in the bowel wall or pacemaker cells in the intestine (Leong et al., 2011; Southwell, King, \& Hutson, 2005).

Treatment methods for constipation and fecal incontinence have greatly evolved in the past years and there exists a substantial body of research on the efficacy of different treatment approaches. However, success rates for treatment remain limited and many children continue to struggle with constipation and fecal incontinence into adulthood (Van Ginkel et al., 2003; Michaud et al., 2009; Pijpers et al., 2010). The currently accepted biopsychosocial model of functional gastrointestinal disorders along with growing knowledge of the role of the brain-gut axis and it's neuromodulatory functions, pave the way for occupational therapists with advanced training in sensory integration to take on a more active role in the research on treatment of RFI and other functional gastrointestinal disorders.

\section{Occupational Therapy in the Treatment of Retentive Fecal Incontinence}

The field of OT has not been traditionally involved in the management of children with RFI. However, there are some reports of the involvement of occupational therapists (OTs) in the 
treatment of children with constipation and fecal incontinence (Beaudry Bellefeuille \& Ramos Polo, 2011; Beaudry et al., 2013; Collis, Norton, \& Wallace, 2007; Handley-More et al., 2009).

The Pondering Poos treatment program. The Pondering Poos program, lead by an occupational therapist and a pediatric dietician, consists of education for caregivers and support with the behavioral aspects of a standard medical treatment program (Collis et al., 2007). The program is aimed at parents and caregivers of children aged 2-16 years with chronic constipation, fecal incontinence and toilet refusal for stools. The children and their families were referred to the occupational therapists through the referral system of a public hospital in Australia. Twentyfive percent of referrals to occupational therapy at this hospital were for children with chronic constipation. The overall program included a community parent education group, a community child intervention group, an interdisciplinary hospital clinic, and individual discipline consultations. Pondering Poos represented the community parent education group program of this service delivery model. The child intervention portion of the services was not described.

The parent education program included didactic presentation of definitions, classifications, pathophysiology and medical management of chronic constipation. Dietary and behavioral management was discussed in relation to the implementation of diet and behavioral strategies. Discussion of the emotional aspects of RFI for both children and parents was also included. Informal evaluation of the program using a parent satisfaction survey showed that parents highly valued timely access to accurate information and the possibility to meet with other parents (Collis et al., 2007). The survey and complete results are not included in the report.

A multi-disciplinary school based treatment program. A multi-disciplinary school based approach for fecal incontinence which includes consideration of sensory processing difficulties has been reported to be beneficial for students with fecal incontinence (Handley-More 
et al., 2009). The authors do not describe the assessment or the treatment in detail. An account of the collaborative efforts of a school nurse, counselor and occupational therapist in the management of children with fecal incontinence is given. Handley-More and colleagues (2009) describe hypersensitivity to touch, smell and sound as possible factors interfering with acceptance of the different aspects of toileting. The authors conclude that analyzing the child's difficulties simultaneously from a physiological (nurse), behavioral (counselor) and sensory (occupational therapist) point of view allows for more efficacious management of fecal incontinence.

The Happy Potty treatment program. Another program, co-lead by the student investigator and a pediatric gastroenterologist, includes standard medical management as well as treatment of sensory processing difficulties and their effects on participation in toileting routines and medical recommendations. The children that participated in this program had all failed at least one trial of conventional medical management. The children's ages ranged from 2 to 15 years, with 11 of the children with ages between 2 and 5 years. Eleven of the twelve children were identified as having sensory over-responsivity in at least one sensory system according to the responses given by one of the parents on the Sensory Profile (Dunn, 1999). Seven children presented signs of vestibular over- responsivity, 4 had tactile over-responsivity, 4 had auditory over-responsivity and 1 had oral over-responsivity. Five of the children presented overresponsivity in 2 different systems, while the remaining 6 children had signs of over-responsivity in a single sensory system. Preliminary clinical data from this program reveals that over $80 \%$ of the participants (ten of the twelve participants) showed significant improvement in regulating their defecation once the treatment was individually tailored to address the sensory issues of each child (Beaudry Bellefeuille \& Ramos Polo, 2011). A more detailed account of another child who participated in the same treatment regime and presented with RFI and tactile defensiveness also 
supports the use of this individualized treatment approach which includes consideration of sensory issues and conventional medical management (Beaudry et al., 2013).

\section{Reflections on the management of children with retentive fecal incontinence in}

occupational therapy. Following recent recommendations for evidenced based practice (Schaaf \& Blanche, 2012), occupational therapists could become key components of multidisciplinary teams for children with defecation disorders. Schaaf and Blanche (2012) formulate the Data Driven Intervention Process (DDIP) and describe the steps designed to organize and guide the therapist's reasoning:

1) Identify participation challenges, 2) Describe current behavior and identify theory/approach, 3) Identify and administer standardized and non-standardized assessments, 4) Create hypothesis about the factors affecting participation challenge and consider strengths and environmental targets, 5) Implement intervention protocol and, 6) Identify proximal and distal outcomes and strategies for measuring and charting outcomes (Schaaf \& Blanche, 2012, p.504).

The DDIP is meant to create a continuous link between assessment, hypothesis generation and the development of intervention strategies that can be methodically tested with clearly identified outcome measures.

Occupational therapists who have acquired basic knowledge concerning defecation disorders could apply their professional expertise to: a) analyze in detail the child's participation challenges in regard to toileting routines and/or adherence to conventional medical treatment recommendations, b) systematically assess the strengths and weaknesses of the individual and the environment that support or limit participation in toileting routines and/or adherence to conventional medical treatment recommendations, c) build upon the strengths and address the 
weaknesses of the individual and the environment to create individually-tailored interventions that maximize participation in toileting routines and/or adherence to conventional medical treatment recommendations.

Available literature clearly acknowledges a behavioral component to RFI and researchers agree that behavioral issues that interfere with treatment recommendations or that affect the child's well being should be specifically evaluated and treated (Benninga et al., 2004; Culbert \& Banez, 2007; Van Dijk et al., 2008). However, current research examines these behavioral problems mainly from a psychological perspective. An alternative perspective, based on sensory integration theory, could offer additional insight. For example, some of the behaviors exhibited by children with RFI appear to be related to their sensory function, and these differences in sensory processing could possibly be affecting children's participation in normal toileting routines and/or adherence to conventional medical treatment recommendations for RFI (Beaudry Bellefeuille \& Ramos Polo, 2011; Beaudry et al., 2013; Handley-More et al., 2009). Analysis of these difficulties using the DDIP (Schaaf \& Blanche, 2012) described above could contribute to improving the current treatment success rates in children with RFI.

To thoroughly apply the DDIP, a stronger knowledge base concerning the characteristics of children with RFI needs development. Physiological, emotional, behavioral and psychosocial characteristics have been and continue to be studied by researchers in the fields of medicine and psychology but our knowledge of the sensory characteristics of these children is grossly inadequate. The field of OT has developed an expertise in the assessment of sensory processing and has documented the sensory characteristics of a variety of diagnostic groups. For example atypical sensory responsivity has been identified in children with autism (Kientz \& Dunn, 1997; Reynolds, Bendixen, Lawrence, \& Lane, 2011; Tomchek \& Dunn, 2007), apraxia of speech 
(Newmeyer et al., 2009), ritualistic behavior (Dar, Kahn, \& Carmeli, 2012), attention deficit hyperactivity disorder (ADHD) (Lane, Reynolds, \& Thacker, 2010; Parush, Sohmer, Steinberg, \& Kaitz, 2007; Reynolds \& Lane, 2009) and dysfunctional elimination syndrome (DES) (Pollock, 2012).

It is therefore reasonable that the analysis of the sensory characteristics of children with RFI be carried out within OT. There is also an urgent need to develop specific assessment tools that will assist us in the systematic assessment of the participation difficulties of these children, an essential element of the DDIP (Schaaf \& Blanche, 2012).

Knowledge concerning the sensory processing characteristics of children with RFI as well as the availability of screening tools to filter out children at risk of sensory based toileting difficulties would contribute to the development of more efficacious diagnostic procedures and treatment programs for this common childhood problem. The present study aims to fill the gap that currently exists in our knowledge concerning the sensory processing characteristics of children with RFI. 


\section{Chapter 3 Methodology}

Information is emerging that is strongly suggestive of a link between RFI and sensory over-responsivity. Recent work from the student investigator's clinical population indicated that a majority of children with RFI referred to OT had some type of sensory over-responsivity (Beaudry Bellefeuille \& Ramos Polo, 2011). Further, Handley-Moore and colleagues (2009) suggested that a multidisciplinary intervention program for fecal incontinence which included consideration of sensory over-responsiveness by an occupational therapist was key in successfully helping students with fecal incontinence (Handley-Moore et al., 2009). A detailed case report of a child with RFI and tactile over-responsiveness also supports the use of a treatment approach which specifically deals with the sensory issues that affect toileting (Beaudry et al., 2013).

A recent study revealed a link between auditory startle reflexes and functional abdominal pain among children, possibly providing evidence of a general hypersensitivity of the central nervous system among children with gastrointestinal disorders (Bakker et al., 2010). And, researchers have found that children with autism spectrum disorder and higher levels of sensory over-responsivity also displayed the most gastrointestinal problems (Mazurek et al., 2012). This mounting evidence points to the possibility that sensory over-responsivity could be a common underlying condition in RFI and other types of gastrointestinal problems. However, this relationship requires further examination. 


\section{Research Questions and Hypotheses}

Question 1. In three to five year olds, how well does the Toilet Habit Profile Questionnaire (THPQ) differentiate between typical children and children with physician diagnosed retentive fecal incontinence that has not responded to first line treatment from a general practitioner or pediatrician?

Hypothesis for question 1. In three to five year olds, the THPQ will differentiate between typical children and children with retentive fecal incontinence that has not responded to first line treatment from a general practitioner or pediatrician.

Parents have described a series of particular behaviors that are common to many of the children who are referred to OT for RFI. These behaviors have been gathered in a questionnaire format and, following revision by a group of experts, the questionnaire has been used in this study to determine if the behaviors described are specific to a broader group of children with RFI.

Question 2. What are the relationships among sensory over-responsivity (SOR), scores on the THPQ, and RFI which has not responded to first line treatment from a general practitioner or pediatrician, in children aged three to five years old?

Hypotheses for question 2.The following hypotheses have been examined: 1) a low SOR score (greater sensory over-responsivity) will be associated with decreased scores on the THPQ, 2) children with RFI will show lower scores on the THPQ than children without RFI, and 3) children with RFI will show lower SOR scores than children without RFI.

\section{Study Design}

In examining the relationship between retentive fecal incontinence (RFI) and sensory over-responsivity, this investigation first addressed the face validity of the Toileting Habit Profile Questionnaire (THPQ) and confirmation of the validity of the Spanish version of the SSP (S- 
SSP) for Spanish (Spain) caregivers. The face validity of the THPQ was assessed through expert panel consultation with 3 gastroenterologists, representing private practice and the major hospitals of the province of Oviedo. Consultation with occupational therapists with expertise in sensory integration and knowledge of potential issues related to activities of daily living in children was also sought. Members of the expert panel were bilingual (English-Spanish). To assess the validity of the S-SSP in Spain, parents of children aged 3 to 5 were recruited from among the families who attend the private OT clinic of the student investigator and asked to participate in cognitive interviews.

Following refinement of the tools, parents of three to five year old children with physician diagnosed RFI were asked to complete two different questionnaires; the THPQ, a bilingual (English-Spanish) tool, and the S-SSP (R-Spain). A comparison group of parents of typical children, age and gender matched, was also recruited and asked to complete both questionnaires.

\section{Subjects}

Conservative estimations based on clinical experience with a previous version of the THPQ showed an expected difference of 7 points in the mean scores of typical children and children with RFI. Based on these estimates and N-Query Advisor ${ }^{\circledR}$ sample size calculations for a Wilcoxon rank-sum test, it was determined that a minimum of 19 parents should be interviewed in each group. Concerning the correlation of TPHQ and SOR scores, sample size calculations for an expected correlation of 0.4 , with a power of 0.8 , were done using $G^{*}$ Power version 3.1.5; a sample size of 46 was recommended. Accordingly, efforts were made to recruit over a period of 4 months, two groups of 25 parents of children aged between 36 and 71 months at the time the questionnaires are filled out. For the group comprised of parents of children with physician diagnosed RFI, who did not respond to first line treatment by the child's pediatrician or general 
practitioner, 16 participants were recruited and met the inclusion criteria. For the second group, comprised of parents of typically developing children, 27 participants were recruited and eligible for the study. Since sample sizes of 25 were not achieved for both groups at the end of the 4 month recruitment period, the data has been analyzed and treated as a pilot study to gather information about effect sizes, validity and reliability of the measures in order to provide information for a larger study in the future.

Parents whose 3 to 5 year old children experience fecal incontinence as part of the symptoms of functional constipation according to Rome III criteria and have no other diagnosis were included in the RFI group. Children with organic causes of RFI, including Hirschsprung's disease, muscle disorders, prior rectoanal surgery, spina bifida, mental retardation, or hypothyroidism were not eligible. Diagnosis of RFI and screening for medical conditions was done by the child's referring physician as part of the standard medical management of constipation and fecal incontinence. During the initial contact with potential participants, questions about the child's defecation habits were asked to screen for RFI. In the case of parents interested in participating in the study and coming from referral sources other than physicians, children with suspected RFI were referred for medical screening by a physician prior to participation. For both the RFI group and the typical group, parents of children with intellectual disability, neurological conditions, such as cerebral palsy, or with psychiatric disorders, such as bipolar disorder or oppositional defiance disorder were excluded. In Spain, children aged 3 to 5 are typically enrolled in preschool programs which screen for developmental disorders. Therefore children who have a curricular adaptation at school or who qualify for their school's special needs program were excluded. Furthermore, pediatricians of the public health services also periodically screen children for mental health and developmental disorders and refer to early 
intervention programs accordingly. Children who had been referred to these programs were also excluded.

This age range was chosen for multiple reasons. It has been hypothesized, that the symptoms of feeling pain upon defecation and toilet avoidance may be more significant at younger ages, at the onset of RFI (Borowitz, Cox, Sutphen, 1999). It has also been hypothesized that these symptoms could be related to sensory over-responsivity to the sensations associated with defecation and partly responsible for the onset and maintenance of the difficulties children with RFI have establishing healthy toileting routines (Beaudry Bellefeuille \& Ramos Polo, 2011; Beaudry et al., 2013; Handley-More et al., 2009).

Also this age range has been reported to be the age of highest prevalence for childhood constipation (Van den Berg et al., 2006). Finally, although the diagnosis of encopresis (fecal incontinence) according to DSM V (APA, 2013) is not given before age four, studies have shown that most children acquire fecal continence by approximately the age of 3 years (Schum et al., 2002; Wald et al., 2009).

Subject recruitment. This study took place in Spain. Participants in cognitive interviews were recruited using a quota sampling method. This method is adequate for cognitive interviews and allows the investigator to recruit participants according to a pre-established range of characteristics (Willis, 2005). Sample sizes using this method usually range from 5 to 10 participants (Willis, 2005). As in the study described by Roman-Oyala and Reynolds (2010), a sample of eight caregivers was recruited based on a heterogeneous representation of the following characteristics: private vs public school, parent education, and family income. To avoid asking directly for family income, a cultural taboo in Spain, income level was determined based on eligibility of the family to receive governmental scholarships for school supplies and lunch at 
school. Families are eligible for scholarships when the total annual income of the family is inferior to 5000 Euros per member.

Local pediatric gastroenterologists and occupational therapists from both public and private clinics were contacted for recruitment of parents of children aged three through five diagnosed with retentive fecal incontinence that had not responded to a first trial of treatment by the child's pediatrician. Word of mouth and snowball recruitment was also used. Parents of typically developing children were recruited through the parent-student associations of local schools, both public and private, and arising from a representative social economic background. Personal meetings, flyers and permission to contact forms were offered to all potential recruitment sources. The exclusion criteria described previously was applied.

\section{Measures}

Toileting Habit Profile Questionnaire. The Toileting Habit Profile Questionnaire (Appendix A) was developed by the student investigator, an occupational therapist, in Spain in a bilingual (Spanish-English) format. It has been reviewed for linguistic accuracy by Miguel Sanz Ovies an experienced translation consultant and by Dr. Ramos Polo, pediatric gastroenterologist with experience in the translation of assessments to Spanish. Grade level for the THPQ was 5.8 as determined through Microsoft WORD. Slightly different versions have been used clinically for the last several years. The THPQ explores what can be considered normal toileting behaviors and normal reactions to defecation. It is divided in two sections: a) over-responsivity and b) underresponsivity. Scored using a 5 point likert scale (almost always through never), questions on the TPHQ include the following:

- My child hides while defecating.

- My child asks for a diaper when he feels the need to defecate. 
- My child refuses to sit on the potty or the toilet to defecate.

- My child always follows the same ritual when defecating.

- My child seems to feel pain when defecating.

- My child defecates only when paying attention to something else (while playing or watching television for example).

- My child refuses to go to the toilet outside of the home.

- My child's reaction to the odor of his/her feces is exaggerated.

- My child refuses to wipe or be wiped after defecating.

- My child does not seem to feel the urge to defecate.

- My child does not realize he has soiled (feces) his clothes

The questionnaire is meant to be a screening tool for OTs or other child development professionals to help differentiate typical toileting behaviors and reactions to toileting sensations, from those that are associated with RFI.

What represents typical toileting behaviors and typical reactions to toileting sensations is currently not well documented. Response to sensations related to sitting on the toilet/potty, feeling the passage of stool and removing clothing seem to have an impact on the acceptance of toilet training and the response to the urge to defecate in some children with RFI (Beaudry Bellefeuille \& Ramos Polo, 2011; Beaudry et al., 2013). An earlier version of the Toileting Habit Profile Questionnaire (THPQ) has been used in the previously mentioned treatment program for RFI combining OT and conventional medical treatment (Beaudry Bellefeuille \& Ramos Polo, 2011).

To examine the face validity of the THPQ, consultation was done using an expert panel format with 3 pediatric gastroenterologists representing private practice and the major hospitals 
of the province of Oviedo. Three occupational therapists with expertise in ASI® and knowledge of potential issues related to activities of daily living in children were also sought to form part of the expert panel. The consultation process took place through an internet based survey system hosted by Virginia Commonwealth University. The THPQ along with a cover letter and a series of probe questions was made available to each expert. Prior to the actual consultation process, an initial contact with potential experts was carried out to verify credentials, to inquire about knowledge related to activities of daily living and toileting issues in children (in the case of occupational therapists), and to ask about knowledge level of Spanish and English. The following probe questions were asked about each of the items: 1) How do you interpret what the item is asking?, 2)Why do you think a child would have such a behavior?, 3) Do you think that typically developing children have this behavior? 4) Do you think that this behavior is common in children with constipation and fecal incontinence? 5) Do you think that this behavior could be related to over-responsivity to the sensations related to defecation (feel of potty/toilet on skin, anal/rectal distention; smell of feces, etc.)? Other spontaneous questions and comments made by the respondents were taken into account. The comments and feedback from the expert panel were used to modify THPQ questions as needed.

Short Sensory Profile. The Spanish version of the Short Sensory Profile (SSP) (McIntosh et al., 1999) was used to assess sensory processing abilities. The SSP is a 38 item condensed version of the original 125 item Sensory Profile (SP) (Dunn, 1999). Both the SP and the SSP are caregiver questionnaires that measure responses to sensory events in daily life, in children aged between 3 and 10 years. The data provided by these questionnaires allows therapists to analyze how certain patterns in sensory processing may be related to performance and participation difficulties in daily occupations (Dunn, 1999). 
The SP research sample included 1037 typical children between the ages of three and ten years from all areas of the United States. Boys and girls were evenly represented. Representation by race was predominately white $(91.4 \%)$. Hispanic children represented $1.5 \%$ of the sample. Data extracted from this sample was also used for the principal component factor analysis carried out during the development of the SSP (Dunn, 1999).

The internal consistency of the SP was calculated using Cronbach's alpha and ranged from 0.47 to 0.91 for the various sections. The SP's content validity was evaluated by 155 expert occupational therapists who categorized items into 8 pre-determined categories. Eighty percent of the therapists agreed on category placement of $63 \%$ of the items (Dunn, 1999). Convergent and discriminate validity was evaluated by comparing scores of the SP with functional tasks on the School Function Assessment (SFA) (Coster, Deeney, Haltiwanger, \& Haley, 1998 in Dunn, 1999). Correlations between Factor 9 of the SP (Fine Motor/Perceptual) and the performance items of the SFA were large and meaningful ranging from -.502 to -.720. The correlations between the Behavioral Regulation and Positive Interaction sections of the SFA and the modulation sections from the SP were moderate, and also suggest convergent validity. Low correlations on the more detailed performance items of the SFA and the items of the SP provide evidence of discriminate validity.

The development of the SSP consisted of choosing key items from the SP to create a short questionnaire useful for screening and for research. This was done in three phases (McIntosh et al., 1999). The first phase involved removing all of the items not directly related to the construct of sensory modulation and examining the remaining items for their discrimination ability. Next, a principal component factor analysis was conducted to establish the seven sections of the SSP: 1) Tactile Sensitivity, 2) Taste / Smell Sensitivity, 3) Movement Sensitivity, 4) Underresponsive / 
Seeks Sensation, 5) Auditory Filtering, 6) Low Energy / Weak, and 7) Visual Auditory

Sensitivity. Finally researchers calculated the item-to-total correlations and coefficient alpha for each section and conducted another principal component factor analysis with the 38 remaining items.

The reliability coefficients of the SSP were estimated by calculating Cronbach's alpha. The reliabilities for test total and sections range from .70 to .90 (McIntosh et al., 1999). Internal validity was examined by analyzing the intercorrelations of the SSP total and section scores. The correlations ranged from .25 to .76 , suggesting that the sections of SSP represent relatively unique constructs (McIntosh et al., 1999). Comparison of SSP scores and electrodermal responses (EDR) to a protocol of sensory inputs was used to examine construct validity. Children who had abnormal EDR scored significantly lower $(\mathrm{p}=<.05)$ on all sections of the SSP than children with normal EDR, therefore providing evidence of construct validity for the SSP (McIntosh et al., 1999). The SSP is also shown to adequately discriminate between children with sensory modulation disorder and typically developing children (McIntosh et al., 1999).

The 38 questions of the SSP, explore the child's reaction to sensation in daily situations. For example question 3 is "Avoids going barefoot, especially in sand or grass." The caregiver determines how often the stated behavior occurs and a 5 point classification system allows obtaining a sum of scores for each section (always: 5 points, often: 4 points, sometimes: 3 points, rarely: 2 points, never: 1 point). Answers are summed and a score is calculated for each section. Higher scores reflect more behaviors which are within normal limits. Lower scores reflect difficulty processing sensory input in daily life.

Short Sensory Profile - Spanish version (S-SSP). According to Roman-Oyala and Reynolds (2010), the SSP was translated into Spanish using a back translation process. Using this 
process the questionnaire was translated from English to Spanish, and then translated back into English by a translator who had no knowledge of the original version. Finally, the original and back-translated versions were compared to verify for accuracy. This technique is widely accepted and has been used in the translation process of the SP into other languages and in the translation process of other English questionnaires into Spanish (Martinez, Marín, \& Schoua-Glusberg, 2006; Neuman, Greenberg, Labovitz, \& Suzuki, 2004; Wild, Furtado, \& Angalakuditi, 2012).

Validation of the use of the Spanish version of the SSP (Dunn, 1999) in Spain is warranted as this tool was originally aimed at Spanish speakers living in the United States. In the student investigator's clinical practice, Spanish speaking parents living in Spain have not shown any difficulties understanding the current Spanish version, and overall have found the questions pertinent to their culture. To confirm these impressions cognitive interviews with caregivers of children aged 3 to 5 years were conducted using the methodology described by Roman-Oyala and Reynolds (2010) in their study validating the Spanish version of the SSP for Puerto Rican caregivers. Other authors describe similar approaches in the study of surveys and questionnaires (Christodoulou, Junghaenel, DeWalt, Rothrock, \& Stone, 2008; Watt et al., 2008; Yorkston et al., 2008).

Cognitive interviewing is a common method for evaluating the comparability of survey questions in different languages (Ridolfo \& Schoua-Glusberg, 2011). This technique allows researchers to examine the manner in which targeted audiences understand, mentally process, and respond to questions presented to them (Willis, 2005). The insight gained through this process guides the researcher in the modification of the questions to enhance comprehension and clarity (Willis, 2005). Sample sizes used in cognitive interviewing are small, generally between 5 and 15 (Willis, 2005). Subject recruitment usually depends on quota sampling in an effort to obtain 
subject variation across a range of characteristics (Willis, 2005). Interviews are conducted individually and it is recommended that audio or video recording be used to attend to subtle issues that may be missed during the live interview (Willis, 2005).

Cognitive interviewing to verify the validity of the S-SSP in Spain involved eight caregivers of children aged 3 to 5 years recruited from among the families who attend the private OT clinic of the student investigator. Caregivers were asked a series of open ended questions concerning each item during an individual, audio-recorded interview following response to the questionnaire in a paper and pencil format. During the interview, participants were asked to communicate questions or doubts concerning the S-SSP. They were also encouraged to share suggestions on how to make the S-SSP more understandable. The following probe questions were asked about each of the items after completing each one of the questionnaire's sections:

1) How do you interpret what the item is asking?, 2)What are some examples of your child's behavior that made you choose that answer?, and 3) What changes, if any, would you make to the item to improve its understanding? (Roman-Oyala \& Reynolds, 2010, p.200).

Other spontaneous questions and comments made by the respondents were taken into account. Questions that were unclear to the majority of interviewed parents were revised for clarity. Questions that have been substantially revised were posed to 4 parents for affirmation; 2 who had initially identified the questions as unclear and 2 additional parents. The same probe questions were used to verify the revised questions.

\section{Data Analysis}

Since the purpose of the study is to examine sensory over-responsivity, data analysis was done on a subset of relevant items from the THPQ and the SSP. In relation to the THPQ, the 
analysis included the score obtained on the first section (over-responsivity) of the questionnaire. Lower scores in the first section of the THPQ are more indicative of behaviors hypothesized to be specific to children with RFI. In the case of the SSP, analysis was done as described by Mazurek and colleagues (2012). A sensory over-responsivity score was calculated using the scores of the items designed to detect over- responsivity: Tactile Sensitivity (items 1-7), Taste/Smell Sensitivity (items 8- 11), Movement Sensitivity (items 12-14), and Visual Auditory Sensitivity (items 34-38). Lower scores on the SSP indicate greater difficulties; therefore a lower sensory over-responsivity score is indicative of greater sensory over-responsivity.

Group comparisons between children with and without RFI were conducted using Mann Whitney U test. Differences were considered statistically significant when $p<.05$. A correlation coefficient was calculated to analyze the relationships between the SOR score and the THPQ score. Research questions, hypothesis, variables and statistical analysis are summarized in Table 1.

\section{Data and Safety Monitoring}

Letter coding was used to identify participants and the key linking the codes to demographic data and questionnaires is kept in a locked location in the researcher's home. Results of the questionnaires and data entered into data-analysis software are kept on the researcher's personal computer and protected by a password. A copy of the coded, computerized data is kept on an external thumb drive and stored in a locked location in the researcher's home, different from the location for safekeeping of the code key. Hand filled questionnaires are stored under the subjects' letter code and kept in a file in the researcher's home, separate from the code key.

Parents were informed that only the researcher would have access to demographic data and the code key. Three years after the researcher presents her results, all demographic 
Table 1: Research Question and Hypotheses

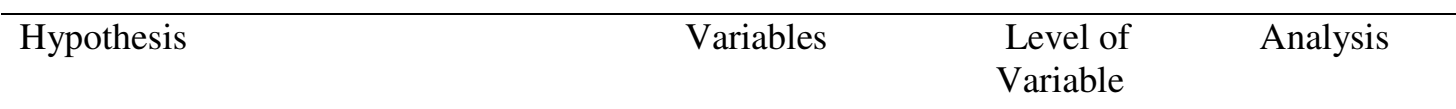

Research Question 1. In three to five year olds, does the THPQ differentiate between typical children and children with physician diagnosed retentive fecal incontinence that has not responded to first line treatment from a general practitioner or pediatrician?

\begin{tabular}{llll}
\hline $\begin{array}{l}\text { In three to five year olds, the THPQ will } \\
\text { differentiate between typical children and } \\
\text { children with retentive fecal incontinence } \\
\text { that has not responded to first line }\end{array}$ & $\begin{array}{l}\text { IV: RFI or } \\
\text { TYPICAL }\end{array}$ & $\begin{array}{l}\text { Categorical } \\
\text { (Dichotomous) }\end{array}$ & $\begin{array}{l}\text { Mann- } \\
\text { Whitney U } \\
\text { test }\end{array}$ \\
$\begin{array}{l}\text { pediatrician. } \\
\text { pediant from a general practitioner or }\end{array}$ & DV: THPQ score & $\begin{array}{l}\text { Ordinal } \\
\text { (treated as }\end{array}$ & \\
& & $\begin{array}{l}\text { continuous } \\
\text { without any } \\
\text { distributional }\end{array}$ & \\
& & assumptions)
\end{tabular}

Research Question 2. What are the relations among SOR, scores on the THPQ, and RFI which has not responded to first line treatment from a general practitioner or pediatrician, in children aged three to five years old?

\begin{tabular}{|c|c|c|c|}
\hline $\begin{array}{l}\text { A low SOR score (greater sensory } \\
\text { over-responsivity) will be associated } \\
\text { with decreased scores on the THPQ. }\end{array}$ & $\begin{array}{l}\text { IV: THPQ score } \\
\text { DV:SOR score }\end{array}$ & $\begin{array}{l}\text { Ordinal (treated } \\
\text { as continuous } \\
\text { without any } \\
\text { distributional } \\
\text { assumptions) }\end{array}$ & $\begin{array}{l}\text { Spearman } \\
\text { Correlation }\end{array}$ \\
\hline $\begin{array}{l}\text { Children with RFI will show lower } \\
\text { scores on the THPQ than children } \\
\text { without RFI. }\end{array}$ & $\begin{array}{l}\text { IV: RFI } \\
\text { DV: THPQ score }\end{array}$ & $\begin{array}{l}\text { Categorical } \\
\text { Ordinal (treated } \\
\text { as continuous } \\
\text { without any } \\
\text { distributional } \\
\text { assumptions) }\end{array}$ & $\begin{array}{l}\text { Mann- } \\
\text { Whitney U } \\
\text { test }\end{array}$ \\
\hline $\begin{array}{l}\text { Children with RFI will show lower } \\
\text { SOR scores than children without RFI. }\end{array}$ & $\begin{array}{l}\text { IV: RFI } \\
\text { DV:SOR score }\end{array}$ & $\begin{array}{l}\text { Categorical } \\
\text { Ordinal (treated } \\
\text { as continuous } \\
\text { without any } \\
\text { distributional } \\
\text { assumptions) }\end{array}$ & $\begin{array}{l}\text { Mann- } \\
\text { Whitney U } \\
\text { test }\end{array}$ \\
\hline
\end{tabular}

IV= Independent variable; DV= Dependent variable; RFI= Retentive fecal incontinence; $S O R=$ Sensory over-responsivity; THPQ= Toileting Habit Profile Questionnaire 
information will be destroyed.

\section{Informed Consent}

The parent of each child was presented with informed consent forms. The contents of those forms, the purpose of the study and methods used for the storage of data was explained to parents. Approval by the Virginia Commonwealth University Institutional Review Board was obtained before the beginning of the study. 


\section{Chapter 4 Results}

\section{Face Validity of the Toileting Habit Profile Questionnaire}

The face validity of the Toileting Habit Profile Questionnaire (THPQ) was assessed through expert panel consultation with 3 gastroenterologists, representing private practice and the major hospitals of the province of Oviedo and with 3 occupational therapists with expertise in sensory integration and knowledge of potential issues related to activities of daily living in children. All members of the expert panel were bilingual (English-Spanish).

Probe questions were asked about each of the items. The first question, "How do you interpret what the item is asking?", was interpreted as intended by only one expert. One expert systematically left this question blank. The remaining four experts proposed reasons for the behaviors described by the items, a response expected in the second question.

Experts responded to the second question, "Why do you think a child would have such a behavior?", with more than one rationale. For each item, responses were grouped into categories based on the wording and general idea transmitted by the statements from the experts. Responses showed relative agreement between experts; $90.9 \%$ of the items obtained at least $66.7 \%$ agreement on one of the factors considered to contribute to the behaviors described in the THPQ. The results are summarized in Table 2 .

Question 3, "Do you think that typically developing children have this behavior?", revealed that the panel of experts believed that many behaviors hypothesized by the investigator to be associated with RFI sometimes occur in typically developing children. The results are 
Table 2: Expert panel responses to probe question 2: Why do you think a child would have such a behavior?

\begin{tabular}{|c|c|}
\hline Item & Why do you think a child would have such a behavior? \\
\hline $\begin{array}{l}\text { 1. My child asks for } \\
\text { a diaper when he } \\
\text { feels the need to } \\
\text { defecate. }\end{array}$ & $\begin{array}{l}\text { - Negative association established with defecation outside } \\
\text { of diaper (pain, discomfort): } 4 \text { (66.7\% agreement) } \\
\text { - Self-concious: } 1 \\
\text { - } \quad \text { Poor toilet training: } 1\end{array}$ \\
\hline $\begin{array}{l}\text { 2. My child refuses } \\
\text { to sit on the potty } \\
\text { or the toilet to } \\
\text { defecate. }\end{array}$ & $\begin{array}{l}\text { - Negative emotions associated with defecation in potty or } \\
\text { toilet (pain, fear, discomfort, anxiety):6 (100\% } \\
\text { agreement) } \\
\text { - Sensory avoidance or over-responsivity: } 2 \\
\text { - Motor /postural challenges:2 } \\
\text { - Cognitive challenges: } 1\end{array}$ \\
\hline $\begin{array}{l}\text { 3. My child always } \\
\text { follows the same } \\
\text { ritual when } \\
\text { defecating. }\end{array}$ & $\begin{array}{l}\text { - Seeks security (minimize discomfort, reduce anxiety):5 } \\
(83.3 \% \text { agreement) } \\
\text { - } \quad \text { Rigid behavior associated with autism: } 1 \\
\text { - } \quad \text { Unable to answer: } 1\end{array}$ \\
\hline $\begin{array}{l}\text { 4. My child seems } \\
\text { to feel pain when } \\
\text { defecating. }\end{array}$ & $\begin{array}{ll} & \text { Feels pain:4 (66.7 \% agreement) } \\
\text { - } & \text { Constipated: } 1 \\
\text { - } & \text { Hyper-sensitive to the sensations related to defecation: } 1 \\
\end{array}$ \\
\hline $\begin{array}{l}\text { 5. My child } \\
\text { defecates only } \\
\text { when paying } \\
\text { attention to } \\
\text { something else. } \\
\end{array}$ & $\begin{array}{l}\text { - Attention shifted away from stressful/painful event and } \\
\text { therefore more relaxed: } 4 \text { (66.7\% agreement) } \\
\text { - Doesn't feel urge: } 1 \\
\text { - Learnt behavior:1 }\end{array}$ \\
\hline $\begin{array}{l}\text { 6. My child refuses } \\
\text { to go to the toilet } \\
\text { outside of the } \\
\text { home. }\end{array}$ & $\begin{array}{l}\text { - Negative emotions associated with defecation outside } \\
\text { the home (lack of control, disgust, discomfort):5 (83.3\% } \\
\text { agreement) } \\
\text { - Behavior learnt from parents: } 1\end{array}$ \\
\hline $\begin{array}{l}\text { 7. My child's } \\
\text { reaction to the } \\
\text { odor of his/her } \\
\text { feces is } \\
\text { exaggerated. }\end{array}$ & $\begin{array}{l}\text { Olfactory over-responsiveness: } 4 \text { (66.7 \% agreement) } \\
\text { - } \quad \text { Negative association of odor and unpleasant event } \\
\text { (defecation): } 1 \\
\text { - No answer: } 1\end{array}$ \\
\hline $\begin{array}{l}\text { 8. My child refuses } \\
\text { to wipe or be } \\
\text { wiped after } \\
\text { defecating. }\end{array}$ & $\begin{array}{l}\text { - Over-responsive to touch:3 (50\% agreement) } \\
\text { - Negative association due to painful experience:3 } \\
\text { - Behavior:2 }\end{array}$ \\
\hline $\begin{array}{l}\text { 9. My child does } \\
\text { not seem to feel } \\
\text { the urge to } \\
\text { defecate. }\end{array}$ & $\begin{array}{l}\text { Poor body awareness or loss of sensation in rectum due } \\
\text { to chronic distention:6 (100\% agreement) } \\
\text { - Developmental delay:1 }\end{array}$ \\
\hline $\begin{array}{l}\text { 10. My child does } \\
\text { not realize he has } \\
\text { soiled (feces) his } \\
\text { clothes. }\end{array}$ & $\begin{array}{l}\text { - Doesn't feel it/underresponsive:6 (100\% agreement) } \\
\text { - Ignores it: } 1 \\
\text { - Developmental delay:1 }\end{array}$ \\
\hline
\end{tabular}


summarized in the Table 3.

Table 3: Expert panel responses to probe question 3: Do you think that typically developing children have this behavior?

\begin{tabular}{|c|c|c|}
\hline \multicolumn{2}{|c|}{ Item } & \multirow{2}{*}{$\begin{array}{l}\text { Do you think that typically developing children } \\
\text { have this behavior? } \\
\text { - Yes, but infrequent: } 4 \text { (66.7\% agreement) } \\
\text { - No: } 2\end{array}$} \\
\hline 1 & $\begin{array}{l}\text { My child hides while } \\
\text { defecating. }\end{array}$ & \\
\hline 2 & $\begin{array}{l}\text { My child asks for a diaper } \\
\text { when he feels the need to } \\
\text { defecate. }\end{array}$ & $\begin{array}{l}\text { - } \quad \text { Yes, but infrequent: } 3 \text { (50\% agreement) } \\
\text { - No: } 3\end{array}$ \\
\hline 3 & $\begin{array}{l}\text { My child refuses to sit on the } \\
\text { potty or the toilet to defecate. }\end{array}$ & $\begin{array}{l}\text { - Yes, but infrequent: } 5 \text { (83.3\% agreement) } \\
\text { - No: } 1\end{array}$ \\
\hline 4 & $\begin{array}{l}\text { My child always follows the } \\
\text { same ritual when defecating. }\end{array}$ & $\begin{array}{l}\text { - Yes: } 1 \\
\text { - } \quad \text { Yes, but infrequent: } 2 \\
\text { - No: } 3(50 \% \text { agreement })\end{array}$ \\
\hline 5 & $\begin{array}{l}\text { My child seems to feel pain } \\
\text { when defecating. }\end{array}$ & $\begin{array}{l}\text { - Yes, if constipated: } 3 \text { (50\% agreement) } \\
\text { - Yes:2 } \\
\text { - No answer: } 1\end{array}$ \\
\hline 6 & $\begin{array}{l}\text { My child defecates only when } \\
\text { paying attention to something } \\
\text { else. }\end{array}$ & $\begin{array}{l}\text { - } \quad \text { Yes but infrequent:2 } \\
\text { - } \quad \text { No:4 (66.7\% agreement) }\end{array}$ \\
\hline 7 & $\begin{array}{l}\text { My child refuses to go to the } \\
\text { toilet outside of the home. }\end{array}$ & $\begin{array}{ll}\text { - } & \text { Yes:4 (66.7 \% agreement) } \\
\text { - } & \text { Yes but infrequent: } 1 \\
\text { - } & \text { No:1 }\end{array}$ \\
\hline 8 & $\begin{array}{l}\text { My child's reaction to the odor } \\
\text { of his/her feces is exaggerated. }\end{array}$ & $\begin{array}{l}\text { - } \text { Yes:2 } \\
\text { - } \quad \text { Yes but infrequent:2 } \\
\text { - No:1 } \\
\text { - No answer: } 1\end{array}$ \\
\hline 9 & $\begin{array}{l}\text { My child refuses to wipe or be } \\
\text { wiped after defecating. }\end{array}$ & $\begin{array}{l}\text { - Yes but infrequent:3 (50 \% agreement) } \\
\text { - No:3 }\end{array}$ \\
\hline 10 & $\begin{array}{l}\text { My child does not seem to feel } \\
\text { the urge to defecate. }\end{array}$ & $\begin{array}{ll}\text { - } & \text { Yes: } 1 \\
\text { - } & \text { No:4 (66.7 \% agreement) } \\
\text { - } & \text { No answer: } 1 \\
\end{array}$ \\
\hline 11 & $\begin{array}{l}\text { My child does not realize he } \\
\text { has soiled (feces) his clothes. }\end{array}$ & $\begin{array}{ll}\text { - } & \text { Yes: } 1 \\
\text { - } & \text { Yes but infrequent: } 2 \\
\text { - } & \text { No:3 }(50 \% \text { agreement }) \\
\end{array}$ \\
\hline
\end{tabular}

The fourth probe question, "Do you think that this behavior is common in children with constipation and fecal incontinence?", sought to justify the inclusion of the behaviors included in THPQ on the basis of their frequency of occurrence in children with RFI. Responses showed high 
agreement among experts with all of the items obtaining at least $66.7 \%$ agreement in the direction expected by the investigator. Item 8 , "My child's reaction to the odor of his/her feces is exaggerated", although not considered a common behavior in children with RFI by the expert panel or by the investigator was maintained on the revised version of the THPQ as there was $100 \%$ agreement on its relationship to sensory over-responsivity (probe question 5). Results are summarized in Figure 2.

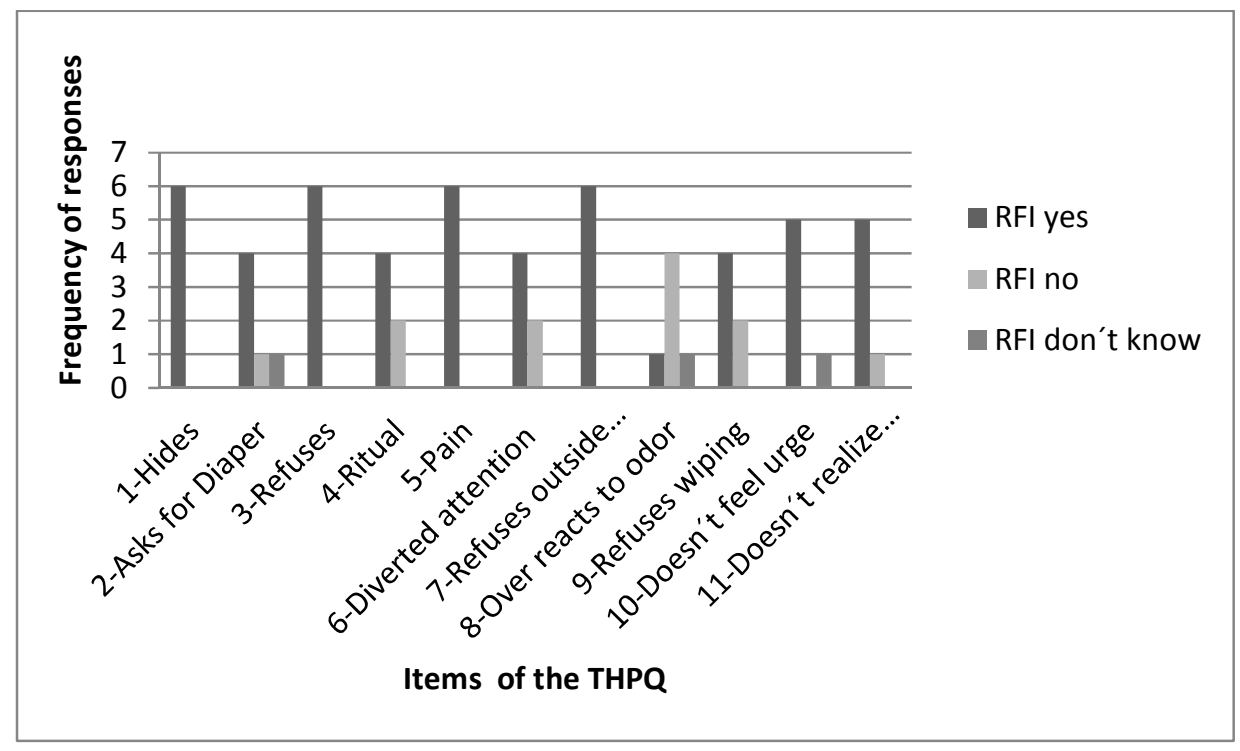

Figure 2: Expert panel responses to probe question 4: Do you think that this behavior is common in children with constipation and fecal incontinence?

THPQ= Toileting Habit Profile Questionnaire; RFI= Retentive fecal incontinence

Our final question, "Do you think that this behavior could be related to over-responsivity to the sensations related to defecation (feel of potty/toilet on skin; anal/rectal distention; smell of feces, etc.)?”, showed high agreement in the expected direction on items $1,2,3,4,7,8,9$.

The experts were divided when responding to our final question for item 5 ("My child seems to feel pain when defecating"). Half of them felt that this behavior could be related to sensory over-responsiveness while the other half felt it was not. Amongst those who felt it was 
not related, two clarified that feeling pain was probably due to the hard consistency of feces. In this case pain would be fully justified; however, our clinical experience with children with RFI shows that many continue to manifest pain even when they take medications which soften stools. The investigator hypothesizes that feeling pain while defecating could be due to overresponsivity to typical bodily sensations. In order to clarify item 5, it was slightly modified to include a reference to the consistency of the stool; "My child seems to feel pain when defecating even if the stool is soft.".

Responses to the last probe question ("Do you think that this behavior could be related to over-responsivity to the sensations related to defecation (feel of potty/toilet on skin; anal/rectal distention; smell of feces, etc.)") concerning item 6 ("My child defecates only when paying attention to something else.") were also divided. Three of the experts felt the behavior could be due to over-responsiveness, two felt it was not related and one could not answer. On the one hand a majority of experts felt this behavior was common amongst children with RFI (probe question 4), however they did not clearly associate it with over-responsivity. A review of our recent clinical data on this item has shown that it is neither common nor related to over-responsivity. Considering this entire information, item 6 was eliminated from the revised version of the THPQ. Items 10 ("My child does not seem to feel the urge to defecate.") and 11 ("My child does not realize he has soiled (feces) his clothes.") are hypothesized to be related to underresponsiveness to sensory input. When experts were asked the fifth probe question ("Do you think that this behavior could be related to over-responsivity to the sensations related to defecation ?") for items 10 and 11, it was expected that they would unanimously respond no; not feeling the urge to defecate or not noticing that one is soiled with feces is not a behavior that is expected to be related to sensory over-responsiveness. Surprisingly some experts responded 
affirmatively to probe question 5 for item 10 and 11 . On item 11 one expert answered both yes and no. There seems to have been some confusion in the comprehension of this question on the part of some our experts. Clinically, these two last items of the THPQ have not posed any problems. The items were maintained on the revised version of the THPQ and closely monitored to pick up on possible misunderstandings. Clinically, it has been observed that behaviors described in items 10 and 11, designed to detect sensory under-responsiveness, are not usually present in children who present with the behaviors hypothesized to be related to overresponsivity. Therefore, incompatible responses between the first section of the THPQ (designed to detect over-responsiveness) and items 10 and 11 (designed to detect under-responsiveness) would alert the examiner to possible misunderstanding of the items by the respondent. This was not the case in any of our participants.

The analysis of the data from this study focused on sensory over-responsiveness; participant responses from items 10 and 11 were not included in the analysis as they are not behaviors hypothesized to be related to sensory over-responsiveness. Responses from the expert panel are summarized in Figure 3.

Based on the responses from experts, the revised version of the THPQ used in the current study included 10 items.

- My child hides while defecating.

- My child asks for a diaper when he feels the need to defecate.

- My child refuses to sit on the potty or the toilet to defecate.

- My child always follows the same ritual when defecating.

- My child seems to feel pain when defecating, even if the stool is soft. 


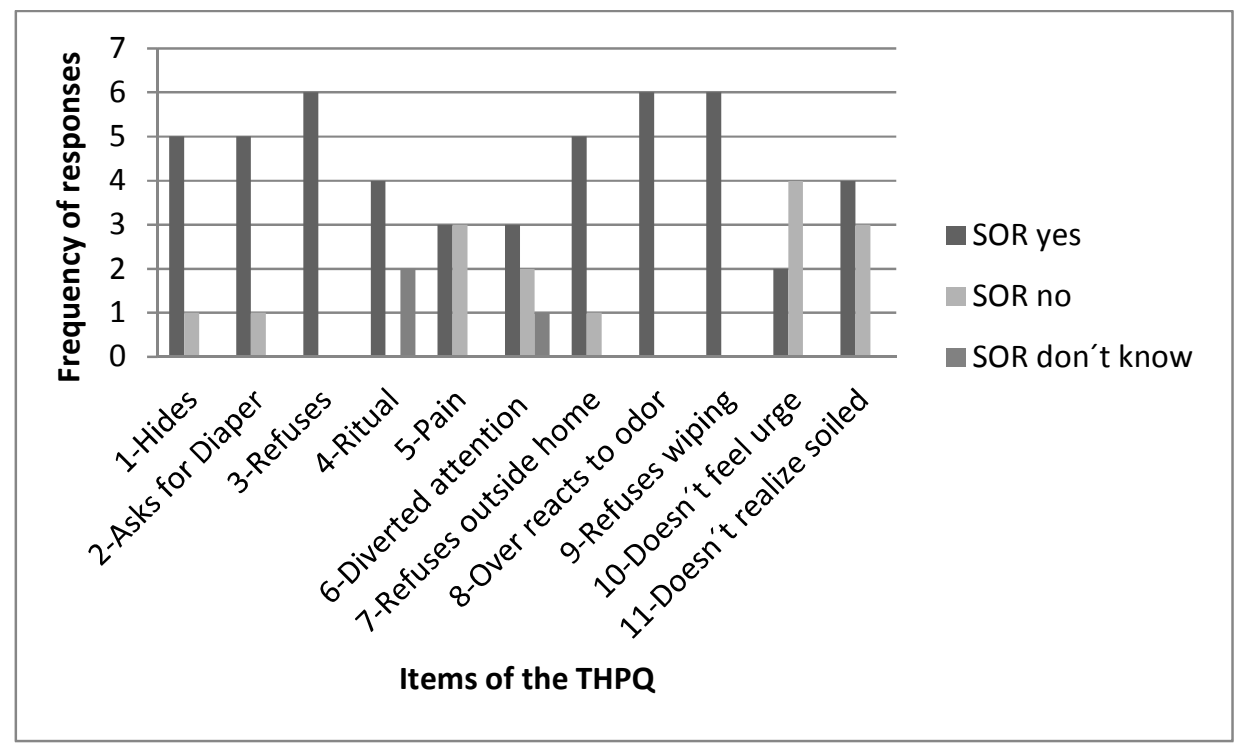

Figure 3: Expert panel responses to probe question 5. Do you think that this behavior could be related to over-responsivity to the sensations related to defecation (feel of potty/toilet on skin; anal/rectal distention; smell of feces, etc.)?

THPQ= Toileting Habit Profile Questionnaire; SOR= Sensory over-responsivity

- My child refuses to go to the toilet outside of the home.

- My child's reaction to the odor of his/her feces is exaggerated.

- My child refuses to wipe or be wiped after defecating.

- My child does not seem to feel the urge to defecate.

- My child does not realize he has soiled (feces) his clothes.

\section{Validity of the Spanish Version of the SSP (S-SSP) for Spanish (Spain) Caregivers}

To assess the validity of the S-SSP in Spain, parents of children aged 3 to 5 were recruited from among the families who attend the private OT clinic of the student investigator and were asked to participate in cognitive interviews. Participant demographics are presented in Table 4. After completing each one of the questionnaire's sections, parents were asked the following probe questions: 
Table 4: Descriptive Statistics of Participants in Cognitive Interviews

\begin{tabular}{lr}
\hline Descriptive Variables & $\begin{array}{r}\text { Frequency } \\
(\mathrm{N}=8)\end{array}$ \\
\hline Cognitive Interview Participants & \\
Fathers & 1 \\
Mothers & 7 \\
Children & \\
Boys & 2 \\
Girls & 6 \\
& \\
Age of Children & \\
3 & 3 \\
4 & 3 \\
5 & 2 \\
School & \\
Public & \\
Subsidized Private & 4 \\
Fully Private & 3 \\
Annual Family Income & 1 \\
More than 5000 Euros / family member & \\
Less than 5000 Euros / family member & 5 \\
Education Level of caregivers & 3 \\
Primary School & \\
Superior Level High School & \\
University & \\
\hline
\end{tabular}

1) How do you interpret what the item is asking?; 2)What are some examples of your child's behavior that made you choose that answer?; and 3) What changes, if any, would you make to the item to improve its understanding? (Roman-Oyala \& Reynolds, 2010, p.200).

Questions 1 and 2 were especially useful to determine comprehension of the items by our participants. Question 3 provided the investigator with suggestions to rephrase the questions in 
order to improve understanding and cultural adequacy. All of items from the S-SSP, both the ones that had been rephrased to include the participants' suggestions and the unaltered items from the original S-SSP, were reviewed by an experienced linguistic consultant to ensure grammatical and cultural (Spain) accuracy.

As expected, no major issues with comprehension were raised. Thirty-four of the 38 items were correctly understood and interpreted by all of the parents. However to insure maximal clarity in item wording, several minor changes were made reflecting suggestions made by parents and the linguistic consultant. As such 25 items have been slightly modified and 13 items have remained completely unchanged.

Items that posed comprehension issues. Items 9, 10 and 19 caused some confusion for 1 or 2 parents. Only item 14 contained words or expressions that were poorly understood by a majority of parents.

Item 9: “Come sólo algunas comidas de ciertos sabores-Will only eat certain tastes”. Only one participant misunderstood this item. She interpreted Come sólo to mean eats by herself. In Spanish the word sólo can mean only or by oneself. Once the meaning of the item was explained, the participant suggested we use the word solamente instead of sólo. The linguistic consultant agreed that the use of the word sólo could easily lead to confusion and agreed that using the word solamente not only improved the clarity of the item but was also better from a grammatical point of view. The revised item, "Come solamente algunas comidas de ciertos sabores", was used in this study.

Item 10: "Se limita él sólo a comer nada más comidas de cierta textura/temperaturaLimits self to particular food textures/temperaturas". This item created confusion similar to that of item 9 in two participants, one being the participant who had misunderstood item 9. Sólo, 
solamente and nada más can be considered synonymous and mean only. Sólo can also mean by oneself. Parents were not clear on whether the item was referring to the child eating by himself or limiting himself. The 2 participants who were confused about the meaning of the item as well as 2 other participants, all made similar suggestions to clarify the item. The linguistic consultant agreed with the proposed changes and the revised item, "Se limita a comer solamente comidas de cierta textura/temperature", was used in this study to better reflect the intent of the query "Limits self to particular food textures/temperatures".

Item 14: "No le gustan las actividades en las cuales se queda boca abajo (por ejemplo, marometas, juegos rudos)-Dislikes activities where head is upside down (for example, somersaults, roughhousing)"'. This item contained words and expressions that confused most parents. Five parents questioned the meaning of the word marometas (somersaults). In Spain the word volteretas is used to describe this sort of movement and all parents as well as the linguistic consultant suggested using this word.

The expression boca abajo was also confusing to 2 of the participants. It is used in this item to mean upside down but it can also be understood to describe the prone position. The participants who were not clear on the intended meaning of this expression suggested changing it to con la cabeza hacia abajo, which translates literally to with the head in a downward direction. The linguistic consultant considered that this modification improved clarity.

Although understood by all, one parent and the linguistic consultant questioned the use of the expression juegos rudos as a translation of roughhousing. The word rudo means rough but it also means rude or coarse, and is mostly used to express these concepts in Spain. To express rough, such as in the expression roughhousing, both the linguistic consultant and parent suggested the word brusco. 
Although various changes were made to this item, the overall structure of the statement was not modified. The revised ítem, "No le gustan las actividades en las cuales se queda con la cabeza hacia abajo (por ejemplo, volteretas, juegos bruscos)", was used in the study.

\section{Item 19: “No parece notar cuándo tiene la cara y las manos sucias-Doesn't seem to} notice when face and hands are messy". Two parents commented that this item was somewhat confusing due to the fact that is a negative statement. Neither the parents nor the linguistic consultant could come up with alternative statements and therefore the item was unchanged for this study. However parents who participated in the study were forewarned to be vigilant of the items presented in negative statements as they were found to be confusing by some parents.

Items that were understood but have been adapted. Although comprehension of most items was not an issue, many minor adjustments were recommended both by parents and the linguistic consultant to improve clarity, adapt the items to typical usage of the Spanish language in Spain and/or improve grammatical aspects of the original S-SSP. These modifications affected items $1,3,4,5,8,11,12,15,17,20,21,23,24,25,26,29,30,31,32,33$ and 36. Items 21 and 32 were presented again to 2 of the original participants as well as 2 new parents since the structure of the statements changed substantially in the process of improving clarity and grammatical aspects.

One item (18: "Toca a gente y objetos-Touches people and objects") was adjusted to reflect Spanish culture. It is seen as normal that people touch when speaking to each other or pick up objects when looking at them. Therefore adding the word excesivamente (excessively) to the statement was recommended, as several parents commented that this behavior was common in everyone. All of the modifications are summarized in Table 5. The bold font indicates words that were changed or added during the adaptation process. 
Table 5: Modifications for items of the S- SSP that were understood but adapted

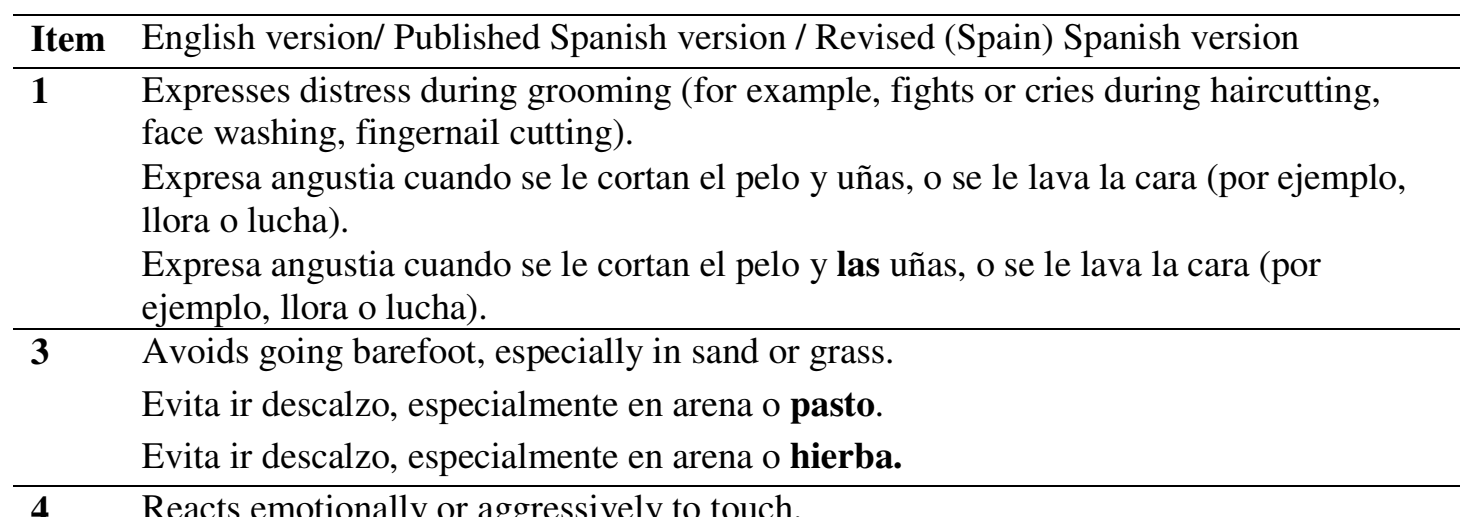

$4 \quad$ Reacts emotionally or aggressively to touch.

Reacciona emocional o agresivamente al ser tocado.

Reacciona emocional o agresivamente cuando lo tocan.

$5 \quad$ Withdraws from splashing water.

Se retira de agua que le pueda salpicar.

Se aleja del agua que le puede salpicar.

$8 \quad$ Avoids certain tastes or food smells that are typically part of children's diets.

Evita ciertos sabores u olores que típicamente forman parte de las dietas de los niños.

Evita ciertos sabores u olores que habitualmente forman parte de las dietas de los niños.

11 Picky eater, especially regarding food textures.

Es exigente en cuanto a lo que come, especialmente con referencia a las texturas de los alimentos.

Es exigente con lo que come, especialmente en lo que se refiere a las texturas de los alimentos.

12 Becomes anxious or distressed when feet leave the ground.

Se vuelve ansioso o desesperado cuando sus pies dejan el suelo.

Se vuelve ansioso o angustiado cuando sus pies se separan del suelo.

15 Enjoys strange noises/seeks to make noise for noise's sake.

Disfruta de ruidos extraños/trata de hacer ruido sólo para hacer ruido.

Disfruta de ruidos extraños/trata de hacer ruido sólo por hacer ruido.

17 Becomes overly excitable during movement activities.

Se emociona demasiado con las actividades móviles.

Se emociona demasiado con las actividades de movimiento.

18 Touches people and objects.

Toca a gente y objetos.

Toca excesivamente a gente y objetos.

20 Jumps from one activity to another so that it interferes with play.

Brinca de una actividad a otra al punto de interferir con el juego.

Pasa de una actividad a otra al punto de interferir con el juego.

(continued) 
Table 5: Modifications for items of the S- SSP that were understood but adapted (continued)

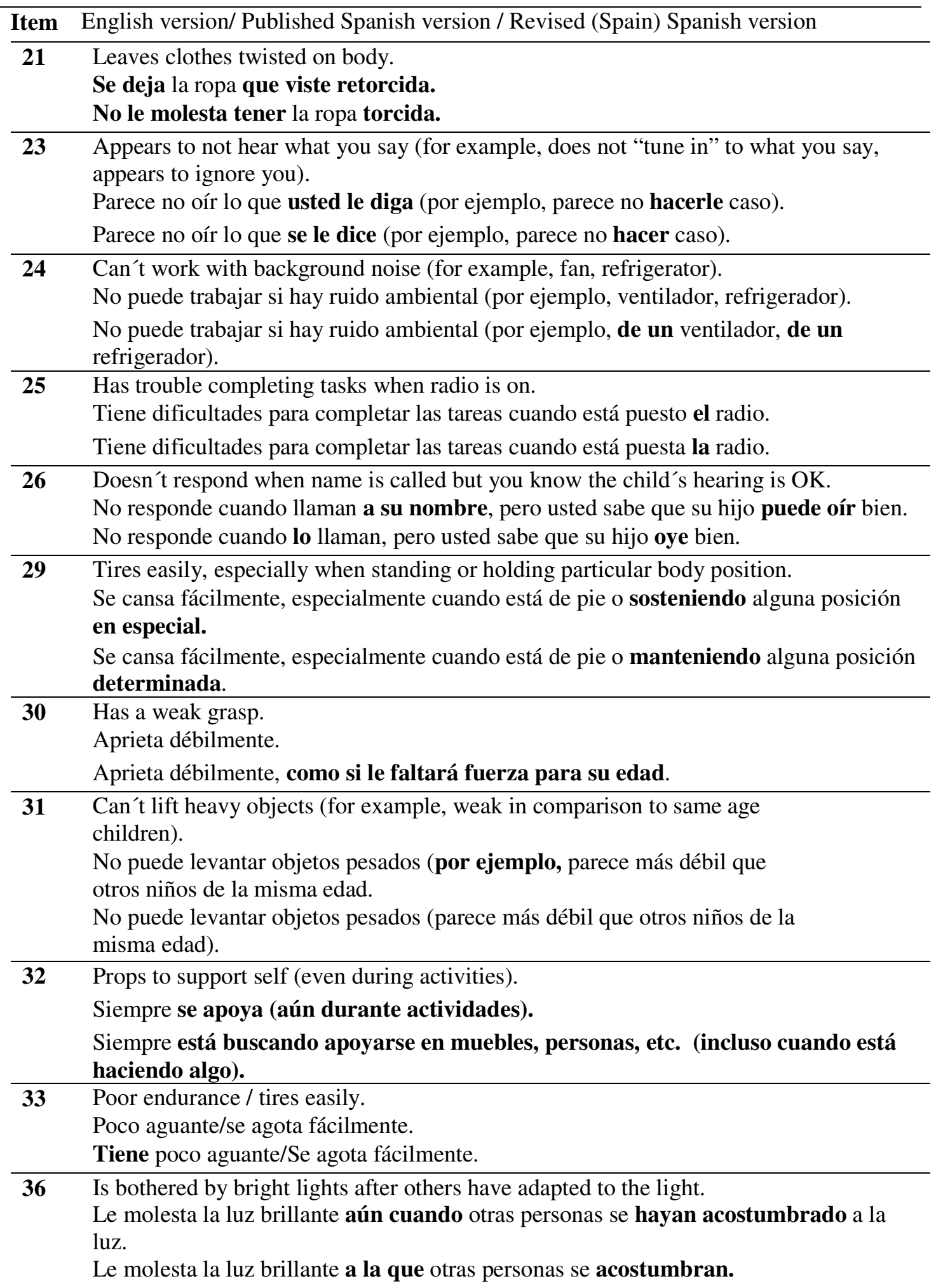




\section{Participant Responses}

Participants for the group composed of parents with children diagnosed with RFI were recruited with the help of pediatric gastroenterologists and occupational therapists from both public and private clinics in Spain. Parents of typically developing children were recruited through the parent-student associations of local schools, both public and private, and arising from a representative social economic background. Personal meetings, flyers and permission to contact forms were offered to all potential recruitment sources. For both groups, word of mouth and snowball recruitment was also used. Participants were asked to respond to the S-SSP, revised for Spain (R-Spain) by the cognitive interview participants and linguistic consultant and the THPQ revised by a panel of experts. Parents were also asked to provide basic information on the child's routines and habits. Participant demographics are presented in Table 6.

Basic information about the child's routines and habits. All of the participants responded to a questionnaire concerning their child's toileting routines and habits. Results are summarized in Table 7.

Results of the Toileting Habit Profile Questionnaire. The analysis of the THPQ data included scores on the first 8 items of the questionnaire; items which compose the overresponsiveness section. Lower scores are more indicative of behaviors hypothesized to be specific to children with RFI. In this section; 40 represents the maximum possible score and 8 represents the minimum possible score.

Group differences were examined on the sensory over-responsiveness items of the THPQ using a Mann-Whitney U test. Results indicated a significant difference between the RFI group 
Table 6: Descriptive Statistics of Participants

\begin{tabular}{lll}
\hline Descriptive Variable & \multicolumn{2}{c}{ Frequency } \\
\cline { 2 - 3 } & RFI group & TYP group \\
\hline Participant & $4(25 \%)$ & 0 \\
Fathers & $12(75 \%)^{*}$ & $27(100 \%)$ \\
Mothers & & \\
Children & $10(62.5 \%)$ & $14(51.85 \%)$ \\
Boys & $6(37.5 \%)$ & $13(48.15 \%)$ \\
Girls & & \\
Age of Children & $6(37.5 \%)$ & $6(22.22 \%)$ \\
3 & $7(43.75 \%)$ & $12(44.44 \%)$ \\
4 & $3(18.75 \%)$ & $9(33.33 \%)$ \\
5 & & \\
School & $11(68.75 \%)$ & $19(70.37 \%)$ \\
Public & $4(25 \%)$ & $6(22.22 \%)$ \\
Subsidized Private & $1(6.25 \%)$ & $2(7.41 \%)$ \\
Fully Private & & \\
& & \\
Annual Family Income** & $15(93.75 \%)$ & $25(92.6 \%)$ \\
More than 5000 Euros & $1(6.25 \%)$ & $2(7.4 \%)$ \\
Less than 5000 Euros & & $14(51.85 \%)$ \\
Education Level of & $1(6.25 \%)$ & $1(3.70 \%)$ \\
Participant & 0 & $4(14.81 \%)$ \\
Primary School & $4(25 \%)$ & $8(29.63 \%)$ \\
Middle School & $11(68.75 \%)$ & \\
High School & & \\
University & & \\
& &
\end{tabular}

*p $<0.05 ; * *$ per family member; RFI= Retentive fecal incontinence; TYP= Typically developing

$(\mathrm{Mdn}=23.50 ; \mathrm{Q} 1=17.50 ; \mathrm{Q} 3=28.00)$ and the TYP group $(\mathrm{Mdn}=36 ; \mathrm{Q} 1=34 ; \mathrm{Q} 3=38 ; \mathrm{p}=0.000)$.

Results are represented graphically in Figure 4.

The hypothesis, that in three to five year olds the THPQ would differentiate between typical children and children with RFI that had not responded to first line treatment from a 
Table 7: Basic information about the child's routines and habits

Observations

1. What are your child's typical meal times?

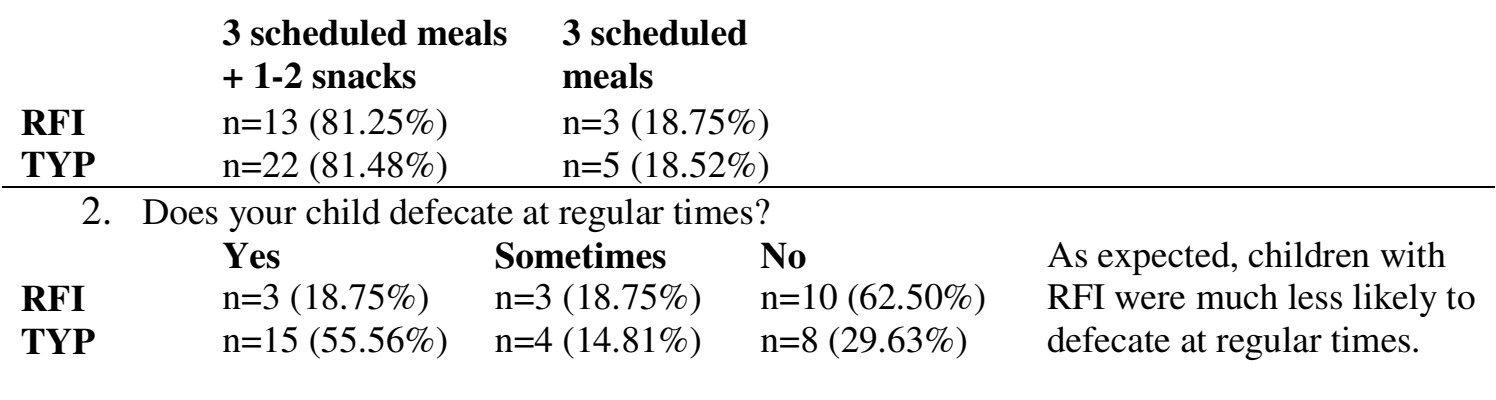

\begin{tabular}{|c|c|c|c|c|c|}
\hline \multicolumn{5}{|c|}{ 3. Do you set a routine for your child to defecate? } & \multirow[b]{2}{*}{$\begin{array}{l}\text { Establishing routines for } \\
\text { defecation is often part of } \\
\text { the medical management o } \\
\text { constipation. }\end{array}$} \\
\hline $\begin{array}{l}\text { RFI } \\
\text { TYP }\end{array}$ & $\begin{array}{l}\text { Yes } \\
n=9 \\
(56.25 \%) \\
n=4 \\
(14.82 \%)\end{array}$ & $\begin{array}{l}\text { No } \\
\mathrm{n}=7 \\
(43 \\
\mathrm{n}=2 \\
(85\end{array}$ & & & \\
\hline \multirow{2}{*}{ TYP } & There does y & ur child de & ate? & & \\
\hline & Toilet & Potty & Diaper & Clothing & $\begin{array}{l}\text { The main place of } \\
\text { defecation is reported. }\end{array}$ \\
\hline RFI & $\begin{array}{l}\mathrm{n}=6 \\
(37.5 \%)\end{array}$ & $\begin{array}{l}\mathrm{n}=3 \\
(18.75 \%)\end{array}$ & $\begin{array}{l}\mathrm{n}=3 \\
(18.75 \%)\end{array}$ & $\begin{array}{l}\mathrm{n}=4 \\
(25 \%)\end{array}$ & $\begin{array}{l}\text { Children in the RFI group } \\
\text { were reported to have other }\end{array}$ \\
\hline TYP & $\begin{array}{l}\mathrm{n}=26 \\
(96.3 \%)\end{array}$ & $\begin{array}{l}\mathrm{n}=1 \\
(3.7 \%)\end{array}$ & $\mathrm{n}=0$ & $\mathrm{n}=0$ & $\begin{array}{l}\text { places for defecation } \\
\text { (bathtub, floor, etc.) and to } \\
\text { be selective about where } \\
\text { they defecate. }\end{array}$ \\
\hline
\end{tabular}

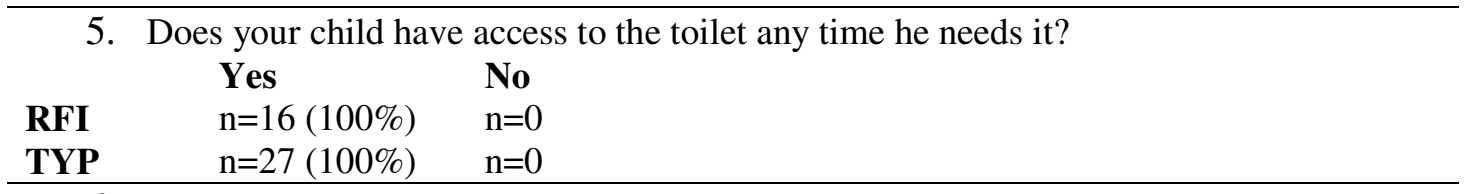

\begin{tabular}{llll}
\multicolumn{2}{c}{ 6. } & Does your child appear to feel secure in the bathroom? & \\
& Yes & No & Children with RFI were \\
RFI & $\mathrm{n}=9(56.25 \%)$ & $\mathrm{n}=7(43.75 \%)$ & much more likely to feel \\
TYP & $\mathrm{n}=23(85.12 \%)$ & $\mathrm{n}=4(14.81 \%)$ & insecure in the bathroom.
\end{tabular}

RFI= Retentive fecal incontinence; TYP= Typically developing; $\mathrm{N}=43 ; \mathrm{n}(\mathrm{RFI})=16 ; \mathrm{n}(\mathrm{TYP})=27$ (continued) 
Table 7: Basic information about the child's routines and habits (continued)

Observations

7. Can your child manage clothing for toileting without help?

\begin{tabular}{llll} 
& Yes & No & $\begin{array}{l}\text { Children with RFI were } \\
\text { much more likely to }\end{array}$ \\
RFI & $\mathrm{n}=11(68.75 \%)$ & $\mathrm{n}=5(31.25 \%)$ & $\begin{array}{l}\text { require help with } \\
\text { management of clothing. } \\
\text { TYP }\end{array}$ \\
\hline
\end{tabular}

8. Can your child wipe without help after toileting?

\begin{tabular}{|c|c|c|c|c|}
\hline RFI & $\begin{array}{l}\text { Yes } \\
n=3\end{array}$ & $\begin{array}{l}\text { Sometimes } \\
n=0\end{array}$ & $\begin{array}{l}\text { No } \\
n=13\end{array}$ & $\begin{array}{l}\text { Many parents in the RFI } \\
\text { group whose children } \\
\text { did not wipe by }\end{array}$ \\
\hline & $\begin{array}{l}(18.75 \%) \\
n=13\end{array}$ & & $\begin{array}{l}(81.25 \%) \\
n=12\end{array}$ & $\begin{array}{l}\text { did not wipe by } \\
\text { themselves thought their }\end{array}$ \\
\hline & $\begin{array}{l}n=15 \\
(48.15 \%)\end{array}$ & $(7.41 \%)$ & $(44.44 \%)$ & $\begin{array}{l}\text { child could wipe but } \\
\text { refused to do so. }\end{array}$ \\
\hline
\end{tabular}

9. What strategies or adaptations do you use to help your child with toileting?

\begin{tabular}{|c|c|c|c|c|c|}
\hline RFI & $\begin{array}{l}\text { None } \\
n=0\end{array}$ & $\begin{array}{l}\text { Potty } \\
n=2 \\
(12.5 \%)\end{array}$ & $\begin{array}{l}\text { Reducer } \\
\mathrm{n}=5 \\
(31.25 \%)\end{array}$ & $\begin{array}{l}\text { Other } \\
n=15 \\
(93.75 \%)\end{array}$ & $\begin{array}{l}\text { Parents of typically developing } \\
\text { children used one or no } \\
\text { strategies. Parents from the RFI }\end{array}$ \\
\hline TYP & $\begin{array}{l}n=19 \\
(70.37 \%)\end{array}$ & $\begin{array}{l}\mathrm{n}=1 \\
(3.70 \%)\end{array}$ & $\begin{array}{l}n=6 \\
(22.22 \%)\end{array}$ & $\begin{array}{l}\mathrm{n}=1 \\
(3.70 \%)\end{array}$ & $\begin{array}{l}\text { group mostly used a } \\
\text { combination of strategies. Other } \\
\text { strategies include: leave alone, } \\
\text { enemas, positive and negative } \\
\text { reinforcement, agenda, stories. }\end{array}$ \\
\hline
\end{tabular}

RFI= Retentive fecal incontinence; TYP= Typically developing; N=43; $\mathrm{n}(\mathrm{RFI})=16 ; \mathrm{n}(\mathrm{TYP})=27$

general practitioner or pediatrician, has been supported. The results also support the hypothesis

that children with RFI would show lower scores on the THPQ than children without RFI.

Results of the S-SSP (R-Spain). The purpose of this study was to examine sensory overresponsivity, therefore data analysis was done on a subset of relevant items from the SSP, as described by Mazurek and colleagues (2012). A sensory over-responsivity (SOR) score was calculated using the items designed to detect over responsivity: Tactile Sensitivity (items 1-7), Taste/Smell Sensitivity (items 8- 11), Movement Sensitivity (items 12-14), and Visual Auditory Sensitivity (items 34-38). Low SOR scores are indicative of greater sensory over-responsivity. 


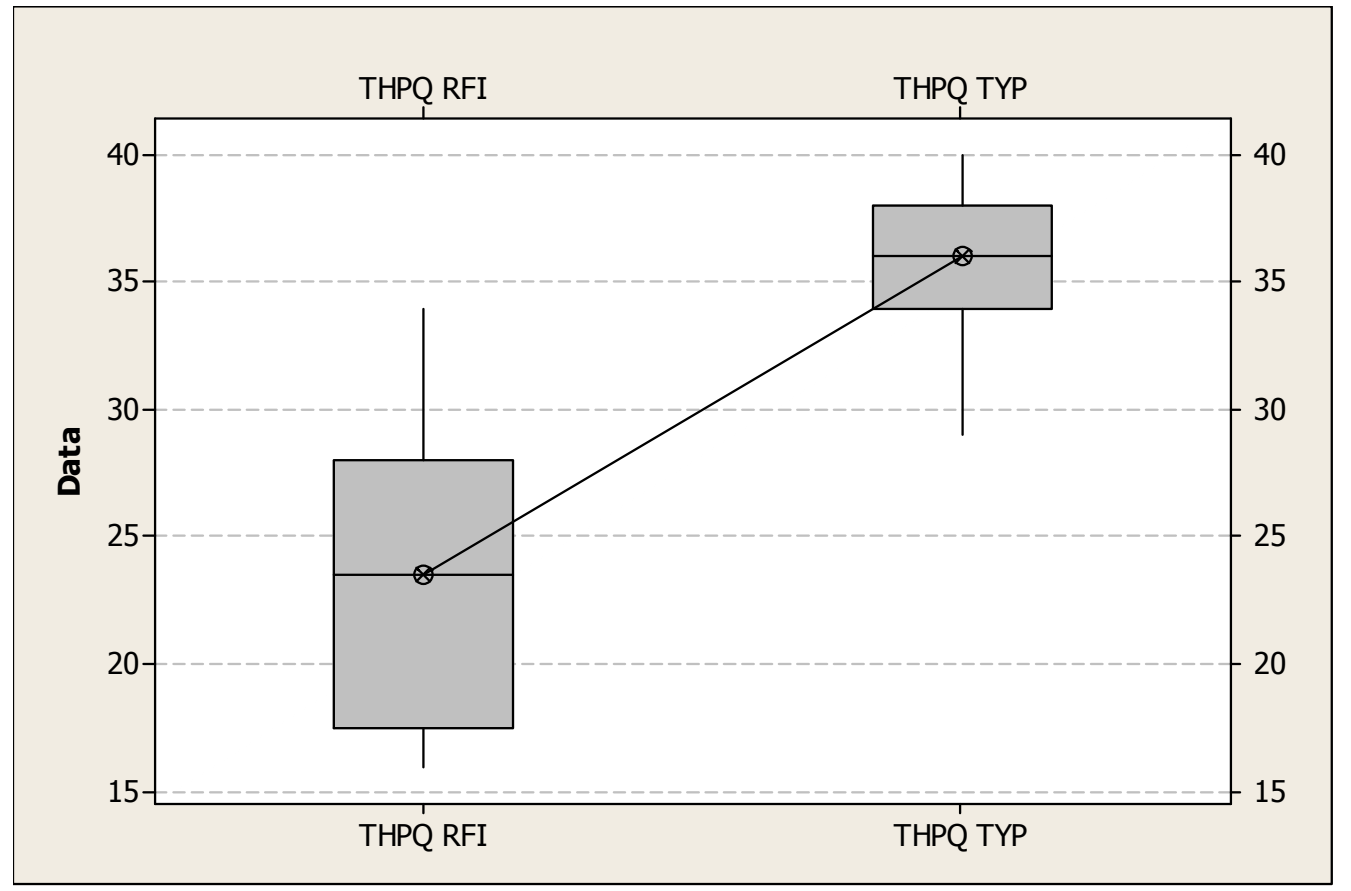

Figure 4: Boxplot of Toileting Habit Profile Questionnaire scores; THPQ= Toileting Habit Profile Questionnaire; RFI= Retentive fecal incontinence; TYP= Typically developing Group differences were examined for the SOR scores using a Mann-Whitney U test. Results indicated a significant difference between the RFI group (Mdn=76.50; Q1=71.25; Q3=85.25) and the TYP group (Mdn=84.00; Q1=76.00; Q3=90.00; $\mathrm{p}=0.0346)$. Results are represented graphically in Figure 5.

The S-SSP (R-Spain) SOR scores were examined to determine if greater sensory overresponsivity (lower SOR scores) was associated with decreased scores on the THPQ, and whether children with RFI showed lower SOR scores than children without RFI. The above results support the hypothesis that children with RFI would show lower SOR scores, or a greater degree of sensory over-responsivity, than children without RFI. 


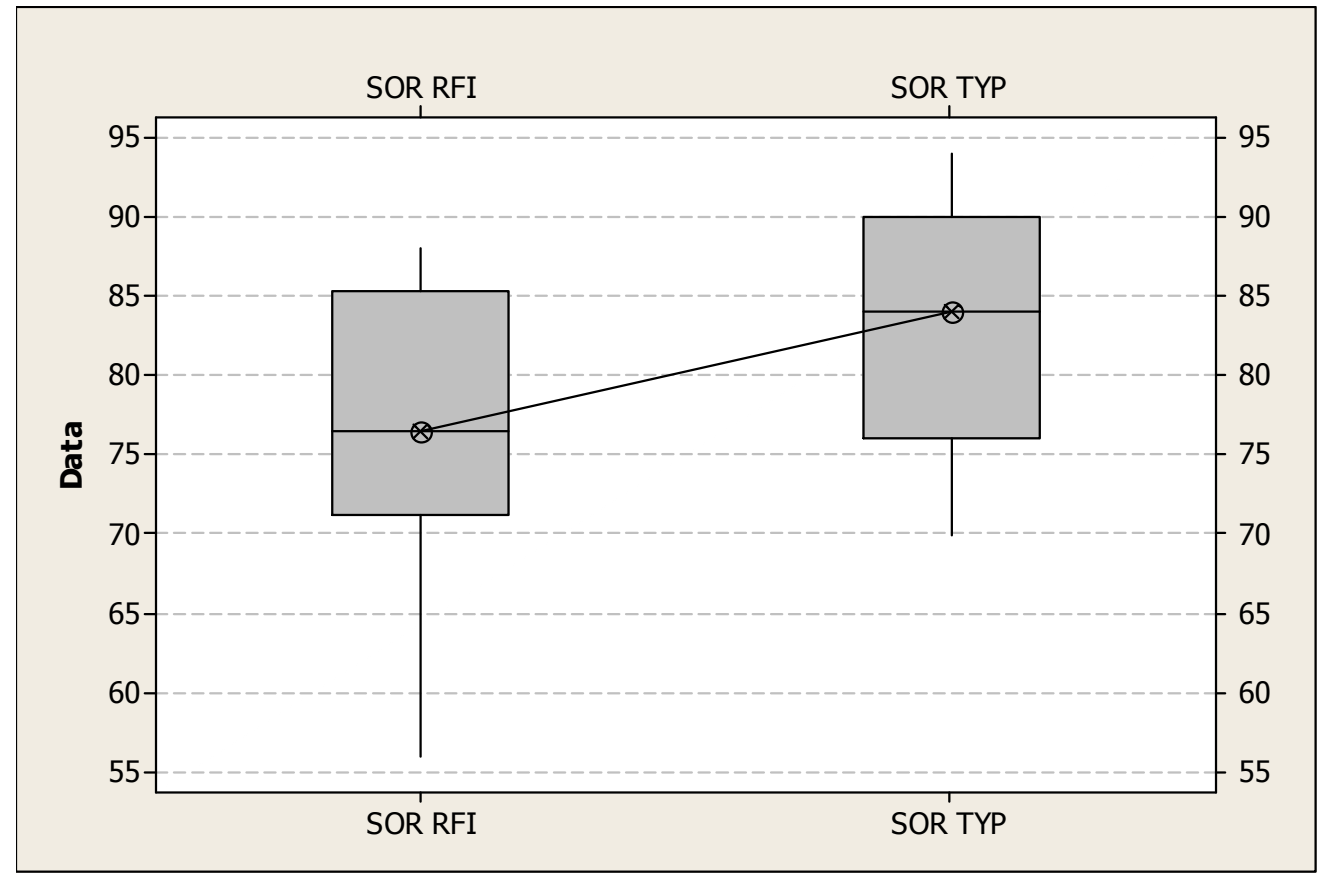

Figure 5: Boxplot of sensory over-responsivity scores

$\mathrm{SOR}=$ Sensory over-responsivity score $; \mathrm{RFI}=$ Retentive fecal incontinence; $\mathrm{TYP}=$ Typically developing

To confirm our hypothesis that a low SOR score would be associated with decreased scores on the THPQ, we examined the correlation between SOR scores and THPQ scores. A Spearman Correlation produced $r_{s}=.423$ which confirms a moderate but significant $(p=.005)$ linear dependency between SOR and THPQ scores. A scatter plot of SOR scores versus THPQ scores is shown in Figure 6. 


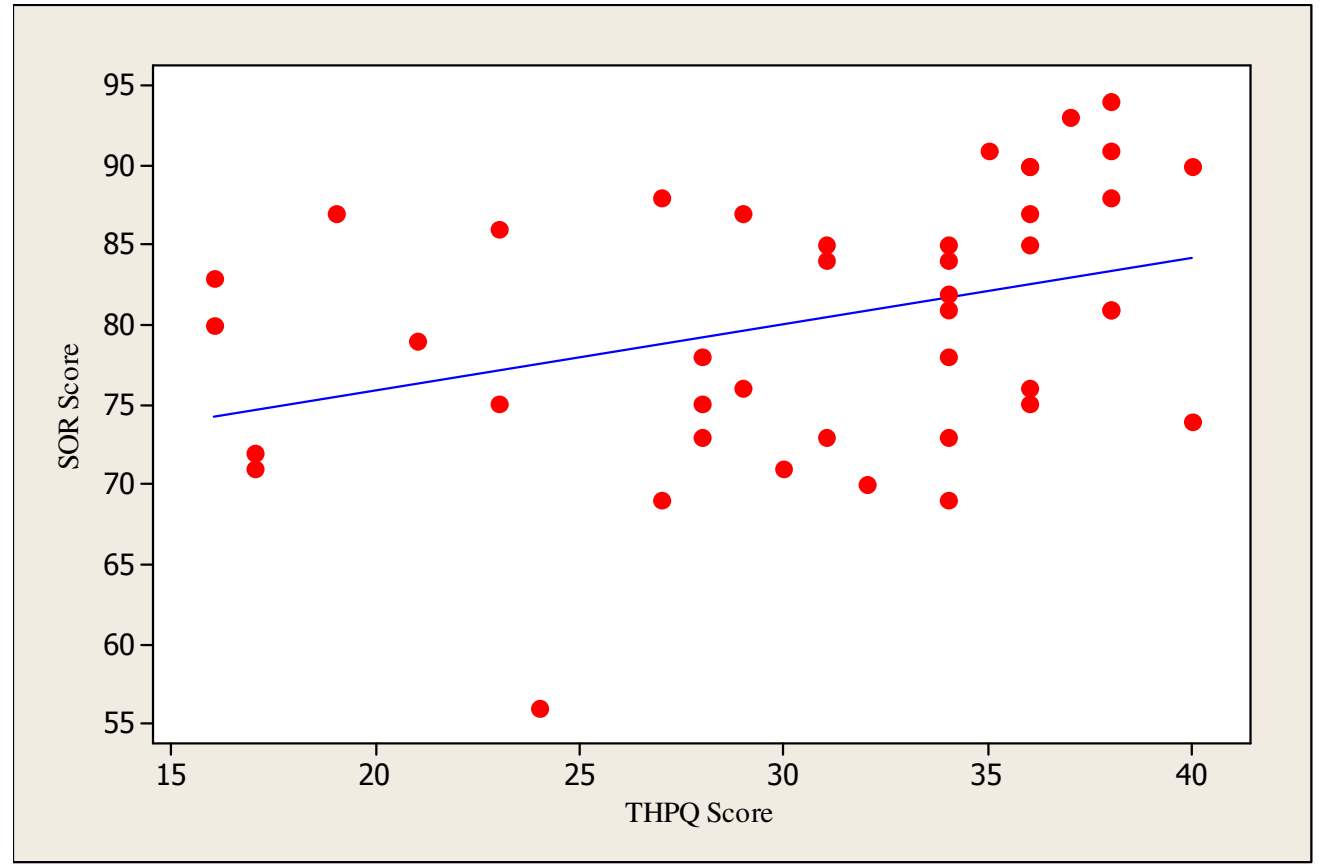

Figure 6: Scatter plot of SOR scores versus THPQ scores

$\mathrm{SOR}=$ sensory over-responsivity; THPQ $=$ Toilet Habit Profile Questionnaire 


\section{Chapter 5 Discussion}

Two major findings become apparent in the results of this study. First, results support the hypothesis that children with treatment resistant RFI show a greater degree of sensory overresponsivity than typically developing children. Fecal incontinence and constipation are two of the most common gastrointestinal complaints in children (Tabbers et al., 2011a). However, success rates for the treatment of children with constipation and fecal incontinence remain limited (Pijpers et al., 2010). Identifying underlying factors that have not previously been considered is crucial in an effort to improve treatment outcomes. Sensory over-responsivity could possibly be one of the factors responsible for the limited success of conventional approaches in some children with RFI.

Second, results validate the use of the THPQ as an effective tool to discriminate between the toileting behaviors of children with RFI and those of typically developing children. This study substantiates the hypothesis that the behaviors described in the first section of the THPQ are associated with sensory over-responsivity. Early identification of emerging developmental problems is considered to be a key component of successful intervention in many childhood conditions (Oberklaid, Baird, Blair, Melhuish, \& Hall, 2013; Zwaigenbaum, Bryson, \& Garond, 2013). The THPQ could potentially be used for early identification of atypical toileting behaviors and useful in screening for risk of developing RFI. 
The questions which gave rise to this study were forged in the context of a long standing collaboration between an occupational therapist (the student investigator) and a seasoned pediatric gastroenterologist (Dr. Eduardo Ramos). The collaboration initially involved children with feeding refusal. These children were usually being referred to psychologists for treatment once gastro-intestinal issues had been addressed. However, many of them did not respond to psychological approaches which lead Dr. Ramos to turn to alternative treatment options. Occupational therapy using a sensory integration (OT/SI) approach offered a distinct view of the refusal behaviors of these children and many who had failed previous treatments progressed with OT. This represented a new treatment approach in Spain but sensory issues and OT interventon in relation to feeding refusal were already well documented (Cermak et al., 2010; Chatoor, 2002; Dunn, 2007; Nadon et al., 2011).

Shortly after looking at sensory issues and feeding refusal, Dr. Ramos began to recognize sensory issues in children with RFI who were not responding to conventional treatments. RFI and feeding refusal are very similar in that both involve gastro-intestinal and behavioral factors. Conventional treatment methods are also similar. Given the clinical success obtained examining feeding refusal from a sensory perspective it seemed reasonable to hypothesize that sensory issues could also be affecting the progress of children with RFI. At this time, very little literature was available to support the use of OT/SI with this diagnostic group (Handley-More et al., 2009), but the student investigator nonetheless began to use this approach with children who had failed conventional medical and psychological treatment. With the support and encouragement of Dr. Ramos, the student investigator closely documented the behaviors and the progress of the children and observed early on that almost all of them had sensory over-responsivity (Beaudry Bellefeuille \& Ramos Polo, 2011). This marked the beginning of the development of the THPQ. 
The goal was to document toileting behaviors as they related to sensory processing, much as the SP (Dunn, 1999) documents feeding behaviors in its oral sensory processing section. From the beginning it seemed clear that certain toileting behaviors, which are common in children with RFI and interfere with the establishment of healthy defecation routines, were associated with sensory over-responsivity.

\section{Toileting Habit Profile Questionnaire}

Content validity of the THPQ was established in this investigation using a panel of experts consisting of pediatric gastroenterologists and occupational therapists with postprofessional training in the treatment and evaluation of children with difficulties processing and integrating sensory input. Overall, there was a high degree of agreement on the items and intended use of the THPQ, and input from the expert panel was useful in improving this tool before its use with the study participants.

As expected, a significant linear relationship was found between SOR scores and the first 8 items of the THPQ which were hypothesized to be related to sensory over-responsiveness. It should be noted that individual items on the THPQ are not intended to indicate sensory overresponsiveness, but rather it is the collection of scores on the first 8 items which indicate difficulties participating in normal toileting due to sensory over-responsiveness. As such it is not a surprise that some typical children occasionally show some of these behaviors. This is also true for all of the behaviors related to sensory over-responsiveness; typically developing children may have some of these behaviors but not with the frequency that we observe in children who experience difficulties participating in their daily activities (Dunn, 1994). Assessments in other areas also typically depend on multiple instead of single variables. For example, language assessments which include a cluster of variables are found to be valuable in determining 
children's aptitudes for symbol (word) learning and helpful in plotting a course of treatment (Brady, Thiemann-Bourque, Fleming, \& Matthews, 2013). Similarly, other authors report on the multiple variables involved in the effective prediction of writing competence, development of social-cognitive play or school readiness (Cameron et al., 2012; Dunsmuir \& Blatchford, 2004; Porter, 2009).

The data from this study reveals that toileting behaviors reported by parents of typically developing children are significantly different from those reported by parents from the RFI group. The responses from the participants in the typically developing group provide valuable insight into what can be considered normal toileting behaviors and substantiate the concerns expressed by parents of children with RFI. This significant difference in the responses of the 2 groups further validates the THPQ given that the items of the questionnaire were compiled based on the behaviors reported by parents whose children were struggling with defecation. Often this later group of parents described how different their child's toileting behavior was from the behavior of siblings or other children at daycare but up until now the THPQ had not formally been administered to a wider group of parents of typically developing youngsters.

In fact, the difference between the THPQ scores of typically developing children and those with RFI that has not responded to medical treatment is greater than expected. Prior to the study conservative estimations based on clinical experience with a previous version of the THPQ pointed to an expected difference of 7 points, however the median difference between the scores from the 2 groups was 12.5 points, substantially greater than had been estimated from a clinical perspective. The findings confirm that the combination of behaviors described in the THPQ are atypical and that typically developing children do not usually: hide or ask for a diaper to defecate, refuse to sit on the potty/toilet, feel pain while defecating, overreact to the odor of feces or refuse 
to be wiped. Although further research is needed with a larger group of typically developing children to confirm these findings, it appears that the THPQ is useful in distinguishing between typical children and children with treatment resistant RFI. Further, the THPQ could potentially be used for early identification of atypical toileting behaviors and those children at risk of developing RFI. For example knowing that parents of children with constipation report more difficulty with toilet training than parents of typical children (Aziz et al., 2011; Borowitz et al., 2003; Inan et al., 2007; Schonwald et al., 2004), the THPQ could be useful to pick up on problematic behaviors early on and quickly orient families to avoid future and more serious defecation difficulties.

Examined from the perspective of sensory modulation, the behaviors described in the THPQ could also be useful with children who have a history of sensory over-responsiveness and who are initiating or about to initiate toilet training. OT clinicians are reporting that toddlers with sensory over-responsiveness who are consulting for issues such as feeding refusal, sleep disturbances or difficulty participating in daily childhood occupations, begin to show some of the behaviors outlined in the THPQ at very young ages. In clinical practice, behaviors such as hiding or following unusual rituals for defecation are frequently reported by parents of young children with SOR before the beginning of formal toilet training. Examining responses to the items of the THPQ not directly related to the use of the potty or toilet (items $1,4,5,7,8$ ) with younger children who have not yet started formal toilet training would be another line of research to pursue. The information collected from these items could be useful to detect potential areas of concern in order to treat them before toilet training is begun. In those children already diagnosed with RFI, the THPQ appears to be useful in identifying those at risk of not responding to conventional medical management alone and in need of a treatment program that addresses 
sensory issues. Confirming these preliminary clinical impressions is another area to consider for future studies.

An interesting finding from the typical group was obtained from the responses on item 4 and is of particular interest for improving the THPQ for future use. On this item (My child always follows the same ritual when defecating) participants were asked to clarify their response and describe the ritual followed by their child. Many parents, from both groups, indicated that their child almost always followed a ritual for defecation. However the rituals described differed greatly from one group to the other. Parents of typically developing children described rituals such as: enters the bathroom, closes the door, and calls me when he's done. On the other hand parents of children with RFI described rituals which involve unusual behaviors such as hiding to defecate, defecating in a place other than the toilet or moving in particular ways (for example, becomes stiff, hangs on to something, dances around). Therefore, for future clinical work and research item 4 should be modified to specify an unusual ritual ("My child follows an unusual ritual when defecating which involves actions or places not typically associated with going to the toilet") to better discriminate between the children with and without RFI.

\section{Short Sensory Profile-Spanish (Revised Spain)}

The SSP was used to measure responses to sensory events in daily life to compile a sensory over-responsiveness score for each participant. The validity of the SSP is well established (McIntosh et al., 1999), however, given that the published Spanish version of the SSP was designed to be used with Spanish speaking individuals who live in the United States, this study involved the validation of the SSP-S for Spain with a small group of parents before it was used with the participants of the study. Establishing culturally valid evaluation tools is a 
necessary first step in carrying out research in different ethnic groups (Harachi, Choi, Abbott, Catalano, \& Bleisner, 2006; Gierl \& ElAtia, 2007).

The cognitive interview method used by Roman-Oyala and Reynolds (2010) for the validation of the SSP-S for Puerto Rican caregivers was replicated for the present study. As expected, the published Spanish version of the SSP did not pose any major comprehension issues. However both the linguistic consultant and the parents who participated in the cognitive interviews suggested many minor adjustments so that the statements of the SSP better reflect local culture and the usage of the Spanish language in Spain. The culturally adapted version of the SSP-S was used in the study.

Analysis of the results of the SSP-S (revised Spain) focused exclusively on a subset of items designed to identify behaviors related to SOR as described by Mazurek and colleagues (2012). As such a sensory over-responsivity score was calculated using the scores of items 1 to 7 (Tactile Sensitivity), 8 to 11 (Taste/Smell Sensitivity), 12 to 14 (Movement Sensitivity), and 34 to 38 (Visual Auditory Sensitivity). The use of this specific measure may have facilitated the strong relationship observed between the first 8 items of the THPQ and SOR.

No previous studies specifically examined the link between RFI and SOR, although mounting evidence indicates a relationship between sensory over-responsivity and gastrointestinal problems. The present study adds to this body of knowledge. Existing evidence indicates that children with autism with any type of gastrointestinal problem, including chronic constipation, show higher levels of sensory over-responsivity than children without such problems (Mazurek et al., 2012). A link between the auditory startle reflex, considered a measure of hyperarousal, and irritable bowel syndrome and functional abdominal pain syndrome has also been established (Bakker et al., 2010). Results of this study support the co-existence of 
gastrointestinal difficulties and SOR, and help complete the picture of this relationship in clinical populations.

Additionally, children diagnosed with dysfunctional elimination syndrome (DES) have been found to have more sensory processing difficulties than typically developing children, providing further evidence of a link between gastrointestinal issues and sensory processing difficulties (Pollock, 2012). Although sensory over-responsivity was not specifically addressed in the case of children with DES, these findings also endorse the consideration of sensory issues in children with elimination difficulties.

\section{Limitations and Future Research}

While this study adds substantively to existing literature, there are limitations. One of the most obvious is the limited sample size. Initial sample size calculations called for a sample of 25 participants in each group; although this number was reached for the typical group ( $n=27)$, it was not attained for the RFI group $(n=16)$. Initial contacts with gastroenterologists and pediatricians for the recruitment of participants for the RFI group were very positive but some bureaucratic difficulties within the public health system were encountered. Research and other collaboration opportunities between professionals working within the public system and those from the private sector are not encouraged by public health administrators in Spain, a fact that was not revealed to the researcher during the initial stages of the study. Participants were therefore obtained mainly from private practitioners who are less likely to encounter participants who fulfilled all of the inclusion criteria specified for this study. This limited sampling heterogeneity constitutes a second limitation. In future studies, recruitment sources should include a broader base, and larger samples are needed to substantiate the findings of the current study. 
Another limitation to consider is that assessment data relied on parent report and interview; objective assessment data were not collected. Nonetheless, parent report and interview are reported to be valid methods of data collection in other areas and can be easily used to collect data from large groups. Evidence supports the use of parent report in relation to health related quality of life in children aged 5 to 16 years (Varni, Limbers \& Burwinkle, 2007a; 2007b). The performance in the mobility of children with cerebral palsy is also shown to be validly reported by parents (Harvey et al., 2010); using the Functional Mobility Scale, a parent report tool, researchers found substantial agreement between parent reports of mobility performance and direct observation of mobility by physiotherapists. Parent report has also been found to be a valid method of evaluating language development in young children (Feldman et al., 2005). Research indicates significant correlations between scores on parent report scales and standardized tests of language development in children aged 3 years (Feldman et al., 2005). Given that parent report has been shown to be a valid data collection method in a variety of areas such as quality of life, mobility and language development, it seems reasonable to assume that parents can also validly report on the toileting behaviors of their children.

Other studies have included stubbornness and compliance with treatment in the analysis of the behavior of children with toileting difficulties (Burket et al., 2006; Levine \& Bakow, 1976). These aspects were not included within the context of this study but they represent relevant issues that could be the focus of future work.

Future research could eventually focus on collecting objective data such as electrodermal responses and cortisol levels in children with RFI, as has been done with other diagnostic groups such ADHD and ASD who share similar behavioral characteristics found to be associated to sensory over- responsiveness (Lane, Reynolds, \& Thacker, 2010; Lane, Reynolds, \& Dumenci, 
2012). However, at this time it may be more appropriate to continue collecting data with simpler methods to gain a better understanding of the sensory issues faced by wider groups of children with RFI and how they affect their toileting habits and daily activities.

\section{Implications for Occupational Therapy}

This study offers a rationale for the inclusion of occupational therapists with postprofessional training in sensory integration as part of the interdisciplinary teams treating children with RFI. Current success rates utilizing conventional treatment regimens remain limited and many children continue to struggle with constipation and fecal incontinence into adulthood (Van Ginkel et al., 2003; Michaud et al., 2009; Pijpers et al., 2010). Correctly diagnosing and treating underlying sensory difficulties could improve the success rates in the treatment of children who are resistant to first line conventional medical management.

Current clinical experience in the treatment of sensory issues in children with RFI has focused mainly on the aspects related to the acceptance of toileting routines (Beaudry Bellefeuille \& Ramos Polo, 2012; Beaudry et al., 2013). For example tactile over-responsivity is frequently observed in children who refuse to remove clothing or sit on the potty or toilet. Preliminary clinical evidence related to the use of OT/SI in the treatment of children with difficulties participating in toileting routines is promising (Beaudry Bellefeuille \& Ramos Polo, 2012; Beaudry et al., 2013). Studying the effectiveness of current treatment approaches using OT/SI in improving acceptance of toileting routines is certainly on the agenda for future studies. However, there are other aspects of treatment to explore. Experiencing anxiety or stressful life events is reported to be linked to childhood constipation and fecal incontinence (Amendola et al., 2003; Bellman, 1966; Devanarayana \& Rajindrajith, 2010; Hesapçığlu et al., 2009; Inan et al., 2007; Mugie, Benninga, \& Di Lorenzo, 2011; Waters et al., 2012). Furthermore it is known that many 
children with RFI have experienced painful bowel movements and express worry in relation to future defecations (Borowitz et al., 2003). This leads to further consider the impact of sensory over-responsiveness in children with RFI. For example, gaining a better understanding of the relationship between stress and anxiety in children with RFI and its relationship to SOR, as has been done in other diagnostic groups (Lane, Reynolds, \& Dumenci, 2012), could help develop better interventions for this common and complex childhood disorder.

The THPQ could be used as a screening tool in the first stages of constipation and stool withholding to alert healthcare providers of the need to refer to occupational therapy for evaluation and treatment of possible sensory issues which may be interfering with participation in healthy and socially acceptable toileting routines. There is growing evidence that OT is successful in improving participation in children with sensory issues (Fazlioglu \& Baran 2008; Pfeiffer, Koenig, Kinnealy, Sheppard, \& Henderson, 2011; Roberts et al., 2007; Schaaf, 2011; Schaaf et al., 2013). There is also some evidence that addressing the sensory issues that appear to be at the root of the behaviors related to the development and maintenance of RFI may contribute to more successful treatment outcomes for children who suffer this complex and often chronic condition (Beaudry Bellefeuille \& Ramos Polo, 2011; Beaudry et al., 2013; Handley-More et al., 2009). 


\section{Chapter 6 References}

Achenbach, T. M. (1991) Manual for the Child Behavior Checklist/4 -18 and 1991 Profiles. Burlington, VT: University of Vermont Department of Psychiatry

Amendola, S., De Angelis, P., Dall'Oglio, L., Federici di Abriola, G., \& Di Lorenzo, M. (2003). Combined approach to functional constipation in children. Journal of Pediatric Surgery, $38(5), 819-823$.

American Occupational Therapy Association. (2008). Occupational therapy practice framework: Domain and process (2nd ed.). American Journal of Occupational Therapy, 62, 625-683.

American Psychiatric Association. (2013). Diagnostic and statistical manual of mental disorders (5th ed.). Arlington, VA: American Psychiatric Publishing.

Aziz, S., Fakih, H. A. M., \& Di Lorenzo, C. (2011). Bowel habits and toilet training in rural and urban dwelling children in a developing country. Journal of Pediatrics, 158(5), 784-788.

Bakker, M. J., Boer, F., Benninga, M. A., Koelman, J. H., Tijssen, M. A. (2010). Increased auditory startle reflex in children with functional abdominal pain. Journal of Pediatrics, $156(2), 285-291$.

Barlow, J. \& Cullen, L. (2002). Increasing touch between parents and children with disabilities: Preliminary results from a new programme. Journal of Family Health Care, 12 (1), 7-9.

Beaudry Bellefeuille, I., \& Ramos Polo, E. (2011). Tratamiento combinado de la retención voluntaria de heces mediante fármacos y terapia ocupacional [Combined treatment of volontary stool retention with medication and occupational therapy ]. Boletín de la Sociedad de Pediatría de Asturias, Cantabria, Castilla y León, 51, 169-176. 
Beaudry, I. B., Schaaf, R. C., \& Ramos, E. P. (2013). Brief Report-Occupational therapy based on Ayres Sensory Integration in the treatment of retentive fecal incontinence in a 3-yearold boy. American Journal of Occupational Therapy, 67, 601-606. http://dx.doi.org/10.5014/ajot.2013.008086

Bellman, M. (1966). Studies on encopresis. Acta Paediatrica Scandinavica, Supplement 170.

Benninga, M. A., Voskuijl, W. P., Akkerhuis, G. W., Taminiau, J. A., \& Büller, H. A. (2004).Colonic transit times and behaviour profiles in children with defecation disorders. Archives of Disease in Childhood, 89(1), 13-16.

Bischoff, A., \& Tovilla, M. (2010). A practical approach to the management of pediatric fecal incontinence. Seminars in Pediatric Surgery, 19(2), 154-159.

Blum, N. J., Taubman, B., \& Nemeth, N. (2003). Relationship between age at initiation of toilet training and duration of training: A prospective study. Pediatrics, 111, 810-814.

Blum, N. J., Taubman, B., \& Nemeth, N. (2004). During toilet training, constipation occurs before stool toileting refusal. Pediatrics, 113, 520-522.

Blum, N. J., Taubman, B., \& Osborne, M. L. (1997). Behavioral characteristics of children with stool toileting refusal. Pediatrics, 99(1), 50-53.

Böhmer, C. J., Taminiau, J. A., Klinkenberg-Knol, E. C., Meuwissen, S.G. (2001). The prevalence of constipation in institutionalized people with intellectual disability. Journal of Intellectual Disability Research, 45(3), 212-218.

Bonaz, B., \& Sabate, J. M. (2009). Le dysfonctionnement du brain-gut [Brain-gut axis dysfuntion]. Gastroentérologie Clinique et Biologique, 33, 8-14.

Bongers, M. E. J., Van Dijk, M., Benninga, M. A., Grootenhuis, M. A. (2009). Health related quality of life in children with constipation-associated fecal incontinence. The Journal of Pediatrics, 154(5), 749-753. 
Bongers, M. E. J., Van Wijk, M. P., Reitsma, J. B., \& Benninga, M. A. (2010). Longterm prognosis for childhood constipation: Clinical outcomes in adulthood. Pediatrics, 126, $156-162$.

Borowitz, S. M., Cox, D. J., \& Sutphen, J. L. (1999). Differences in toileting habits between children with chronic encopresis, asymptomatic siblings, and asymptomatic nonsiblings. Journal of Developmental \& Behavioral Pediatrics, 20(3), 145-149.

Borowitz, S. M., Cox, D. J., Tam, A., Ritterband, L. M., Sutphen, J. L., \& Penberthy, J. K. (2003). Precipitants of constipation during early childhood. The Journal of the American Board of Family Practice, 16(3), 213-218.

Brady, N. C., Thiemann-Bourque, K., Fleming, K., \& Matthews, K. (2013). Predicting language outcomes for children learning augmentative and alternative communication: Child and environmental factors. Journal of Speech, Language \& Hearing Research, 56(5), 15951612. doi:10.1044/1092-4388(2013/12-0102)

Brazelton, T. B. (1962). A child-oriented approach to toilet training. Pediatrics, 29, 121-128.

Brazzelli, M., Griffiths, P. V., Cody, J. D., \& Tappin, D. (2011). Behavioural and cognitive interventions with or without other treatments for the management of faecal incontinence in children. Cochrane Database of Systematic Reviews. doi:10.1002/14651858.CD002240.pub4.+

Burket, R. C., Cox, D. J., Tam, A. P., Ritterband, L., Borowitz, S., Sutphen, J., .. Kovatchev, B. (2006). Does "stubbornness" have a role in pediatric constipation? Journal of Developmental and Behavioral Pediatrics, 27(2), 106-111.

Bytzer, P., Howell, S., Leemon, M., Young, L. J., Jones, M. P., \& Talley, N. J. (2001). Low socioeconomic class is a risk factor for upper and lower gastrointestinal symptoms: A population-based study in 15000 Australian adults. Gut, 49, 66-72.

Cameron, C. E., Brock, L. L., Murrah, W. M., Bell, L. H., Worzalla, S. L., Grissmer, D., \& Morrison, F. J. (2012). Fine motor skills and executive function both contribute to 
kindergarten achievement. Child Development, 83(4), 1229-1244. doi:10.1111/j.14678624.2012.01768.x

Canadian Paediatric Society. (2011). Managing functional constipation in children. Paediatric Child Health, 16(10), 661-665.

Cermak, S. A., Curtin, C., \& Bandini, L. G. (2010). Food selectivity and sensory sensitivity in children with autism spectrum disorders. Journal of the American Dietetic Association, $110,238-246$.

Chan, A. O., Hui, W. M., Lam, K. F., Leung, G., Yuen, M.F., Shiu, K. .. Wong, B. C. (2007). Familial aggregation in constipated subjects in a tertiary referral center. American Journal of Gastroenterology, 102(1), 149-152.

Chase, J., Robertson, V. J., Southwell, B., Hutson, J., \& Gibb, S. (2005). Pilot study using transcutaneous electrical stimulation (interferential current) to treat chronic treatmentresistant constipation and soiling in children. Journal of Gastroenterology \& Hepatology, 20(7), 1054-1061. doi:10.1111/j.1440-1746.2005.03863.x

Chatoor, I. (2002). Feeding disorders in infants and toddlers. Child and Adolescent Psychiatric Clinics of North America, 11, 163-183.

Chiarioni, G., \& Whitehead, W. E. (2008). The role of biofeedback in the treatment of gastrointestinal disorders. Nature Clinical Practice Gastroenterology \& Hepatology, 5(7), 371-382.

Chogle, A., Dhroove, G., Sztainberg, M., Di Lorenzo, C., \& Saps, M. (2010). How reliable are the Rome III criteria for the assessment of functional gastrointestinal disorders in children? American Journal of Gastroenterology, 105(12), 2697-2701.

Christodoulou, C., Junghaenel, D. U., DeWalt, D. A., Rothrock, N., \& Stone, A. A. (2008).Cognitive interviewing in the evaluation of fatigue items: Results from the patientreported outcomes measurement information system (PROMIS).Quality of Life Research, 17, 1239-1246. 
Christophersen, E.R., \& Mortweet, S. L. (2001). Treatments that work with children: Empirically supported strategies for managing childhood problems. Washington, DC: American Psychological Association.

Chung, J. M., Lee, S. D., Kang, D. I., Kwon, D. D., Kim, K. S., Kim, S. Y., Kim, H. G., ... Han, S. W. (2010). An epidemiologic study of voiding and bowel habits in Korean children: A nationwide multicenter study. Urology, 76(1), 215-219.

Clarke, M. C., Chase, J. W., Gibb, S., Robertson, V. J., Catto-Smith, A., Hutson, J. M., \& Southwell, B. R. (2009). Decreased colonic transit time after transcutaneous interferential electrical stimulation in children with slow transit constipation. Journal of Pediatric Surgery, 44(2), 408-412.

Cohn, A. (2011). Clinical features, psychological issues and management of constipation in childhood. Nursing Children and Young People, 23(3), 29-35.

Collis, D.R., Norton, L.N., \& Wallace, M.C. (2007). Childhood chronic constipation: An innovative community-based parent education group program. Australian Occupational Therapy Journal, 54, 307-309.

Costa, M. L., Oliveira, J. N., Tahan, S., \& Morais, M. B. (2011). Overweight and constipation in adolescents. BMC Gastroenterology, 11(40). doi:10.1186/1471-230X-11-40

Cox, D. J., Morris, J. B., Borowitz, S. M., Sutphen, J. L. (2002). Psychological differences between children with and without chronic encopresis. Journal of Pediatric Psychology, 27(7), 585-591.

Cox, D. J., Ritterband, L. M., Quillian, W., Kovatchev, B., Morris, J., Sutphen, J., \& Borowitz, S. (2003). Assessment of behavioral mechanisms maintaining encopresis: Virginia encopresis-constipation apperception test. Journal of Pediatric Psychology, 28(6), 375382.

Culbert, T. P., \& Banez, G. A. (2007). Integrative approaches to childhood constipation and encopresis. The Pediatric Clinics of North America, 54(6), 927-47. 
Dar, R., Kahn, D. T., \& Carmeli, R. (2012). The relationship between sensory processing, childhood rituals and obsessive-compulsive symptoms. Journal of Behavior Therapy \& Experimental Psychiatry, 43(1), 679-684. doi:10.1016/j.jbtep.2011.09.008

De Lorijn, F., Van Wijk, M. P., Reitsma, J. B., Van Ginkel, R., Taminiau, J. A., \& Benninga, M. A. (2004). Prognosis of constipation: clinical factors and colonic transit time. Archives of Disease in Childhood, 89(8), 723-727.

Derogatis, L. R. (1994) SCL-90-R: Administration, scoring, and procedures manual (3rd ed.). Minneapolis, MN: National Computer Systems, Inc.

Devanarayana, N. M., \& Rajindrajith, S. (2010). Association between constipation and stressful life events in a cohort of sri lankan children and adolescents. Journal of Tropical Pediatrics, 56(3), 144-148.

Devanarayana, N. M., \& Rajindrajith, S. (2011). Bowel habits and behaviors related to defecation in 10- to 16-year-olds: Impact of socioeconomic characteristics and emotional stress. Journal of Pediatric Gastroenterology and Nutrition, 52(5), 569-573.

Drossman, D. A. (2006). The functional gastrointestinal disorders and the rome III process. Gastroenterology, 130(5), 1377-1390.

Drossman, D. A. (2011). Abuse, trauma, and GI illness: Is there a link? American Journal of Gastroenterology, 106, 14-25. doi: 10.1038/ajg.2010.453

Drossman D. A., Corazziari E., Delvaux M., Spiller R. C., Talley N. J., Thompson, W. G., \& Whitehead, W. E. (Eds).(2006). Rome III: The Functional Gastrointestinal Disorders, Third Edition. McLean, VA: Degnon Associates, Inc.

Dunn, W. (1994). Performance of typical children on the sensory profile: An item analysis. American Journal of Occupational Therapy, 48, 967-974.

Dunn, W. (1999). Sensory Profile. San Antonio, TX: Pearson Education.

Dunn, W. (2007). Supporting children to participate successfully in everyday life by using sensory processing knowledge. Infants \& Young Children, 20(2), 84-101. 
Dunsmuir, S., \& Blatchford, P. (2004). Predictors of writing competence in 4-to 7-year-old children. British Journal of Educational Psychology, 74(3), 461-483.

Eyberg, S., \& Pincus, D. (1999). Eyberg Child Behavior Inventory and Sutter-Eyberg Student Behavior Inventory-revised: Professional Manual. Odessa, FL: Psychological Assessment Resources.

Fazlioglu, Y., \& Baran, G. (2008). A sensory integration therapy program on sensory problems for children with autism. Perceptual Motor Skills, 106(2), 415-422.

Feldman, H. M., Dale, P. S., Campbell, T. F., Colborn, D. K., Kurs-Lasky, M., Rockette. H. E., \& Paradise, J. L. (2005). Concurrent and predictive validity of parent reports of child language at ages 2 and 3 years. Child Development, 76 (4), 856 - 868.

Fishman, L., Lenders, C., Fortunato, C., Noonan, C., Nurko, S. (2004). Increased prevalence of constipation and fecal soiling in a population of obese children. Journal of Pediatrics, $145(2), 253-254$.

Friman, P. C., Hofstader, K. L., \& Jones, K. M. (2006). A biobehavioral approach to the treatment of functional encopresis in children. Journal of Early and Intensive Behavior Intervention, 3(3), 263-271.

Friman, P. C., Mathews, J. R., Finney, J. W., Christophersen, E. R., \& Leibowitz, J. M. (1988). Do encopretic children have clinically significant behavior problems? Pediatrics, 82(3), 407-409.

Gabel, S., Hegedus, A. M., Wald, A., Chandra, R., Chiponis, D.. (1986). Prevalence of behavior problems and mental health utilization among encopretic children: Implications for behavioral pediatrics. Journal of Developmental and Behavioral Pediatrics, 7(5), 293297.

Gaman, A., \& Kuo, B. (2008). Neuromodulatory processes of the brain-gut axis. Neuromodulation, 11(4), 249-259. 
Garrard, S. D., \& Richmond, J. B. (1952). Psychogenic megacolon manifested by fecal soiling. Pediatrics, 10(4), 474-483.

Gierl, M. J., \& ElAtia, S. (2007). Book Review: Adapting educational and psychological tests for cross-cultural assessment. Applied Psychological Measurement, 31 (1), 74-78. doi: $10.1177 / 0146621606288556$

Guthrie, R. M., \& Bryant, R. A. (2005). Auditory startle response in firefighters before and after trauma exposure. The American Journal of Psychiatry, 162(2), 283-290.

Handley-More, D., Richards, K., Macauley, R., \& Tierra, A. (2009). Encopresis: Multifisciplinary management. Journal of Occupational Therapy, Schools, \& Early Intervention, 2(2), 96-102. doi: 10.1080/19411240903146400

Harachi, T. W., Choi, Y., Abbott, R. D., Catalano, R. F., \& Bliesner, S. L. (2006). Examining equivalence of concepts and measures in diverse samples. Prevention Science, 7(4), 35968.

Harvey, A., Baker, R., Morris, M. E., Hough, J., Hughes, M., \& Graham, H. K. (2010). Does parent report measure performance? A study of the construct validity of the Functional Mobility Scale. Developmental Medicine \& Child Neurology, 52, 181-185. doi: 10.1111/j.1469-8749.2009.03354.x

Hazen, E. P., Reichert, E. L., Piacentini, J. C., Miguel, E., Do Rosario, M., Pauls, D., \& Geller, D. A. (2008). Case series: Sensory intolerance as a primary symptom of pediatric OCD. Annals of Clinical Psychiatry, 20(4), 199-203. doi:10.1080/10401230802437365

Hesapçıoğlu, S., Goker, Z., Aktepe, E., Topbaş, M., \& Kandil, S. (2009). Clinical features of children with encopresis and their comorbid psychiatric disorders. Yeni Symposium, 47(3), 123-128.

Ibrahim, S. H., Voigt, R. G., Katusic, S. K., Weaver, A. L., \& Barbaresi, W. J. (2009). Incidence of gastrointestinal symptoms in children with autism: A population-based study. Pediatrics, 124(2), 680-686. 
Ikeda, K., Ida, S., Kawahara, H., Kawamoto, K., Etania, Y., \& Kubotab, A. (2011). Importance of evaluating for cow's milk allergy in pediatric surgical patients with functional bowel symptoms. Journal of Pediatric Surgery, 46(12), 2332-2335.

Inan, M., Aydiner, C. Y., Tokuc, B., Aksu, B., Ayvaz, S., Ayhan, S., ... Basaran, U. N. (2007). Factors associated with childhood constipation. Journal of Paediatrics \& Child Health, 43, 700-706.

Ireton, H. (1992). Child Development Inventory. Minneapolis, MN: Behavior Science Systems.

Ismail, K.A., Chase, J., Gibb, S., Clarke, M., Catto-Smith, A., ... Hutson, J. M. (2009). Daily transabdominal electrical stimulation at home increased defecation in children with slowtransit constipation: A pilot study. Journal of Pediatric Surgery, 44(12), 2388-2392.

Jennings, A., Davies., G. J., Costarelli, V., \& Dettmar, P. W. (2010). Bowel habit, diet and body weight in preadolescent children. Journal of Human Nutrition and Dietetics, 23(5), 511519.

Joinson, C., Heron, J., Butler, U., \& Von Gontard, A. (2006). Psychological differences between children with and without soiling problems. Pediatrics, 117, 1575-1584.

Kamer, B., Dólka, E., Pyziak, K., \& Blomberg, A. (2011). [Food allergy as a cause of constipation in children in the first three years of life - own observations]. Medycyna Wieku Rozwojowego, 15(2), 157-161.

Karagiozoglou-Lampoudi, T., Daskalou, E., Agakidis, C., Savvidou, A., Apostolou, A., \& Vlahavas G. (2012). Personalized diet management can optimize compliance to a highfiber, high-water diet in children with refractory functional constipation. Journal of the Academy of Nutrition and Dietetics, 112(5), 725-729.

Kaugars, A. S., Silverman, A., Kinservik, M., Heinze, S., Reinemann, L., Sander, M., Schneider, B., \& Sood, M. (2010). Families' perspectives on the effect of constipation and fecal incontinence on quality of life. Journal of Pediatric Gastroenterolgy and Nutrition, 51(6), 743-752. 
Kientz, M. A., \& Dunn, W. (1997). A comparison of the performance of children with and without autism on the Sensory Profile. American Journal of Occupational Therapy, 51(7), 530-537.

Kistner, M. (2009). Dysfunctional elimination behaviors and associated complications in schoolage children. Journal of School Nursing, 25(2), 108-116.

Kocaay, P., Egritas, O., \& Dalgic, B. (2011). Normal defecation pattern, frequency of constipation and factors related to constipation in Turkish children 0-6 years old. The Turkish Journal of Gastroenterology, 22(4), 369-375.

Kuhl, E. S., Felt, B. T., \& Patton, S. R. (2009). Brief Report: Adherence to fluid recommendations in children receiving treatment for retentive encopresis. Journal of Pediatric Psychology 34, 1165-1169. doi:10.1093/jpepsy/jsp017

Lackner, J. M., Coad, M. L., Mertz, H. R., Wack, S. D., Katz, L. A., Krasner, S. S., \& Lockwood, A. H. (2006). Cognitive therapy for irritable bowel syndrome is associated with reduced limbic activity, GI symptoms, and anxiety. Behaviour Research and Therapy, 44(5), 621638.

Lane, S. J., Reynolds, S., \& Dumenci, L. (2012). Sensory overresponsivity and anxiety in typically developing children and children with autism and attention deficit hyperactivity disorder: Cause or coexistence? American Journal of Occupational Therapy, 66, 595603. http://dx.doi.org/10.5014/ajot.2012.004523

Lane, S. J, Reynolds, S., \& Thacker, L. (2010). Sensory over-responsivity and ADHD: Differentiating using electrodermal responses, cortisol, and anxiety. Frontiers in Integrative Neuroscience, 29(4), article 8. doi: 10.3389/fnint.2010.00008.

Leong, L. C. Y., Yik, Y. I., Catto-Smith, A. G., Robertson, V. J., Hutson, J. M., \& Southwell, B. R. (2011). Long-term effects of transabdominal electrical stimulation in treating children with slow-transit constipation. Journal of Pediatric Surgery, 46, 2309-2312. 
Levine, M. D., \& Bakow, H. (1976). Children with encopresis: A study of treatment outcome. Pediatrics, 58, 845-852.

Loening-Baucke, V. (1995). Biofeedback treatment for chronic constipation and encopresis in childhood: Long-term outcome. Pediatrics, 96(1), 105-10.

Loening-Baucke, V. (1996). Encopresis and soiling. The Pediatric Clinics of North America, 43(1), 279-298.

Lucak, S. (2007). Review of Rome III: The functional gastrointestinal disorders. Functional Brain-Gut Research Group Newsletter, Issue 38, Spring 2007. Retrieved from http://neurogastro.ro/pdf/Issue\%2038.pdf

Lundblad, B., \& Hellström, A. (2005). Perceptions of school toilets as a cause for irregular toilet habits among schoolchildren aged 6 to 16 years. Journal of School Health, 75(4), 125128.

Martinez, G., Marin, B. V., \& Schoua-Glusberg, A. (2006). Translating from English to Spanish: The 2002 national survey of family growth. Hispanic Journal of Behavioral Sciences, $28(4), 531-545$.

Mayer, E. A., \& Tillisch, K. (2011). The brain-gut axis in abdominal pain syndromes. Annual Review of Medicine, 62, 381-396.

Mayer, E. A., Tillisch, K. K., \& Bradesi, S. S. (2006). Review article: Modulation of the braingut axis as a therapeutic approach in gastrointestinal disease. Alimentary Pharmacology \& Therapeutics, 24(6), 919-933. doi:10.1111/j.1365-2036.2006.03078.x

Mazurek, M. O., Vasa, R. A., Kalb, L. G., Kanne, S., Rosenberg, D., Keefer, A., ... Lowery, L. A. (2012). Anxiety, sensory over-responsivity, and gastrointestinal problems in children with autism spectrum disorders. Journal of Abnormal Child Psychology. Advance online publication. doi 10.1007/s10802-012-9668-x 
McIntosh, D. N., Miller, L. J., Shyu, V., \& Dunn, W. (1999). Overview of the Short Sensory Profile. In W. Dunn (Ed.), The Sensory Profile: User's manual. San Antonio, TX: The Psychological Corporation.

McGrath, M., Mellon, M., \& Murphy, L. (2000). Empirically supported treatments in pediatric psychology: Constipation and encopresis. Journal of Pediatric Psychology, 25(4), 225254.

Mearin, F., Rey, E., \& Balboa, A. (2011). Trastornos funcionales y motores digestivos [functional and motility gastrointestinal disorders]. Gastroenterology and Hepatology, 34 (Suppl 2), 3-14.

Mellon, M. W., Whiteside, S. P., \& Friedrich, W. N. (2006). The relevance of fecal soiling as an indicator of child sexual abuse: A preliminary analysis. Journal of Developmental and Behavioral Pediatrics, 27(1), 25-32.

Michaud, L., Lamblin, M., Mairesse, S., Turck, D., \& Gottrand, F. (2009). Outcome of functional constipation in childhood: A 10-year follow-up study. Clinical Pediatrics, 48(1), 26-31.

Mostafa, R. (2008). Review of Rome III: The functional gastrointestinal disorders. World Journal of Gastroenterology. 14(13), 2124-2125.

Mugie, S. M., Benninga, M. A., \& Di Lorenzo, C. (2011). Epidemiology of constipation in children and adults: A systematic review. Best Practice \& Research Clinical Gastroenterology, 25(1), 3-18.

Mugie, S. M., Di Lorenzo, C., \& Benninga, M. A. (2011). Constipation in childhood. Nature reviews. Gastroenterology \& Hepatology, 8(9), 502-511.

Nadon, G., Ehrmann-Feldman, D., Dunn,W., \& Gisel, E. (2011). Association of sensory processing and eating problems in children with autism spectrum disorders. Autism Research and Treatment. doi:10.1155/2011/541926 
Neuman, A., Greenberg, D. F., Labovitz, D. R., \& Suzuki, L. A. (2004). Cross-cultural adaptation of the sensory profile: Establishing linguistic equivalency of the Hebrew version. Occupational Therapy International, 11(2), 112-130.

Neveus, T., Von Gontard, A., Hoebeke, P., Hjalmas, K., Bauer, S., Bower, W... Djurhuus, J. C. (2006). The standardization of terminology of lower urinary tract function in children and adolescents: Report from the standardization committee of the international children's continence society. The Journal of Urology, 176, 314-324.

Newmeyer, A. J., Aylward, C., Akers, R., Ishikawa, K., Grether, S., de Grauw, T., ... White, J. (2009). Results of the Sensory Profile in children with suspected childhood apraxia of speech. Physical \& occupational therapy in pediatrics, 29(2), 203-218.

Norgaard, J. P., Van Gool, J. D., Hjalmas, K., Djurhuus, \& Hellstrom, A. L. (1998). Standardization and definitions in lower urinary tract dysfunction in children [Supplemental material]. British Journal of Urology, 81(3), 1-16.

North American Society for Pediatric Gastroenterology, Hepatology and Nutrition. (2006). Clinical practice guideline: Evaluation and treatment of constipation in infants and children. Journal of Pediatric Gastroenterology and Nutrition, 43(3), e1-e13.

Oberklaid, F., Baird, G., Blair, M., Melhuish, E., \& Hall, D. (2013).Children's health and development: Approaches to early identification and intervention. Archives of Disease in Childhood, 98(12), 1008-1011.

Ostwani, W., Dolan, J., \& Elitsur, Y. (2010). Familial clustering of habitual constipation: A prospective study in children from West Virginia. Journal of Pediatric Gastroenterology and Nutrition, 50(3), 287-289.

Ozokutan, B. H., Zoroglu, S., Ceylan, H., \& Ozkan, K. U. (2005). Psychological evaluation of children with idiopathic constipation and their parents. Pediatrics International, 47(3), 311-315.

Pang, K. H., \& Croaker, G. D. (2011). Constipation in children with autism and autistic spectrum disorder. Pediatric Surgery International, 27(4), 353-358. 
Parush, S., Sohmer, H., Steinberg, A., \& Kaitz, M.(2007).Somatosensory function in boys with ADHD and tactile defensiveness. Physiology \& Behavior, 90(4), 553-558.

Peeters, B., Benninga, M. A., \& Hennekam, R. C. (2011). Childhood constipation; An overview of genetic studies and associated syndromes. Best Practice \& Research Clinical Gastroenterology, 25(1), 73-88.

Pfeiffer, B. A., Koenig, K., Kinnealey, M., Sheppard, M., \& Henderson, L. (2011). Effectiveness of sensory integration interventions in children with autism spectrum disorders: A pilot study. The American Journal of Occupational Therapy, 65(1), 76-85.

Pijpers, M. A., Bongers, M. E. J., Benninga, M. A., \& Berger, M. Y. (2010). Functional constipation in children: A systematic review on prognosis and predictive factors. Journal of Pediatric Gastroenterology and Nutrition, 50(3), 256-268.

Plas, R. N. van der, Benninga, M. A, Büller, H. A., Bossuyt, P. M., Akkermans, L. M., Redekop, W. K., \& Taminiau, J. A. (1996). Biofeedback training in treatment of childhood constipation: A randomized controlled study. Lancet, 348, 776-780.

Pollock, M. R. (2012). The association between sensory processing disorder and dysfunctional elimination syndrome in children (Doctoral Scholarly Project, University of Toledo). Retrieved from http://drc.library.utoledo.edu/handle/2374.UTOL/10193

Porter, C. L. (2009). Predicting preschoolers' social-cognitive play behavior: Attachment, peers, temperament, and physiological regulation. Psychological Reports 104(2), 517-528. doi: 10.2466/PR0.104.2.517-528

Procter, E., \& Loader, P. (2003). A 6-year follow-up study of chronic constipation and soiling in a specialist paediatric service. Child: Care, Health and Development, 29(2), 103-109.

Raghunath, N., Glassman, M. S., Halata, M. S., Berezin, S. H., Stewart, J. M., \& Medow, M. S. (2011). Anorectal motility abnormalities in children with encopresis and chronic constipation. The Journal of Pediatrics, 158(2), 293-296. 
Rajindrajith, S., \& Devanarayana, N. M. (2011). Constipation in children: Novel insight into epidemiology, pathophysiology and management. Journal of neurogastroenterology and motility, 17(1), 35-47.

Rajindrajith, S., Mettananda, S., \& Devanarayana, N. M. (2011). Constipation during and after the civil war in Sri Lanka: A paediatric study. Journal of Tropical Pediatrics, 57(6), 439443.

Rappaport, L., Landman, G., Fenton, T., \& Levine, M. D. (1986). Locus of control as predictor of compliance and outcome in treatment of encopresis. The Journal of Pediatrics, 109(6), 1061-1064.

Reynolds, S., Bendixen, R. M., Lawrence, T., \& Lane, S. J. (2011). A pilot study examining activity participation, sensory responsiveness, and competence in children with high functioning autism spectrum disorder. Journal of Autism and Developmental Disorders, 4l(11), 1496-1506. doi 10.1007/s10803-010-1173-x

Reynolds, S., \& Lane, S. J. (2009). Sensory overresponsivity and anxiety in children with ADHD. American Journal of Occupational Therapy, 63, 433-440.

Richmond, J. B., Eddy, E. J., \& Garrard, S. D. (1954). The syndrome of fecal soiling and megacolon. American Journal of Orthopsychiatry. 24(2), 391-401. doi: 10.1111/j.19390025.1954.tb02027.x

Ridolfo, H. \& Schoua-Glusberg, A. ( 2011). Analyzing cognitive interview data using the constant comparative method of analysis to understand cross-cultural patterns in survey data. Field Methods, 23(4), 420-438.

Ritterband, L. M., Cox, D. J., Walker, L. S., Kovatchev, B., McKnight, L., Patel, K., ... Sutphen, J. (2003). An internet intervention as adjunctive therapy for pediatric encopresis. Journal of Consulting and Clinical Psychology, 71(5), 910-917.

Roberts, J. E., King-Thomas, L., \& Boccia, M. (2007). Behavioral indexes of the efficacy of sensory integration therapy. American Journal of Occupational Therapy, 61(5), 565-562. 
Roman-Oyala, R. \& Reynolds, S. E. (2010) Validating the response process of the spanish version of the short sensory profile: A pilot study using cognitive interviews. Journal of Occupational Therapy, Schools, \& Early Intervention, 3(3), 197-206.

Rubin, G., \& Dale, A. (2006). Chronic constipation in children. British Medical Journal, 333(7577), 1051-1055. doi: 10.1136/bmj.39007.760174.47

Rugolotto, S., Sun, M., Boucke, L., Caló, D. G., \& Tató, L. (2008). Toilet training started during the first year of life: A report on elimination signals, stool toileting refusal and completion age. Minerva Pediatrica, 60(1), 27-35.

Schaaf, R. C. (2011). Interventions that address sensory dysfunction for individuals with autism spectrum disorders: Preliminary evidence for the superiority of sensory integration compared to other sensory approaches. In B. Reichow, P. Doehring, D. V. Cicchetti, \& F. R. Volkmar (Eds.), Evidence-based practices and treatments for children with autism (pp. 245-273). New York: Springer.

Schaaf, R. C., Benevides, T., Blanche, E., Brett-Green, B., Burke, J., Cohn, E., ... Schoen, S. (2010). Parasympathetic functions in children with sensory processing disorder. Frontiers in Integrative Neuroscience, 4(4). doi:10.3389/fnint.2010.00004

Schaaf, R. C., Benevides, T., Mailloux, Z., Faller, P., Hunt, J., van Hooydonk, E., ... Kelly, D. (2013). An intervention for sensory difficulties in children with autism: A randomized trial. Journal of Autism and Developmental Disorders. doi: 10.1007/s10803-013-1983-8

Schaaf, R. C., \& Blanche, E. I. (2012). Emerging as leaders in autism research and practice: Using the data-driven intervention process. American Journal of Occupational Therapy, 66, 503-505. doi:10.5014/ajot.2012.006114

Schonwald, A., Sherritt, L., Stadtler, A., \& Bridgemohan, C. (2004). Factors associated with difficult toilet training. Pediatrics, 113(6), 1753-1757.

Schum, T. R., Kolb, T. M., McAuliffe, T. L., Simms, M. D., Underhill, R. L., \& Lewis M. (2002). Sequential acquisition of toilet-training skills: A descriptive study of gender and age differences in normal children. Pediatrics, 109, e48. doi: 10.1542/peds.109.3.e48 
Scott, S. M., Van den Berg, M. M., \& Benninga, M. A. (2011). Rectal sensorimotor dysfunction in constipation. Best Practice \& Research Clinical Gastroenterology, 25(1), 103-118.

Silva, L. M. T., Cignolini, A., Warren, R., Budden, S., \& Skowron-Gooch, A. (2007).

Improvement in sensory impairment and social interaction in young children with autism following treatment with an original qigong massage methodology. American Journal of Chinese Medicine, 35(3), 393-406.

Shaikh, N. (2004). Time to get on the potty: Are constipation and stool toileting refusal causing delayed toilet training? The Journal of Pediatrics, 145(1), 12-13.

Sheth, A. (2007). Review of Rome III: The functional gastrointestinal disorders. Journal of Clinical Gastroenterology, 41(9), 876.

Sonnenberg, A., \& Koch, T. R. (1989). Physician visits in the United States for constipation: 1958 to 1986. Digestive Diseases and Sciences, 34(4), 606-611.

Southwell, B. R., King, S. K., \& Hutson, J. M. (2005). Chronic constipation in children: Organic disorders are a major cause. Journal of Paediatrics and Child Health, 41(1-2), 1-15.

Staiano, A., Andreotti, M., Greco, L., Basile, P., \& Auricchio, S. (1994). Long-term follow-up of children with chronic idiopathic constipation. Digestive Diseases and Sciences, 39, 561564.

Stark, L. J., Opipari, L. C., Donaldson, D. L., Danovsky, M. B., Rasile, D. A., \& DelSanto, A. F. (1997). Evaluation of a standard protocol for retentive encopresis: A replication. Journal of Pediatric Psychology, 22(5), 619-633.

Stark, L. J., Spirito, A., Lewis, A. V., \& Hart, K. J. (1990). Encopresis: Behavioral parameters associated with children who fail medical management. Child Psychiatry and Human Development, 20(3), 169-179.

Sullivan, P. B., Alder, N., Shrestha, B., Turton, L., \& Lambert, B. (2012). Effectiveness of using a behavioural intervention to improve dietary fibre intakes in children with constipation. Journal of Human Nutrition and Dietetics, 25(1), 33-42. 
Tabbers, M. M., Boluyt, N., Berger, M. Y., \& Benninga, M. A. (2010). Constipation in children. Clinical Evidence, 2010, 0303.

Tabbers, M. M., Boluyt, N., Berger, M. Y., \& Benninga, M. A. (2011a). Diagnosis and treatment of functional constipation. European Journal of Pediatrics, 170, 955-96. doi:10.1007/s00431-011-1515-5.

Tabbers, M. M., Boluyt, N., Berger, M. Y., \& Benninga, M.A. (2011b). Non pharmacologic treatments for childhood constipation: Systematic review. Pediatrics, 128(4), 753-761. doi:10.1542/peds.2011-0179

Tam, Y. H., Li, A. M., So, H. K., Shit, K. Y., Pang, K.K., Wong, Y.S., .., Lee, K. H. (2012). Socioenvironmental factors associated with constipation in Hong Kong children and Rome III criteria. Journal of Pediatric Gastroenterology and Nutrition, 55(1), 56-61.

Tang, B, Piazza, C, Dolezal, D, \& Stein, M. T. (2011). Severe feeding disorder and malnutrition in 2 children with autism. Journal of Developmental and Behavioral Pediatrics, 32(3), 264-267.

Taubman, B. (1997). Toilet training and toileting refusal for stool only: A prospective study. Pediatrics, 99(1), 54-58.

Taubman, B., Blum, N. J., \& Nemeth, N. (2003). Stool toileting refusal: A prospective intervention targeting parental behavior. Archives of Pediatrics \& Adolescent Medicine, 157(12), 1193-1196.

Taubman, B., \& Buzby, M. (1997). Overflow encopresis and stool toileting refusal during toilet training: A prospective study on the effect of therapeutic efficacy. The Journal of Pediatrics, 131(5), 768-771.

Tomchek, S. D., \& Dunn, W. (2007). Sensory processing in children with and without autism: A comparative study using the Short Sensory Profile. American Journal of Occupational Therapy, 61, 190-200. 
Van den Berg, M. M., Benninga, M. A., \& Di Lorenzo, C. (2006). Epidemiology of childhood constipation: A systematic review. American Journal of Gastroenterology, 101, 24012409.

Van Dijk, M., Benninga, M. A., Grootenhuis, M. A., \& Last, B. F. (2010). Prevalence and associated clinical characteristics of behavior problems in constipated children. Pediatrics, 125(2), e309-e317.

Van Dijk, M., Benninga, M. A., Grootenhuis, M. A., Van Onland Nieuwenhuizen, A. M., \& Last, B. F. (2007). Chronic childhood constipation: A review of the literature and the introduction of a protocolized behavioral intervention program. Patient Education and Counseling, 67(1-2), 63-77.

Van Dijk, M., Bongers, M. E. J., de Vries, G., Grootenhuis, M., Last, B., \& Benninga, M. (2008). Behavioral therapy for childhood constipation: A randomized controlled trial. Pediatrics, 121(5), 1334-1341.

Van Ginkel, R., Reitsma, J., Büller, H., Van Wijk, M., Taminiau, J., \& Benninga, M. (2003). Childhood constipation: Longitudinal follow-up beyond puberty. Gastroenterology, 125, 357-363.

Varni, J. W., Limbers, C. A., \& Burwinkle, T. M. (2007a). How young can children reliably and validly self-report their health-related quality of life?: An analysis of 8,591 children across age subgroups with the PedsQL 4.0 Generic Core Scales. Health \& Quality of Life Outcomes, 51-13. doi:10.1186/1477-7525-5-1

Varni, J. W., Limbers, C. A., \& Burwinkle, T. M. (2007b). Parent proxy-report of their children's health-related quality of life: An analysis of 13,878 parents' reliability and validity across age subgroups using the PedsQL 4.0 Generic Core Scales. Health \& Quality of Life Outcomes, 52-10. doi:10.1186/1477-7525-5-2

Vd Baan-Slootweg, O. H., Liem, O., Bekkali, N., Van Aalderen, W., Pels Rijcken, T. H., Di Lorenzo, C., \& Benninga, M. A. (2011). Constipation and colonic transit times in children 
with morbid obesity. Journal of Pediatric Gastroenterology and Nutrition, 52(4), 442445 .

Vitito, L. M. (2000). Self-care interventions for the school-aged child with encopresis. Gastroenterology Nursing, 23(2), 73-77.

Von Gontard, A., Baeyens, D., Van Hoecke, E., Warzak, W. J., \& Bachmann, C. (2011). Psychological and psychiatric issues in urinary and fecal incontinence. The Journal of Urology, 185(4), 1432-1436.

Wald, E. R., Di Lorenzo, C., Cipriani, L., Colborn, K., Burgers, R., \& Wald, A. (2009). Bowel habits and toilet training in a diverse population of children. Journal of Pediatric Gastroenterology and Nutrition, 48, 294-298.

Waters, A. M., Schilpzand, E., Bell, C., Walker, L. S., \& Baber, K. (2012). Functional gastrointestinal symptoms in children with anxiety disorders. Journal of Abnormal Child Psychology. Advance publication online. doi 10.1007/s10802-012-9657-0

Watt, T., Rasmussen, A. K., Groenvold, M., Bjorner, J. B., Watt, S. H., Bonnema, S. J., .. FeldtRasmussen, U. (2008). Improving a newly developed patient-reported outcome for thyroid patients, using cognitive interviewing. Quality of Life Research, 17, 1009-1017.

Whitehead, W. E., Di Lorenzo, C., Leroi, A. M., Porrett, T., \& Rao, S. S. (2009). Conservative and behavioural management of constipation. Neurogastroenterology and Motility, 21, Suppl 2, 55-61.

Wild, D., Furtado, T., \& Angalakuditi, M. (2012). The translation and cultural adaptation of the Child Behavior Checklist for use in Israel (Hebrew), Korea, the US (Spanish), India (Malayalam and Kannada), and Spain. Psychology Research and Behavior Management, $5,51-56$.

Willis, G. (2005). Cognitive interviewing: A tool for improving questionnaire design. Thousand Oaks, CA: Sage Publication. 
Wu, T., Chen, L., Pan, W., Tang, R. B., Hwang, S. J., Wu, L., .., Chen, P. H. (2011). Constipation in Taiwan elementary school students: A nationwide survey. Journal of the Chinese Medical Association, 74(2), 57-61.

Yik, Y. I., Ismail, K. A., Hutson, J. M., \& Southwell, B. R. (2012). Home transcutaneous electrical stimulation to treat children with slow-transit constipation. Journal of Pediatric Surgery, 47(6), 1285-1290.

Yorkston, K. M., Baylor, C. R., Dietz, J., Dudgeon, B. J., Eadie, T., Miller, R. M., \& Amtmann, D. (2008). Developing a scale of communicative participation: A cognitive interviewing study. Disability and Rehabilitation, 30(6). 425-433.

Young, M. H., Brennen, L. C., Baker, R. D., \& Baker, S. S. (1995). Functional encopresis: Symptom reduction and behavioral improvement. Journal of Developmental and Behavioral Pediatrics, 16(4), 226-232.

Youssef, N., Langseder, A. L., Verga, B. J., Mones, R. I., \& Rosh, J. R. (2005). Chronic childhood constipation is associated with impaired quality of life: A case-controlled study. Journal of Pediatric Gastroenterology and Nutrition, 41(1), 56-60.

Youssef, N., Peters, J. M., Henderson, W., Schultz-Peters, S., Lockhart, D. K., \& Di Lorenzo, C. (2002). Dose response of peg 3350 for the treatment of childhood fecal impaction. The Journal of Pediatrics, 141(3), 410-41.

Zwaigenbaum, L., Bryson, S., \& Garond, N. (2013). Early identification of autism spectrum disorders. Behavioural Brain Research, 251(15), 133-146. 


\section{Appendix A}

\section{Toileting Habit Profile Questionnaire}

Por favor, señale las respuestas que mejor describan con qué frecuencia su hijo presenta las siguientes conductas. / Please check the answers that best describe the frequency with which your child does the following behaviors.

\begin{tabular}{|c|c|c|c|c|c|c|}
\hline & $\begin{array}{l}\text { Conducta relativa a la defecación (los números entre } \\
\text { paréntesis corresponden a los puntos para la } \\
\text { corrección) }\end{array}$ & 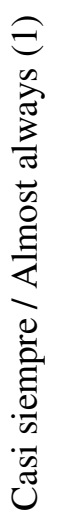 & 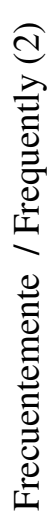 & 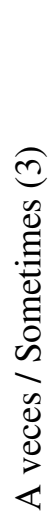 & 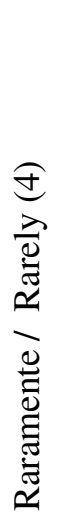 & 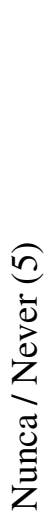 \\
\hline & \multicolumn{6}{|l|}{ Sensibilidad alta / over-responsiveness } \\
\hline 1 & $\begin{array}{l}\text { Mi hijo se esconde en el momento de hacer sus } \\
\text { deposiciones. } \\
\text { My child hides while defecating. }\end{array}$ & & & & & \\
\hline 2 & $\begin{array}{l}\text { Mi hijo me pide un pañal cuando siente la necesidad } \\
\text { de hacer una deposición. } \\
\text { My child asks for a diaper when he feels the need to } \\
\text { defecate. }\end{array}$ & & & & & \\
\hline 3 & $\begin{array}{l}\text { Mi hijo rechaza sentarse en el orinal o en el inodoro } \\
\text { para hacer sus deposiciones. } \\
\text { My child refuses to sit on the potty or the toilet to } \\
\text { defecate. }\end{array}$ & & & & & \\
\hline
\end{tabular}




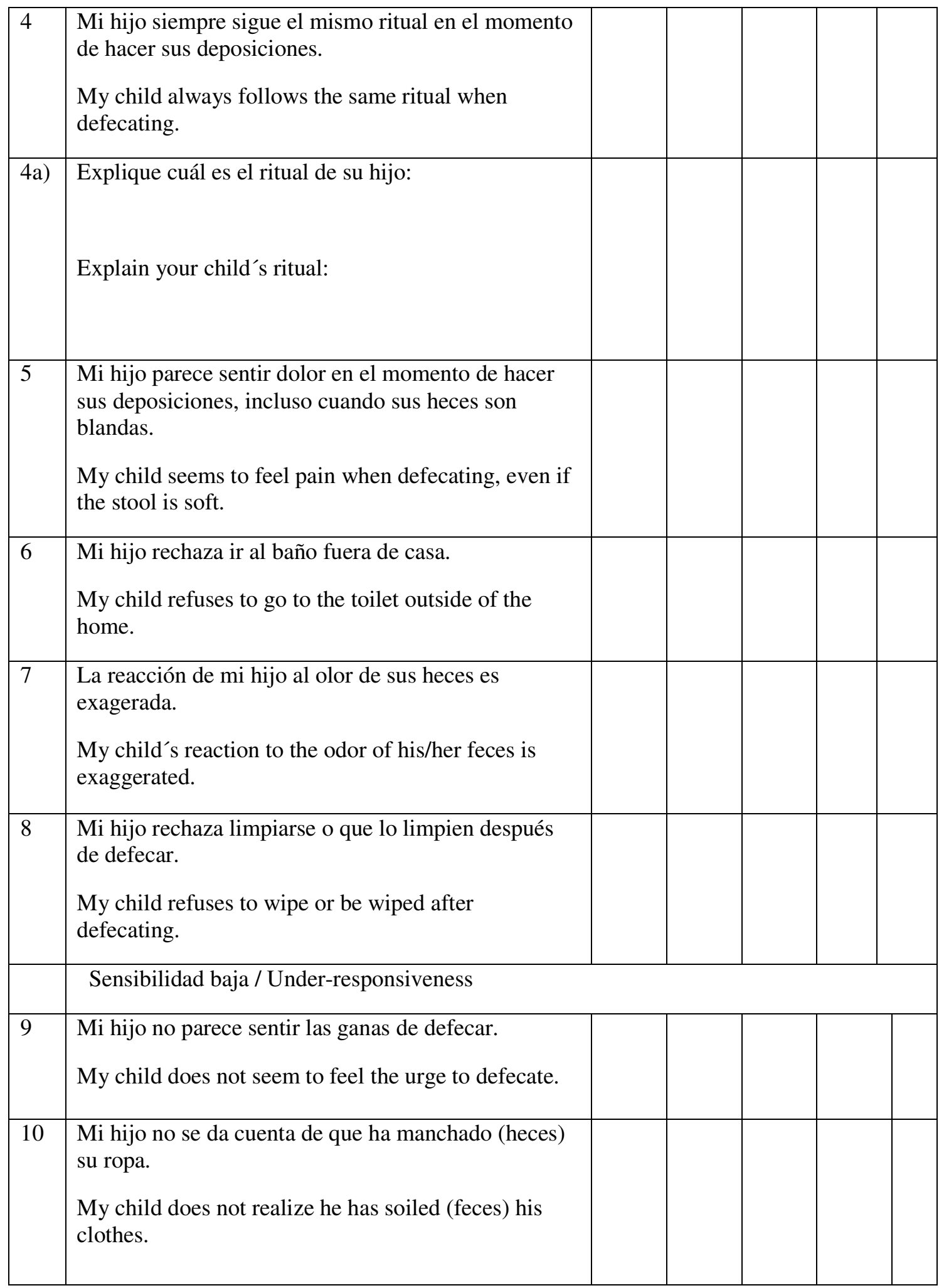




\section{Appendix B}

\section{Spanish version of the Short Sensory Profile revised for Spain}

\section{Short Sensory Profile}

(R-SPAIN)

Nombre del niño:

Cuestionario llenado por:

Nombre del proveedor de servicios:
Fecha de nacimiento:

Fecha:
Relación al niño:

Disciplina:

\section{INSTRUCCIONES}

Por favor marque el cuadrito que mejor representa la frecuencia

con la cual su hijo demuestra los siguientes

comportamientos.

Por favor responda todas las observaciones. Si no es

posible comentar porque no ha observado el

comportamiento o porque

piensa que no se aplica a su hijo, marque con una X el

número correspondiente a esa observación. Escriba

cualquier comentario al final de cada sección. Por favor

no escriba en la sección Resultado Bruto Total por

Sección.
Cuando se le presenta la oportunidad, su hijo siempre responde de

esta manera, $100 \%$ del

tiempo.

Cuando se le presenta la oportunidad, su hijo

frecuentemente res-

ponde de esta manera, un $75 \%$ del tiempo.

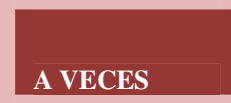

Cuando se le presenta la oportunidad, su hijo a veces responde de esta manera, un $50 \%$ del tiempo.

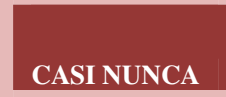

Cuando se le presenta la oportunidad, su hijo casi nunca responde

de esta manera, un $25 \%$ del

tiempo.

Cuando se le presenta la oportunidad, su hijo nunca

responde de

esta manera, $0 \%$ del

tiempo. 


\begin{tabular}{|c|c|c|c|c|c|c|}
\hline Item & $\begin{array}{l}\text { Tactile } \\
\text { Sensitivity }\end{array}$ & S & $\mathrm{F}$ & $\begin{array}{l}\text { A } \\
\text { V }\end{array}$ & $\begin{array}{l}\mathrm{C} \\
\mathrm{N}\end{array}$ & $\mathrm{N}$ \\
\hline 1 & $\begin{array}{l}\text { Expresa angustia cuando se le cortan el pelo y las uñas, o se le lava } \\
\text { la cara (por ejemplo, llora o lucha). }\end{array}$ & & & & & \\
\hline 2 & $\begin{array}{l}\text { Prefiere usar manga larga cuando hace calor o manga } \\
\text { corta cuando hace frío. }\end{array}$ & & & & & \\
\hline 3 & Evita ir descalzo, especialmente en arena o hierba. & & & & & \\
\hline 4 & Reacciona emocional o agresivamente cuando lo tocan. & & & & & \\
\hline 5 & Se aleja del agua que le pueda salpicar. & & & & & \\
\hline 6 & Tiene dificultades para esperar en fila o cerca de otra gente. & & & & & \\
\hline 7 & Frota o rasca el área del cuerpo donde le han tocado. & & & & & \\
\hline \multicolumn{7}{|c|}{ Resultado Bruto Total por Sección } \\
\hline Item & $\begin{array}{l}\text { Taste/Smell } \\
\text { Sensitivity }\end{array}$ & S & $\mathrm{F}$ & $\begin{array}{l}\text { A } \\
\text { V }\end{array}$ & $\begin{array}{l}\mathrm{C} \\
\mathrm{N}\end{array}$ & $\mathrm{N}$ \\
\hline 8 & $\begin{array}{l}\text { Evita ciertos sabores u olores que habitualmente forman parte de las } \\
\text { dietas de los niños. }\end{array}$ & & & & & \\
\hline 9 & $\begin{array}{l}\text { Come solamente algunas comidas de ciertos sabores } \\
\text { (apunte: }\end{array}$ & & & & & \\
\hline 10 & $\begin{array}{l}\text { Se limita a comer solamente comidas de cierta textura/temperatura } \\
\text { (apunte: }\end{array}$ & & & & & \\
\hline 11 & $\begin{array}{l}\text { Es exigente con lo que come, especialmente en lo que se refiere a las } \\
\text { texturas de los alimentos. }\end{array}$ & & & & & \\
\hline \multicolumn{7}{|c|}{ Resultado Bruto Total por Sección } \\
\hline Item & $\begin{array}{l}\text { Movement } \\
\text { Sensitivity }\end{array}$ & S & $\mathrm{F}$ & $\begin{array}{l}\text { A } \\
\text { V }\end{array}$ & $\begin{array}{l}\mathrm{C} \\
\mathrm{N}\end{array}$ & $\mathrm{N}$ \\
\hline 12 & $\begin{array}{l}\text { Se vuelve ansioso o angustiado cuando sus pies se separan del } \\
\text { suelo. }\end{array}$ & & & & & \\
\hline 13 & Teme caerse o estar en lo alto. & & & & & \\
\hline 14 & $\begin{array}{l}\text { No le gustan las actividades en las cuales se queda con la cabeza } \\
\text { hacia abajo (por ejemplo, volteretas, juegos bruscos). }\end{array}$ & & & & & \\
\hline \multicolumn{7}{|c|}{ Resultado Bruto Total por Sección } \\
\hline Item & $\begin{array}{l}\text { Underreponsive/Seeks } \\
\text { Sensation }\end{array}$ & S & $\mathrm{F}$ & $\begin{array}{l}\text { A } \\
\text { V }\end{array}$ & $\begin{array}{l}\mathrm{C} \\
\mathrm{N}\end{array}$ & $\mathrm{N}$ \\
\hline 15 & $\begin{array}{l}\text { Disfruta de ruidos extraños/trata de hacer ruido sólo por hacer } \\
\text { ruido. }\end{array}$ & & & & & \\
\hline 16 & $\begin{array}{l}\text { Busca todo tipo de movimiento y esto interfiere con las actividades } \\
\text { rutinarias (por ejemplo, no se puede quedar quieto). }\end{array}$ & & & & & \\
\hline 17 & Se emociona demasiado con las actividades de movimiento. & & & & & \\
\hline 18 & Toca excesivamente a gente y objetos. & & & & & \\
\hline 19 & No parece notar cuando tiene la cara y manos sucias. & & & & & \\
\hline 20 & Pasa de una actividad a otra al punto de interferir con el juego. & & & & & \\
\hline 21 & No le molesta tener la ropa torcida. & & & & & \\
\hline & Resultado Bruto Total por Sección & & & & & \\
\hline
\end{tabular}




\begin{tabular}{|c|c|c|c|c|c|c|}
\hline Item & $\begin{array}{l}\text { Auditory } \\
\text { Filtering }\end{array}$ & S & $\mathrm{F}$ & $\begin{array}{l}\mathrm{A} \\
\mathrm{V}\end{array}$ & $\begin{array}{l}\mathrm{C} \\
\mathrm{N}\end{array}$ & $\mathrm{N}$ \\
\hline 22 & $\begin{array}{l}\text { Se distrae o tiene dificultades para funcionar normalmente si hay } \\
\text { mucho ruido a su alrededor. }\end{array}$ & & & & & \\
\hline 23 & Parece no oír lo que se le dice (por ejemplo, parece no hacer caso). & & & & & \\
\hline 24 & $\begin{array}{l}\text { No puede trabajar si hay ruido ambiental (por ejemplo, de un } \\
\text { ventilador, de un refrigerador). }\end{array}$ & & & & & \\
\hline 25 & $\begin{array}{l}\text { Tiene dificultades para completar las tareas cuando está puesta la } \\
\text { radio. }\end{array}$ & & & & & \\
\hline 26 & $\begin{array}{l}\text { No responde cuando lo llaman, pero usted sabe que su hijo oye } \\
\text { bien. }\end{array}$ & & & & & \\
\hline 27 & Tiene dificultades para prestar atención. & & & & & \\
\hline \multicolumn{7}{|c|}{ Resultado Bruto Total por Sección } \\
\hline Item & $\begin{array}{l}\text { Low } \\
\text { Energy/Weak }\end{array}$ & S & $\mathrm{F}$ & $\begin{array}{l}\text { A } \\
\text { V }\end{array}$ & $\begin{array}{l}\mathrm{C} \\
\mathrm{N}\end{array}$ & $\mathrm{N}$ \\
\hline 28 & Parece que sus músculos son débiles. & & & & & \\
\hline 29 & $\begin{array}{l}\text { Se cansa fácilmente, especialmente cuando está de pie o } \\
\text { manteniendo alguna posición determinada. }\end{array}$ & & & & & \\
\hline 30 & $\begin{array}{l}\text { Aprieta débilmente, como si le faltara fuerza para su } \\
\text { edad. }\end{array}$ & & & & & \\
\hline 31 & $\begin{array}{l}\text { No puede levantar objetos pesados (parece más débil que otros niños } \\
\text { de la misma edad). }\end{array}$ & & & & & \\
\hline 32 & $\begin{array}{l}\text { Siempre está buscando apoyarse en muebles, personas, etc. (incluso } \\
\text { cuando está haciendo algo). }\end{array}$ & & & & & \\
\hline 33 & Tiene poco aguante/Se agota fácilmente. & & & & & \\
\hline \multicolumn{7}{|c|}{ Resultado Bruto Total por Sección } \\
\hline Item & $\begin{array}{l}\text { Visual/Auditory } \\
\text { Sensitivity }\end{array}$ & S & $\mathrm{F}$ & $\begin{array}{l}\text { A } \\
\text { V }\end{array}$ & $\begin{array}{l}\mathrm{C} \\
\mathrm{N}\end{array}$ & $\mathrm{N}$ \\
\hline 34 & $\begin{array}{l}\text { Responde de manera negativa a sonidos fuertes o inesperados (por } \\
\text { ejemplo, llora o se esconde al oír el ruido de la aspiradora, ladridos } \\
\text { de perro, secador de pelo). }\end{array}$ & & & & & \\
\hline 35 & Se cubre los oídos con las manos para protegerlos de sonidos. & & & & & \\
\hline 36 & Le molesta la luz brillante a la que otras personas se acostumbran. & & & & & \\
\hline 37 & Mira a todas las personas que se mueven a su alrededor. & & & & & \\
\hline 38 & Se cubre los ojos o los entrecierra para protegerse de la luz. & & & & & \\
\hline \multicolumn{7}{|c|}{ Resultado Bruto Total por Sección } \\
\hline
\end{tabular}




\section{Appendix C}

Basic information about the child's routines and habits

\section{Información básica sobre las rutinas y los hábitos del niño.}

Basic information about the child's routines and habits.

\begin{tabular}{|c|c|}
\hline 1 & $\begin{array}{l}\text { ¿Cuáles son los horarios habituales para las } \\
\text { comidas de su hijo? } \\
\text { What are your child's typical meal times? }\end{array}$ \\
\hline 2 & $\begin{array}{l}\text { ¿Su hijo hace sus deposiciones en horarios } \\
\text { habituales? } \\
\text { Does your child defecate at regular times? }\end{array}$ \\
\hline 3 & $\begin{array}{l}\text { ¿Establece usted un momento específico } \\
\text { para la defecación de su hijo (antes de } \\
\text { dormir, después de comer, etc.)? } \\
\text { Do you set a routine for your child to } \\
\text { defecate (before bed, after meals, etc.)? }\end{array}$ \\
\hline 4 & $\begin{array}{l}\text { ¿Dónde realiza su hijo sus deposiciones (en } \\
\text { el cuarto de baño, en su habitación, en una } \\
\text { bacinilla, en el inodoro, en un pañal, en otro } \\
\text { lugar)? } \\
\text { Where does your child defecate (bathroom, } \\
\text { bedroom, toilet, potty, diaper, another } \\
\text { place)? }\end{array}$ \\
\hline 5 & $\begin{array}{l}\text { ¿Su hijo tiene acceso al inodoro siempre } \\
\text { que lo necesita? Por ejemplo, ¿tiene que } \\
\text { esperar su turno o compartir el baño con } \\
\text { varias personas? }\end{array}$ \\
\hline
\end{tabular}




\begin{tabular}{|c|c|c|}
\hline & $\begin{array}{l}\text { Does your child have access to the toilet } \\
\text { any time he needs it? For example does } \\
\text { he/she have to wait his/her turn or share the } \\
\text { bathroom with many people? }\end{array}$ & \\
\hline 6 & $\begin{array}{l}\text { ¿Su hijo parece sentirse seguro en el cuarto } \\
\text { de baño? Por ejemplo, ¿parece tener miedo } \\
\text { a caerse del inodoro o le asusta el ruido de } \\
\text { la cisterna? } \\
\text { Does your child appear to feel secure in the } \\
\text { bathroom? For example, is he/she afraid de } \\
\text { fall off the toilet or afraid of the sound of } \\
\text { the toilet flushing? }\end{array}$ & 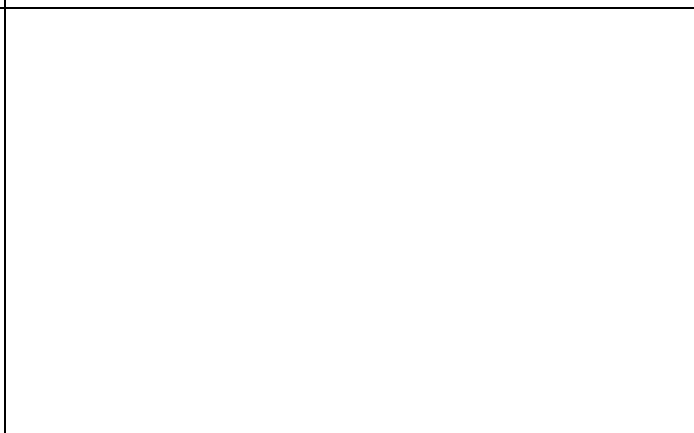 \\
\hline 7 & $\begin{array}{l}\text { Cuando va a hacer sus deposiciones, ¿su } \\
\text { hijo puede quitarse y ponerse la ropa sin } \\
\text { ayuda? } \\
\text { Can your child manage clothing for } \\
\text { toileting without help? }\end{array}$ & \\
\hline 8 & $\begin{array}{l}\text { Cuando va a hacer sus deposiciones, ¿su } \\
\text { hijo puede limpiarse sin ayuda? } \\
\text { Can your child wipe without help after } \\
\text { toileting? }\end{array}$ & \\
\hline 9 & $\begin{array}{l}\text { ¿Qué estrategias o adaptaciones utiliza para } \\
\text { ayudar a su hijo con la defecación? Por } \\
\text { ejemplo, ¿le da premios cuando utiliza el } \\
\text { inodoro, ha instalado un reductor para el } \\
\text { asiento del inodoro? } \\
\text { What strategies or adaptations do you use } \\
\text { to help your child with toileting? For } \\
\text { example do you give your child rewards for } \\
\text { using the toilet, do you use a toilet seat } \\
\text { reducer? }\end{array}$ & \\
\hline
\end{tabular}




\section{Vita}

Isabelle Beaudry Bellefeuille was born on February $2^{\text {nd }} 1968$ in Ottawa, Canada. She resides in Spain and holds citizenship of both her native country and her country of residence. She graduated from Massey-Vanier High School, (Cowansville, Québec, Canada) in 1985 and from Collège Bois de Boulogne (Montreal, Québec, Canada) in 1987. She received her Bachelor of Science in Occupational Therapy from McGill University (Montreal, Québec, Canada) in 1991. She quickly embarked in pediatric clinical practice and currently practices in Oviedo (Spain). She regularly teaches occupational therapists and other health professionals and is the author of several books and articles. 